

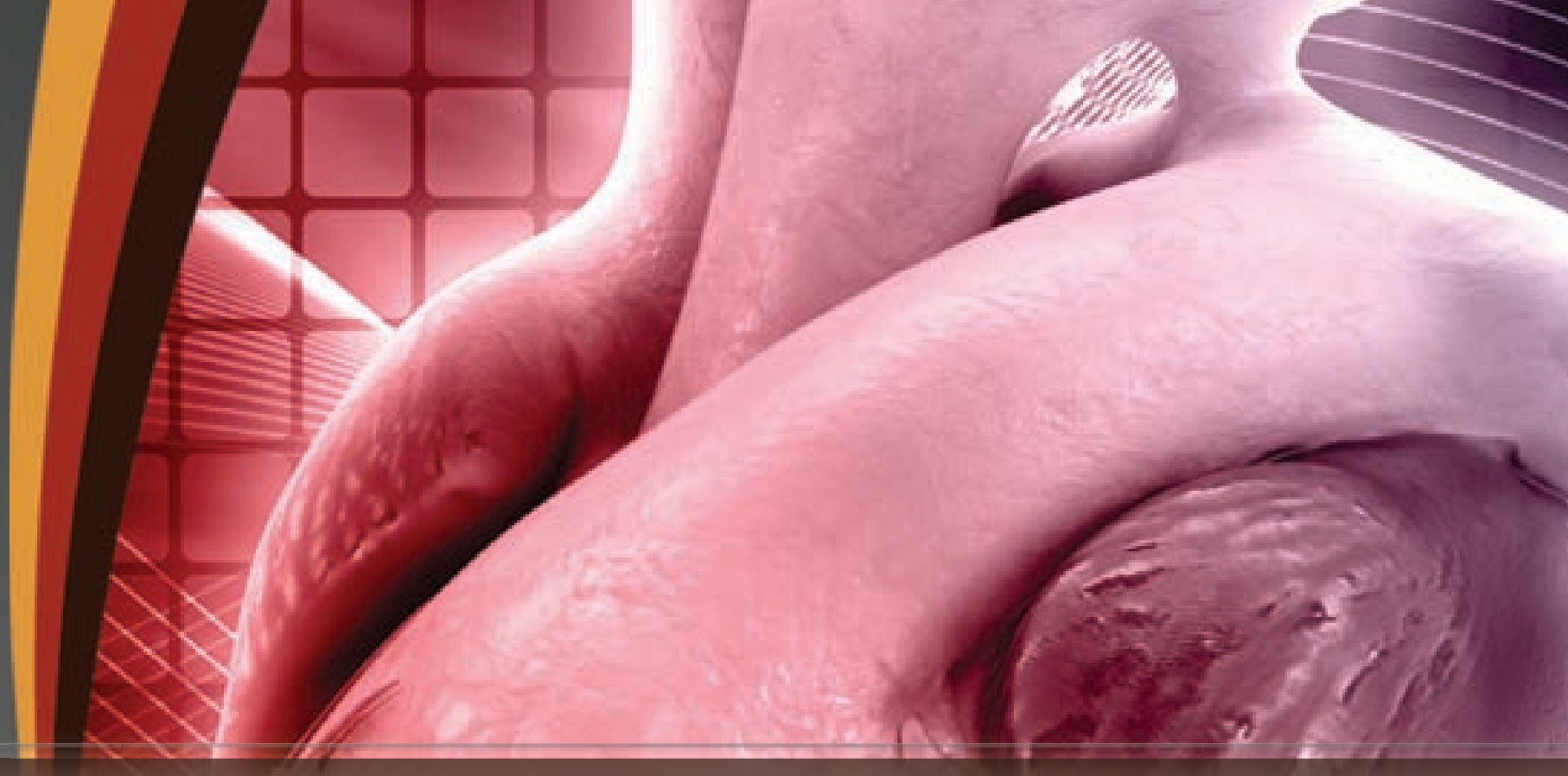

\section{CIRURGIA CARDÍACA DO ADULTO}

ANDRÉ MONTI GARZESI

LEONARDO RUFINO GARCIA MARCELLO LANEZA FELICIO 


\section{CIRURGIA CARDÍACA DO ADULTO}

\section{Autores}

André Monti Garzesi - Médico formado pela Faculdade de Medicina de Marília (FAMEMA). Cirurgião Cardiovascular do Hospital das Clínicas da Faculdade de Medicina de Botucatu - UNESP.

Leonardo Rufino Garcia - Médico formado pela Faculdade de Medicina de Botucatu - FMB UNESP. Cirurgião Cardiovascular do Hospital das Clínicas da Faculdade de Medicina de Botucatu - UNESP.

Marcello Laneza Felicio - Membro Especialista da Sociedade Brasileira de Cirurgia Cardiovascular. Doutor em Cirurgia Cardiovascular pela Universidade Estadual Paulista. Chefe do Serviço de Cirurgia Cardiovascular do Hospital das Clínicas da Faculdade de Medicina de Botucatu UNESP.

\section{Coautores}

Aline Andrea Teodoro dos Santos - Enfermeira Perfusionista do Serviço de Cirurgia Cardiovascular da Faculdade de Medicina de Botucatu - UNESP.

Andréia Cristina Passaroni - Enfermeira Perfusionista do Serviço de Cirurgia Cardiovascular da Faculdade de Medicina de Botucatu - UNESP.

Antônio Sérgio Martins - Professor Assistente Doutor da Disciplina de Cirurgia Cardiovascular do Departamento de Cirurgia e Ortopedia da Faculdade de Medicina de Botucatu - UNESP.

Guilherme Trípoli - Residente de Cirurgia Cardiovascular do Hospital das Clínicas da Faculdade de Medicina de Botucatu - UNESP (2016-2020).

Nelson Leonardo Kerdahi Leite de Campos - Professor Assistente Doutor da Disciplina de Cirurgia Cardiovascular do Departamento de Cirurgia e Ortopedia da Faculdade de Medicina de Botucatu - UNESP. Chefe da Disciplina de Cirurgia Cardiovascular da Faculdade de Medicina de Botucatu - UNESP.

Rubens Ramos de Andrade - Professor Assistente Doutor da Disciplina de Cirurgia Cardiovascular do Departamento de Cirurgia e Ortopedia da Faculdade de Medicina de Botucatu - UNESP. Responsável pelo Serviço de Estimulação Cardíaca Artificial da Faculdade de Medicina de Botucatu - UNESP.

Rubens Tofano de Barros - Membro Titular da Sociedade Brasileira de Cirurgia Cardiovascular. Doutor em Cirurgia Cardiovascular pela Faculdade de Medicina de Botucatu - UNESP

Tassya Bueno Takeda - Residente de Cirurgia Cardiovascular da Faculdade de Medicina de Botucatu - UNESP (2015-2019).

\section{Editoração, diagramação e edição de vídeo}

Ana Silvia Sartori Barraviera Seabra Ferreira - Coordenadora do Núcleo de Educação a Distância e Tecnologias da Informação em Saúde - NEAD.TIS - FMB - UNESP

\section{Desenhista}

Marcos Eduardo Barreiros Aloise - Desenhista do Departamento de Cirurgia e Ortopedia da Faculdade de Medicina de Botucatu - UNESP.

\section{Edição de imagens}

Carlos Luís Miguel - Funcionário do Departamento de Cirurgia e Ortopedia da Faculdade de Medicina de Botucatu - UNESP.

Contato: Departamento de Cirurgia e Ortopedia da Faculdade de Medicina de Botucatu UNESP. Distrito de Rubião Júnior s/n. CEP: 18618-970, Botucatu, SP Tel.: 14-3880-1547

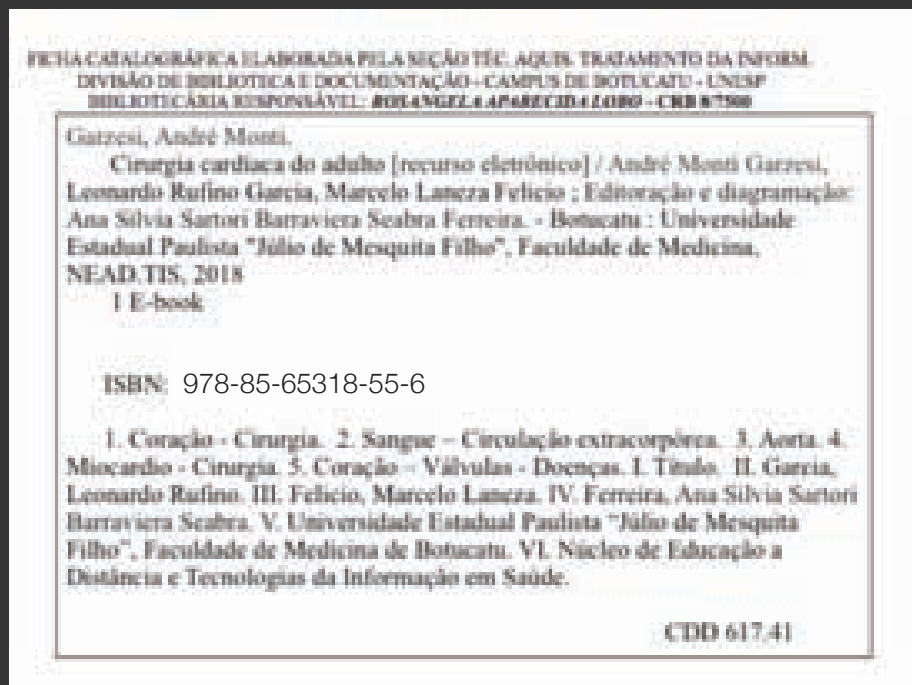

Prefixo Editorial: 65318

Número ISBN: 978-85-65318-55-6

Título: Cirurgia Cardíaca do Adulto

Tipo de Suporte: E-book 


\section{ÍNDICE}

\section{Capítulo 1: Circulação extracorpórea}

Introdução

Circuito de circulação extracorpórea

Fisiologia

Condução da circulação extracorpórea

Complicações da circulação extracorpórea

Perfusionista e perfusóes especiais

Bibliografia

\section{Capítulo 2: Balão intra-aórtico}

Histórico

Introduçãão

Indicações

Contra-indicações

Materiais

Console

Procedimento para inserção do cateter balão

Assistência do cateter balão: contrapulsação

Desmame do BIA e sua remoção

Possíveis efeitos colaterais e complicações do BIA

Cuidados com o paciente que se encontra com a assistência do BIA Bibliografia

\section{Capítulo 3: Dissecção da aorta}

\section{Anatomia da aorta}

Definição

Epidemiologia

Classificação

Quadro clínico

Critério diagnóstico

Tratamento

Bibliografia
Capítulo 4: Cirurgia de revascularização do miocárdio Introdução

Anatomia coronariana

Indicação cirúrgica

Opções de enxertos

Complicą̧ões mecânicas do IAM com indicação de tratamento cirúrgico

Bibliografia

\section{Capítulo 5: Doenças valvares}

Introdução

26

20

Estenose mitral

Insuficiência mitral

Estenose aórtica

Insuficiência aórtica

Valvas protéticas cardíacas

Bibliografia

\section{Capítulo 6: Tamponamento cardíaco}

Anatomia e fisiologia do pericárdio

Definição e etiologia

Sinais e sintomas

Exames complementares

Bibliografia

\section{Capítulo 7: Marcapassos cardíacos}

Introdução

Técnica cirúrgica

Tipos de marcapasso

Recomendações para o implante de marcapasso

Disfuncão do Nó Sinusal (DNS)

Síndrome do Seio Carotídeo (SSC)

Síncope Neurocardiogênica (SNG)

Bloqueio Atrioventricular (BAV)

Código de Nomenclatura de marcapassos

Bibliografia
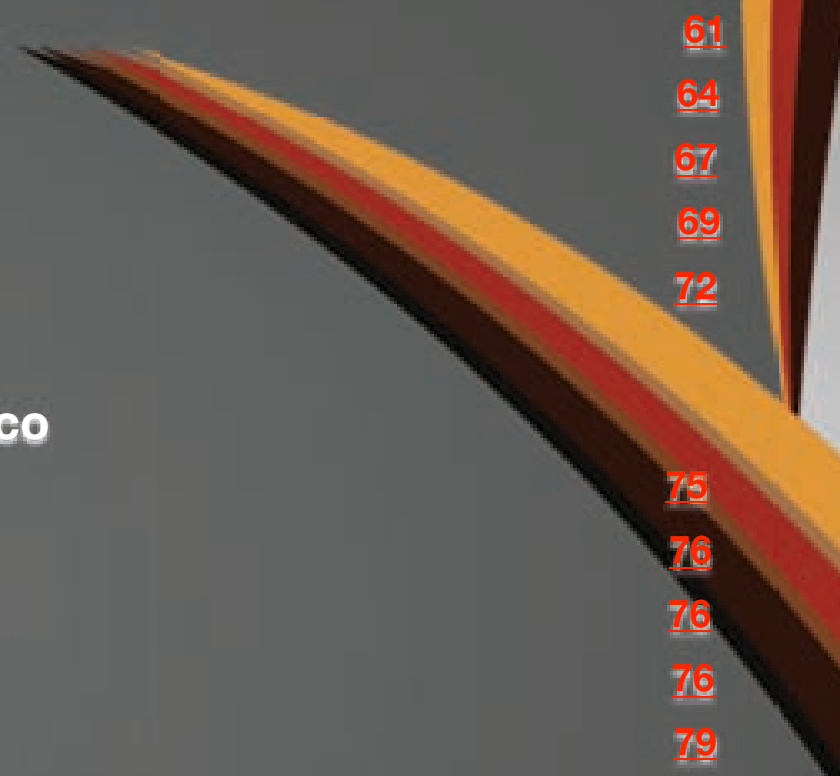


\section{CIRCULAÇÃO EXTRACORPÓREA}

Aline Andrea Teodoro dos Santos

Andréia Cristina Passaroni

Antônio Sérgio Martins

Marcello Laneza Felicio 


\section{Introdução}

"...Durante as horas, naquela noite em que John observava as veias distendidas da paciente, seu pulso fraco, sua pressão e respiração, ocorreu-lhe que suas condições poderiam ser melhoradas, se existisse algum modo de, continuamente, retirar algum sangue de suas veias tumefeitas em um aparelho (Figura 1) em que se pudesse captar oxigênio e eliminar gás carbônico e ser, então, bombeado de volta nas artérias..."

Mary H. Gibbon, "Recollections"

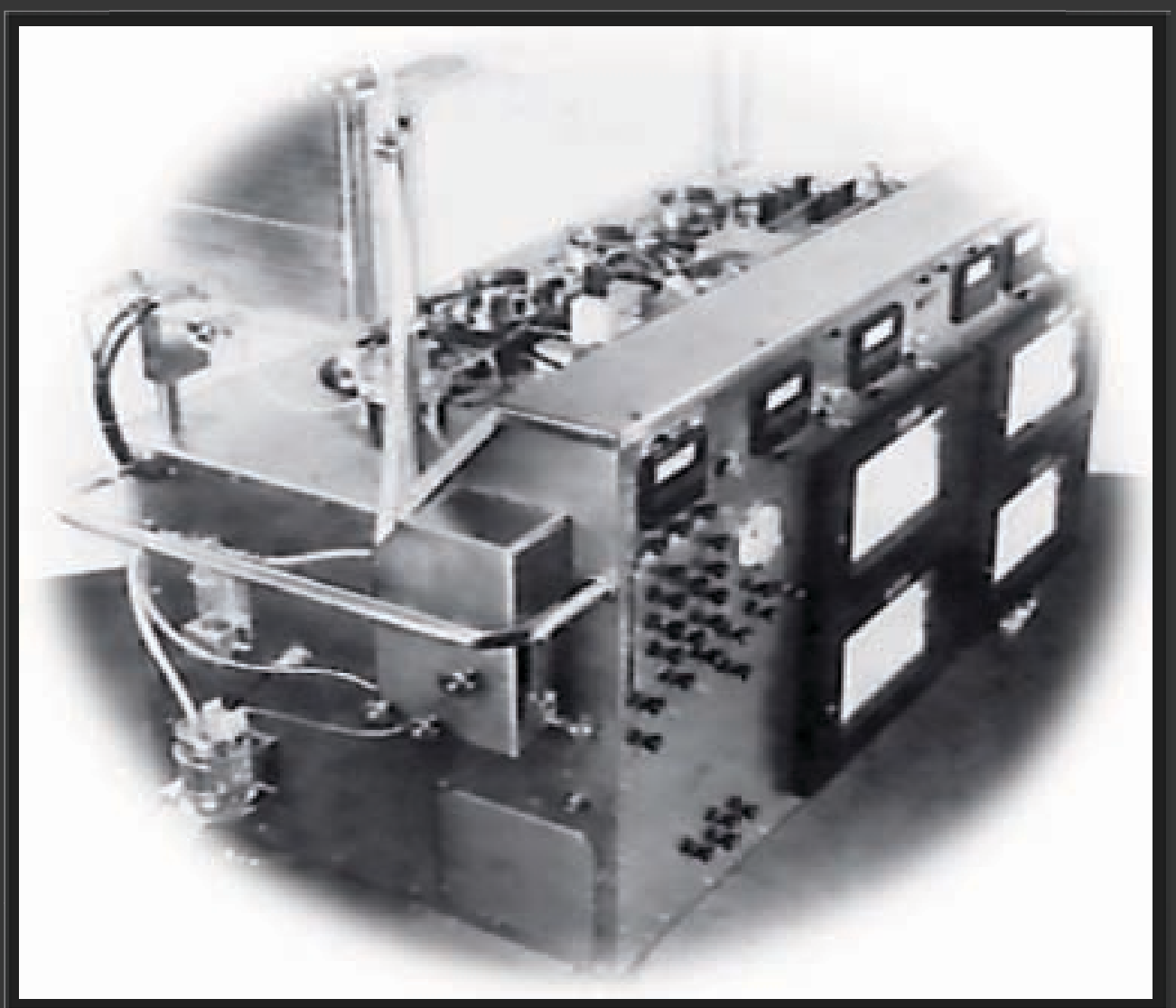

Figura 1: Oxigenador de Telas de Gibbon.

\subsection{Histórico}

No século XIX, o interesse dos fisiologistas em relação à circulação foi voltado para o estudo de órgãos isolados. Interessante que muitos dos trabalhos desenvolvidos nesse período foram fundamentais, alicerçando a circulação extracorpórea (CEC).

Le Gallois em 1813 formulou o primeiro conceito sobre o que seria uma circulação artificial. Já em 1828, Kay demonstrou que seria possível a recuperação da contração de um músculo perfundindo-o com sangue. A partir deste ponto, Brown-Seqüard, entre 1848 e 1858, por meio da obtenção de sangue "oxigenado" através da agitação do mesmo com ar, destacou a importância do sangue na composição do perfusato para obter atividade neurológica em cabeças isoladas de mamíferos. Os pesquisadores Ludwig e Schmidt em 1868 construíram um aparelho para infusão sanguínea sob pressão, podendo assim perfundir melhor um órgão isolado a ser estudado.

Mas foi Von Schroeder que em 1882 desenvolveu e construiu o primeiro protótipo de "oxigenador" de bolhas primitivo, em que havia um reservatório contendo sangue venoso; nele o ar era inserido borbulhando, realizando a transformação do sangue venoso em arterial. Von Frey e Gruber em 1885 desenvolveram um sistema coração-pulmão artificiais, onde a oxigenação do perfusato era realizada sem a interrupção do fluxo sanguíneo, o que não havia sido tentado por Von Schroeder, seu predecessor.

Outras descobertas foram de suma importância para o desenvolvimento de pesquisas e contribuíram continuamente para a CEC. Uma delas 
foi a descoberta dos grupos sanguíneos ABO por Landsteiner em 1900, o que desde então passou a evitar alguns inconvenientes relacionados a esse sistema. Em 1916, Howell e McLean descobriram a heparina enquanto estudavam extratos do fígado de animais. Esta descoberta auxiliou tanto nas pesquisas "in vivo" como "in vitro", que passariam a ser bem sucedidas devido à inibição da coagulação.

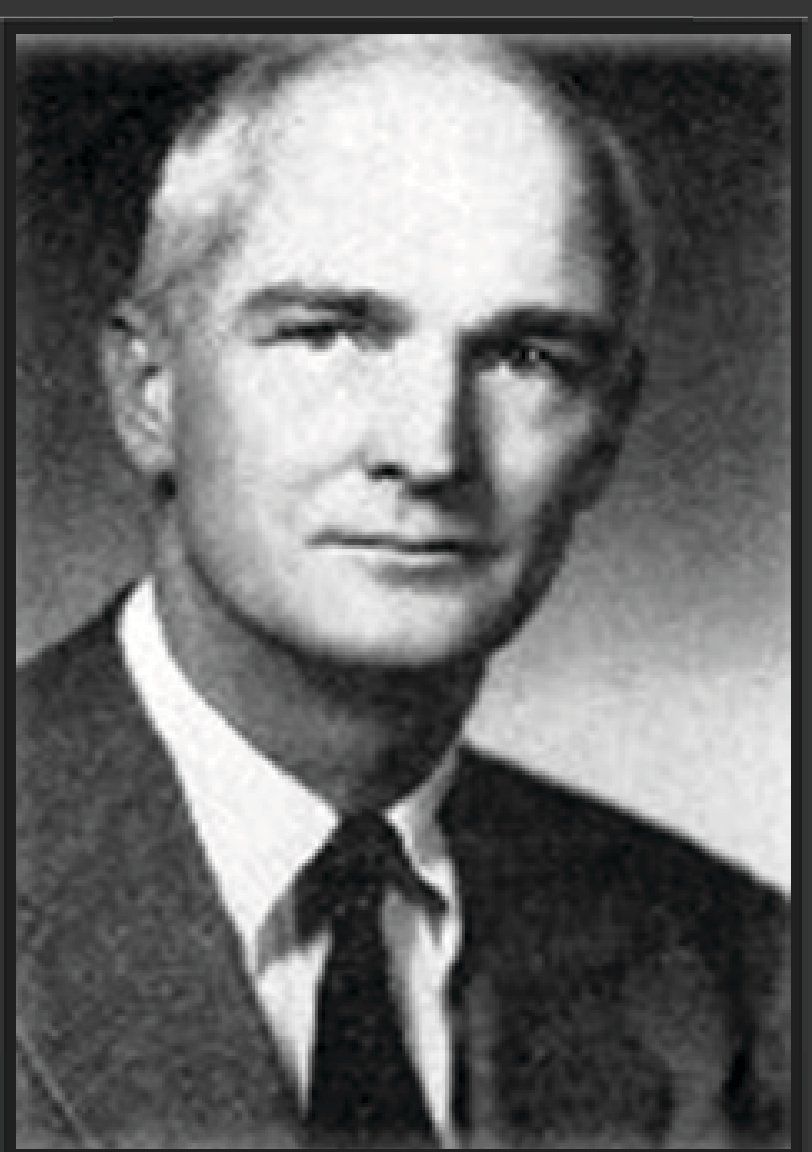

Figura 2: Dr John Gibbon. As pesquisas e publicações de Gibbon, já em 1937, aguçaram a curiosidade de outros estudiosos que começaram projetos da mesma natureza (Figura 2).

Os médicos Taussig e Blalock, ambos assessorados pelo assistente de laboratório Vivien Thomas (Figuras 3, 4 e 5) com suas técnicas cirúrgicas desenvolvidas em laboratório experimental, realizavam correções

paliativas na intenção de assistir com uma qualidade melhor crianças portadoras de doenças congênitas cardíacas graves conhecidas como "bebês azuis".

Figura 3: Dra Taussig.
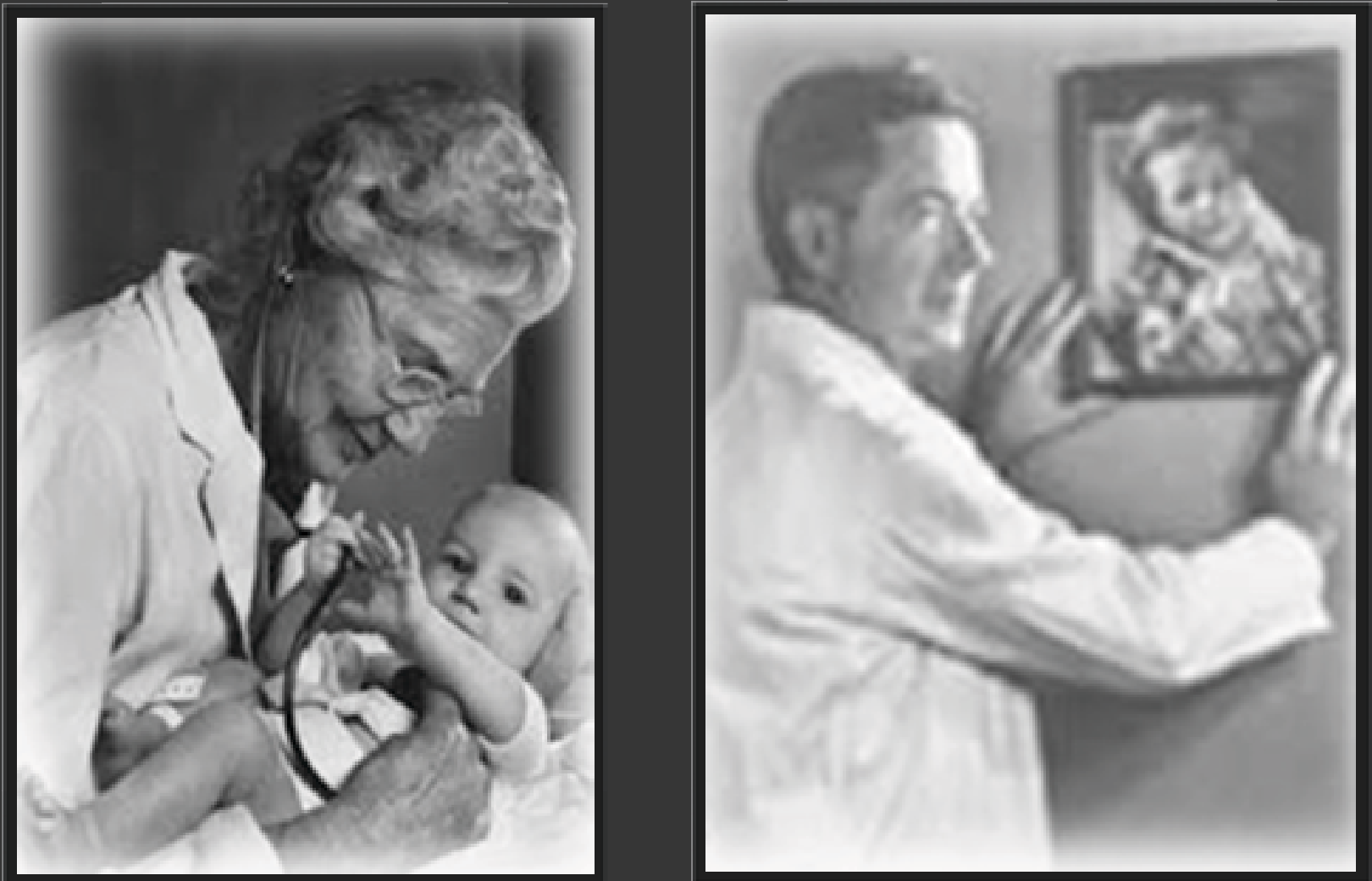

Figura 4: Dr Blalock.

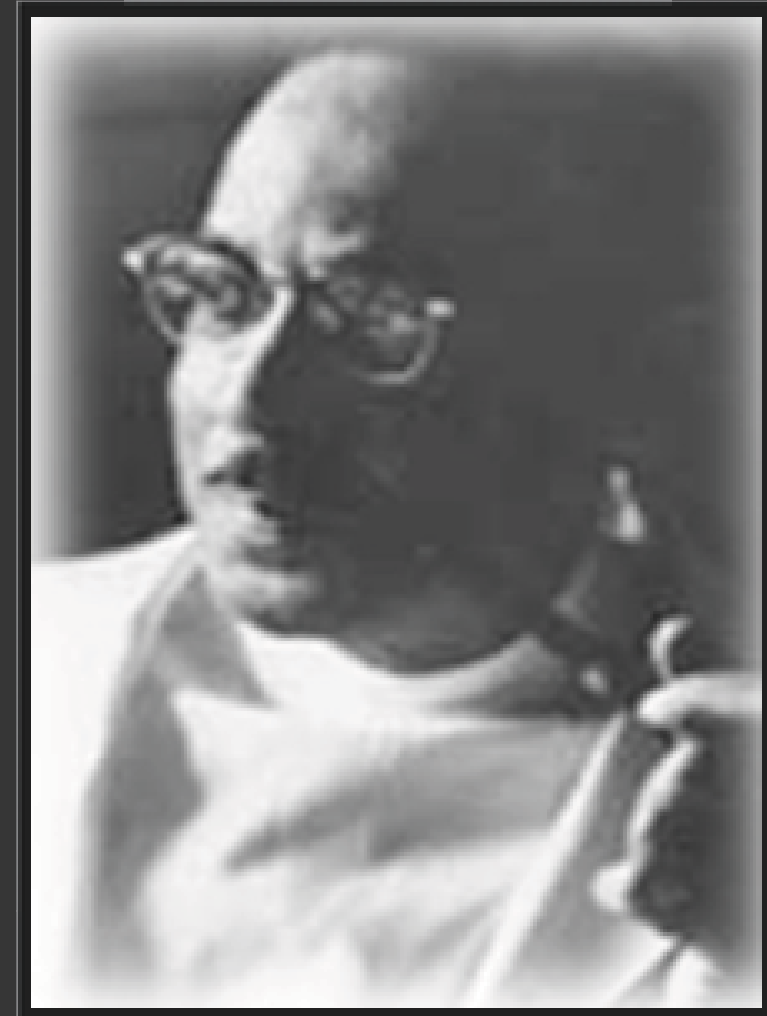

Para Crafoord (Figura 6), a circulação artificial deveria existir, pois para corrigir os defeitos intracardíacos era necessário abrir o coração, mantendo a irrigação sanguínea para todos os órgãos bem como a realização das trocas gasosas. Crafoord posteriormente realizou com sucesso a primeira cirurgia de remoção de um mixoma atrial com a CEC.

A CEC, como método de suporte em cirurgia cardiovascular, consti-

Figura 5: Vivien Thomas. 


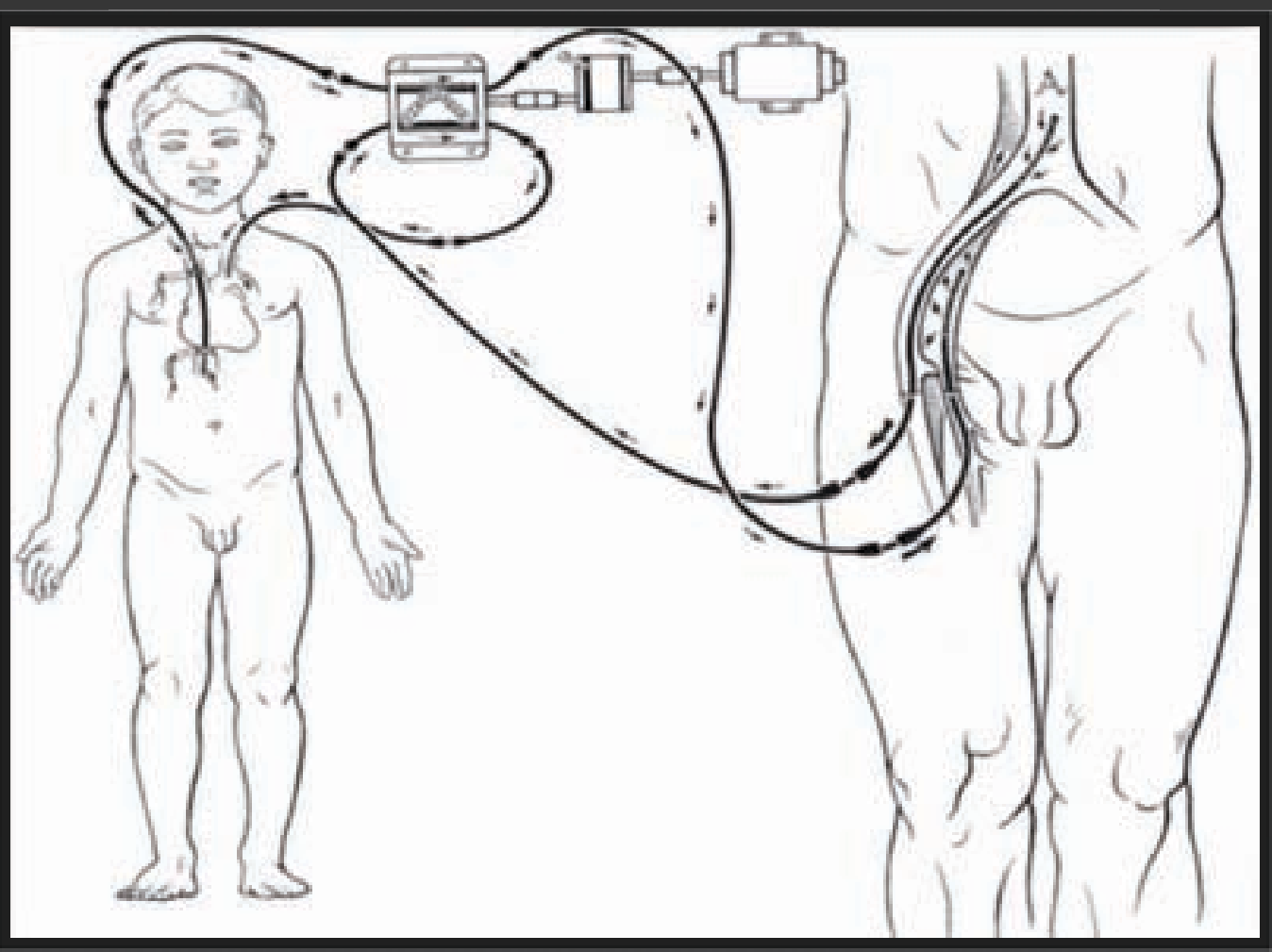

Figura 9: Esquema da circulação cruzada.

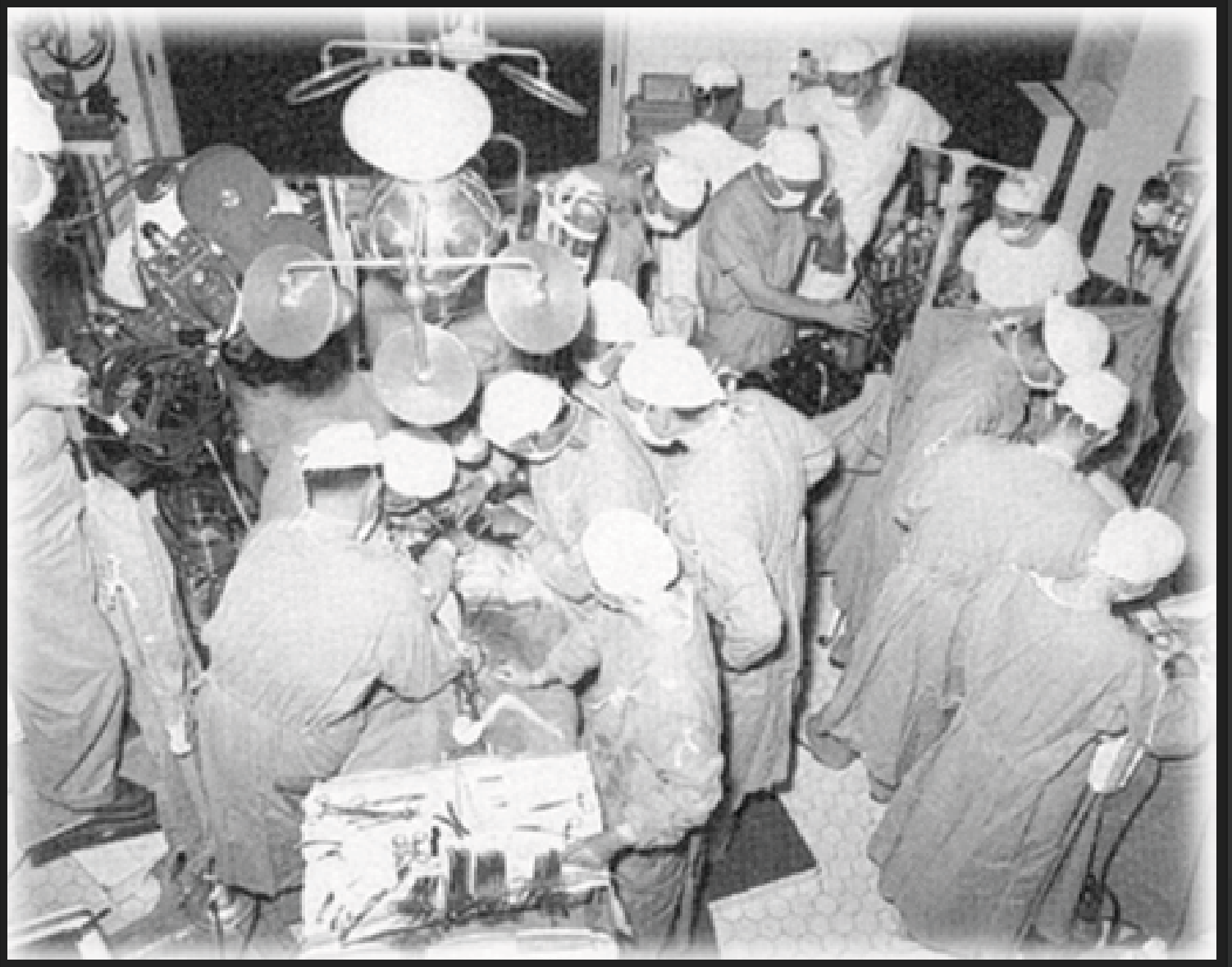

Enquanto isso no Brasil houve o intercâmbio com cirurgiões estrangeiros da especialidade, começando uma fase áurea da cirurgia cardíaca no Hospital das Clínicas. Um dos pioneiros destas pesquisas foi o Professor Hugo João Felipozzi (Figura 11), responsável pela primeira máquina de CEC e pela primeira operação com uso de CEC em outubro de 1955.

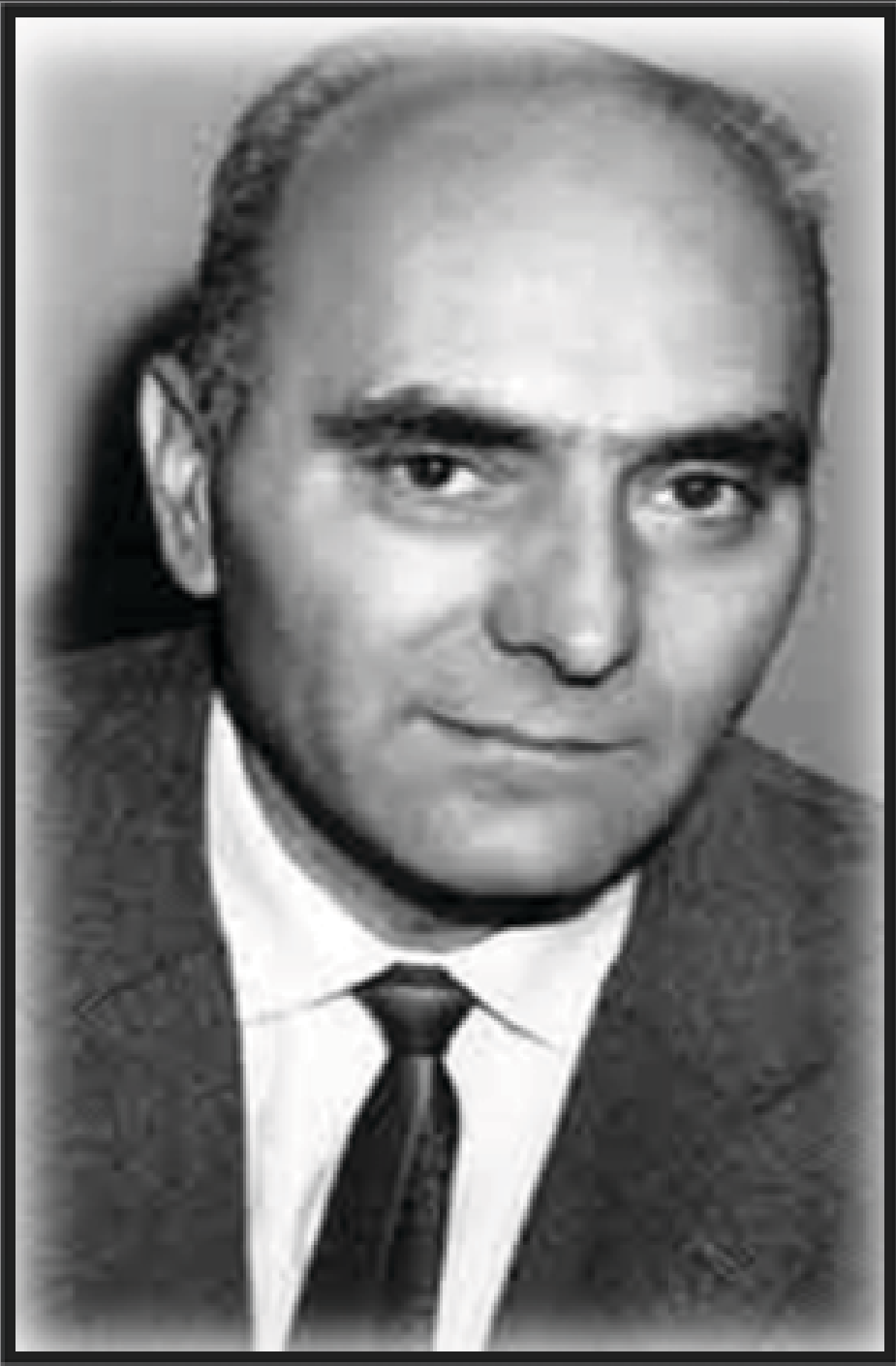

Figura 11: Dr Hugo Felipozzi.

Figura 10: Cirurgia cardiovascular com circulação cruzada, realizada pelo Dr Lillehei. 
Iniciou-se um novo momento na cirurgia cardíaca brasileira. Em São Paulo o grupo do Hospital das Clínicas, sob a liderança do cirurgião Euryclides Zerbini, se transformou no maior centro de cirurgia cardiovascular do país. Christiaan Barnard, cirurgião cardiovascular, realizou o primeiro transplante cardíaco humano em dezembro de 1967 e, em maio de 1968 realizou o primeiro transplante cardíaco no Brasil juntamente com doutor Zerbini, iniciando a era de transplantes em território nacional (Figura 12).

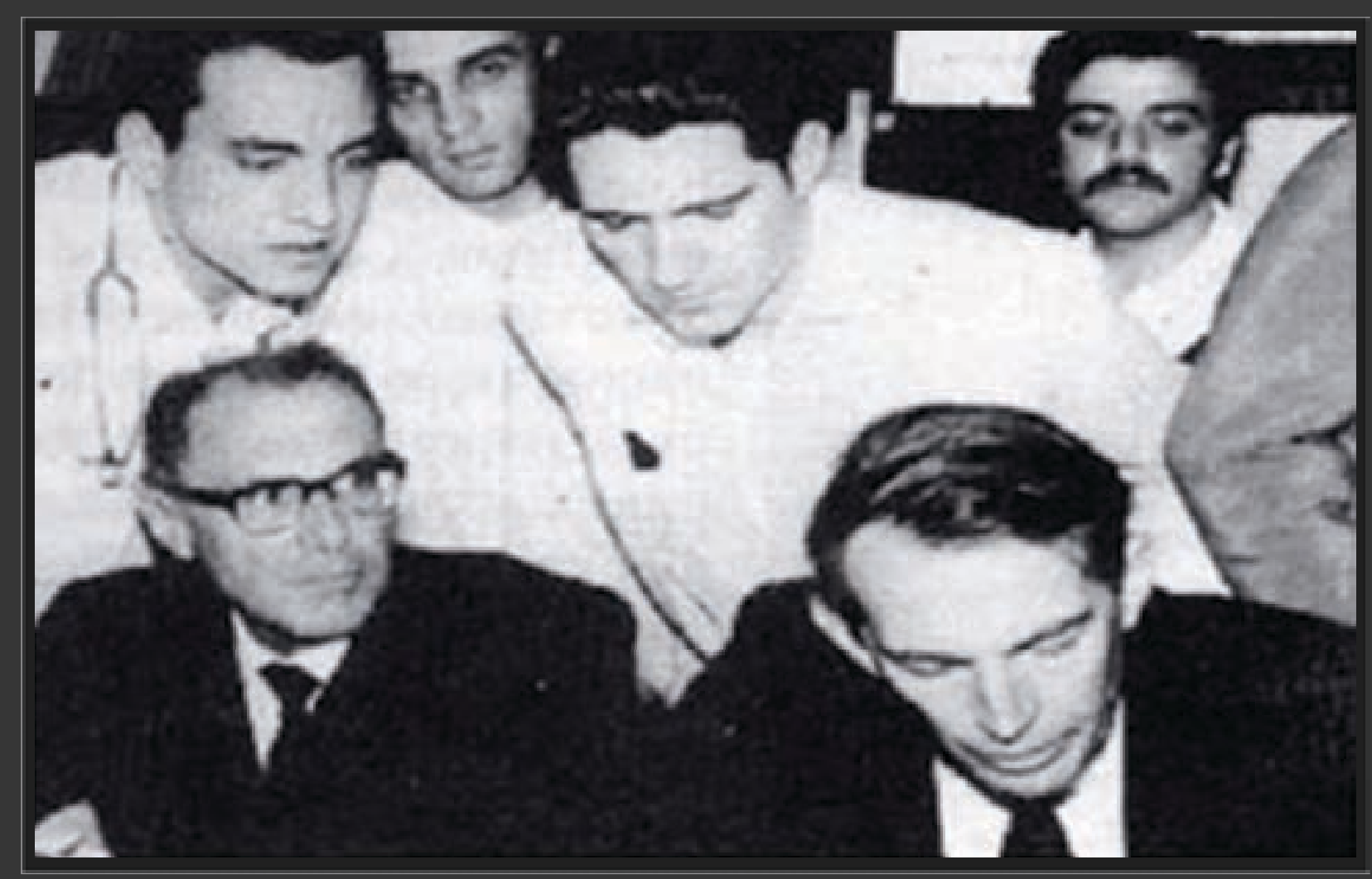

Figura 12: Dr Zerbini (de terno escuro a esquerda) e Dr Barnard (de terno escuro a direita).

Contudo, as dificuldades foram surgindo conforme os passos avançavam. As importações de materiais para a realização das cirurgias eram necessárias e tinham custos elevados. Havia o temor de não se conseguir acompanhar o desenvolvimento americano e europeu na área de equipamentos para cirurgia cardiovascular e isso fez com que os cirurgiões brasileiros se dedicassem na elaboração e construção dos equipamentos para que as cirurgias pudessem acontecer. Então, cirurgiões como Adib Jatene (Figura 13) e Domingos M. Braile (Figura 14), dentre outros, iniciaram a elaboração de máquinas de CEC, oxigenadores, próteses valvares, marcapassos e endopróteses, elevando o nome do Brasil nos centros de cirurgia cardiovascular estrangeiros. A dedicação destes profissionais nas cirurgias, aprimorando suas técnicas por meio de pesquisas em laboratórios experimentais, resultou em avanços na área contribuindo com uma assistência mais eficiente e segura ao paciente com doença cardíaca.

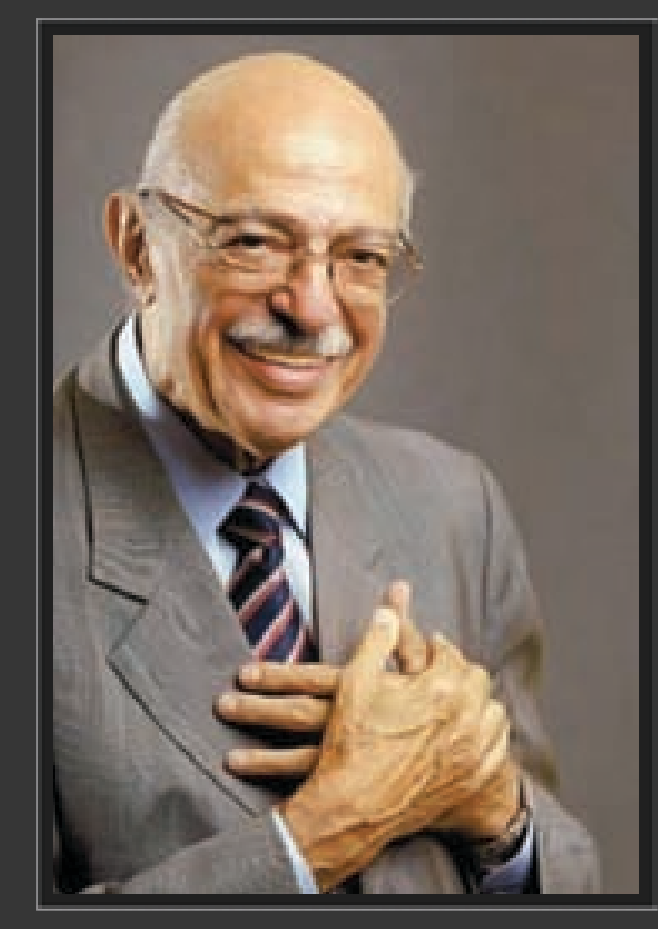

Figura 13: Dr Adib Jatene. 


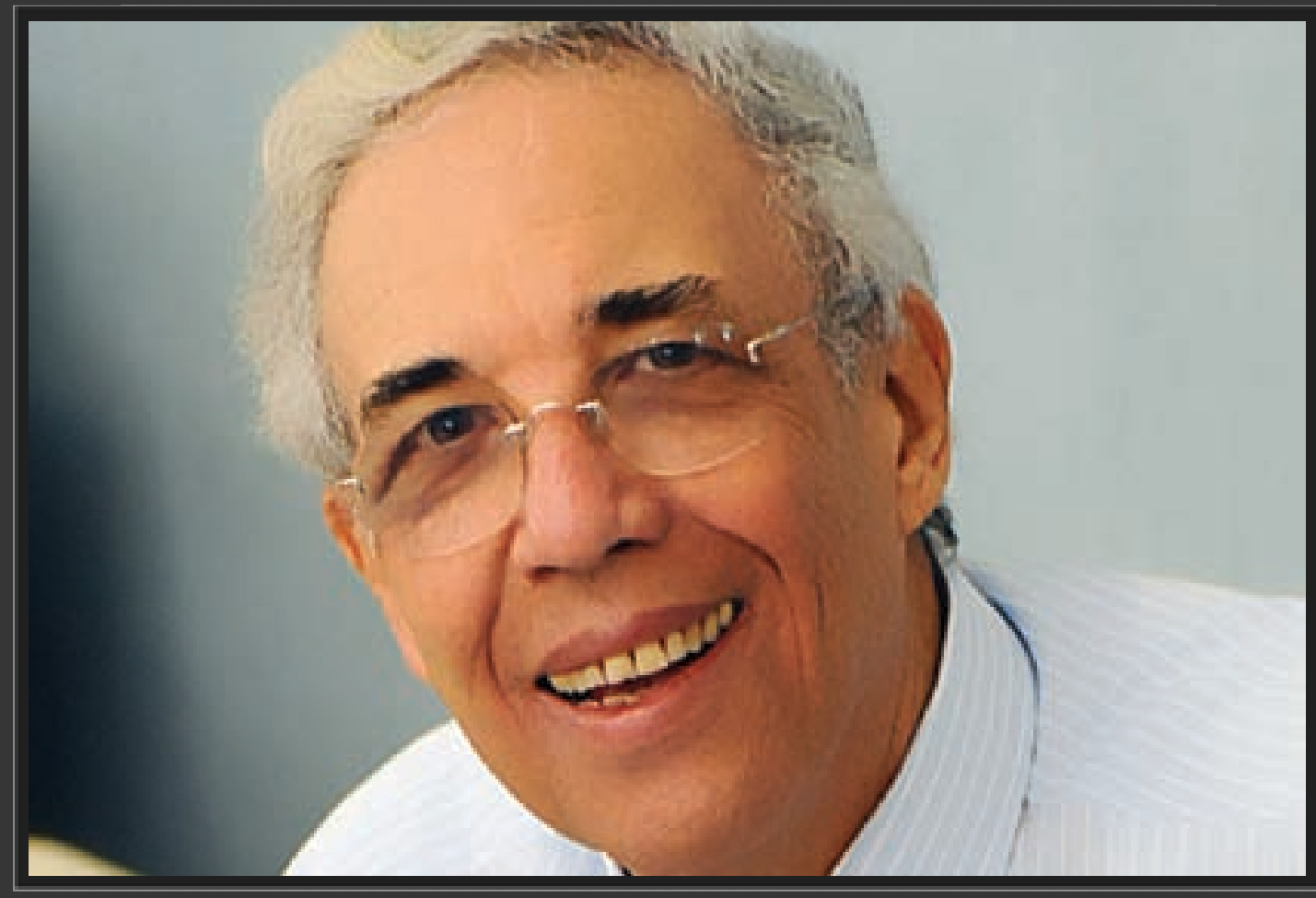

Figura 14: Dr Domingo M. Braile.

Com isso também houve a evolução na CEC, tornando este procedimento ainda mais complexo. Dessa forma, o profissional desta área (perfusionista) necessitou de conhecimentos para que suas decisões fossem rápidas e adequadas. Profissionais experientes como a perfusionista Maria Helena L. Souza e o cirurgião Cardíaco Décio O. Elias, seu esposo, (Figura 15) escreveram livros que permitiram uma visão integral das técnicas e cuidados para perfusão na cirurgia cardiovascular.

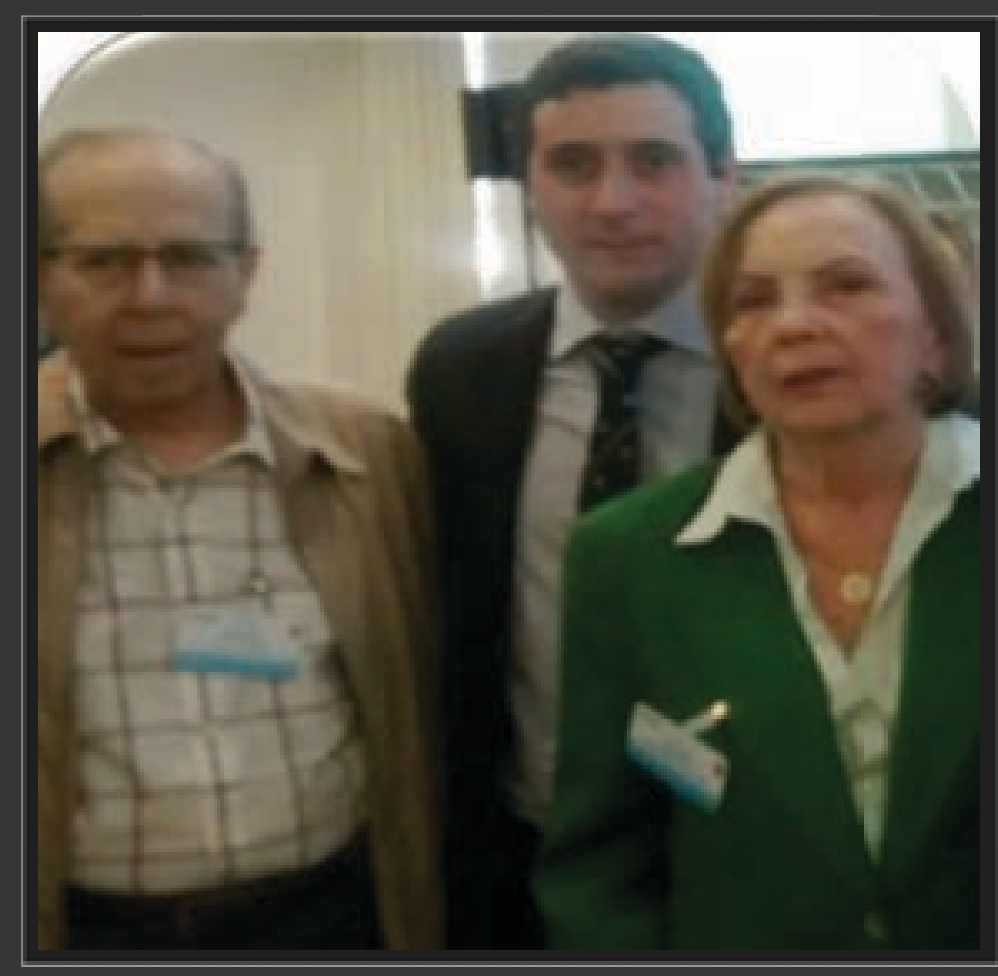

Figura 15: Dr Décio O. Elias (de blazer claro, à esquerda) e Maria H. Souza.

\subsection{Definição da circulação extracorpórea}

A CEC ou perfusão refere-se à passagem de sangue através de um órgão permitindo a substituição temporária da função de bomba cardíaca e da ventilação pulmonar. Além disso, pode- se recuperar o sangue no campo cirúrgico após anticoagulação sistêmica do paciente por meio de bombas aspiradoras. O coração é mantido parado e nutrido por meio da solução de cardioplegia. A função de bombeamento é desempenhada por uma bomba arterial (de roletes ou centrífuga) (Figuras 16 e 17) e a função ventilatória dos pulmões é substituída por um oxi- 
genador (Figura 18). Tubos plásticos biocompatíveis interligam paciente, oxigenador e bomba arterial, permitindo a circulação extracorpórea do sangue.

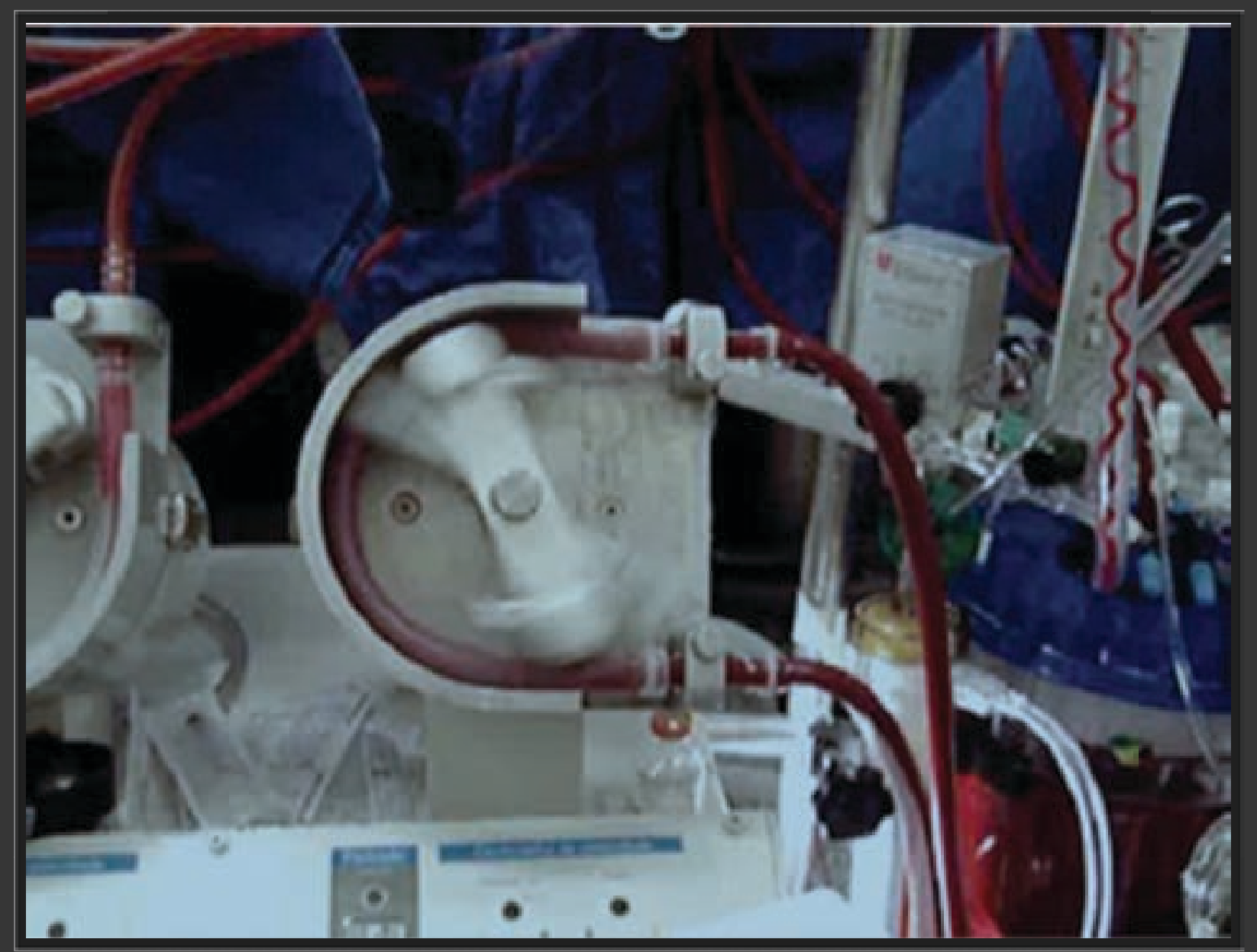

Figura 16: Bomba de roletes.

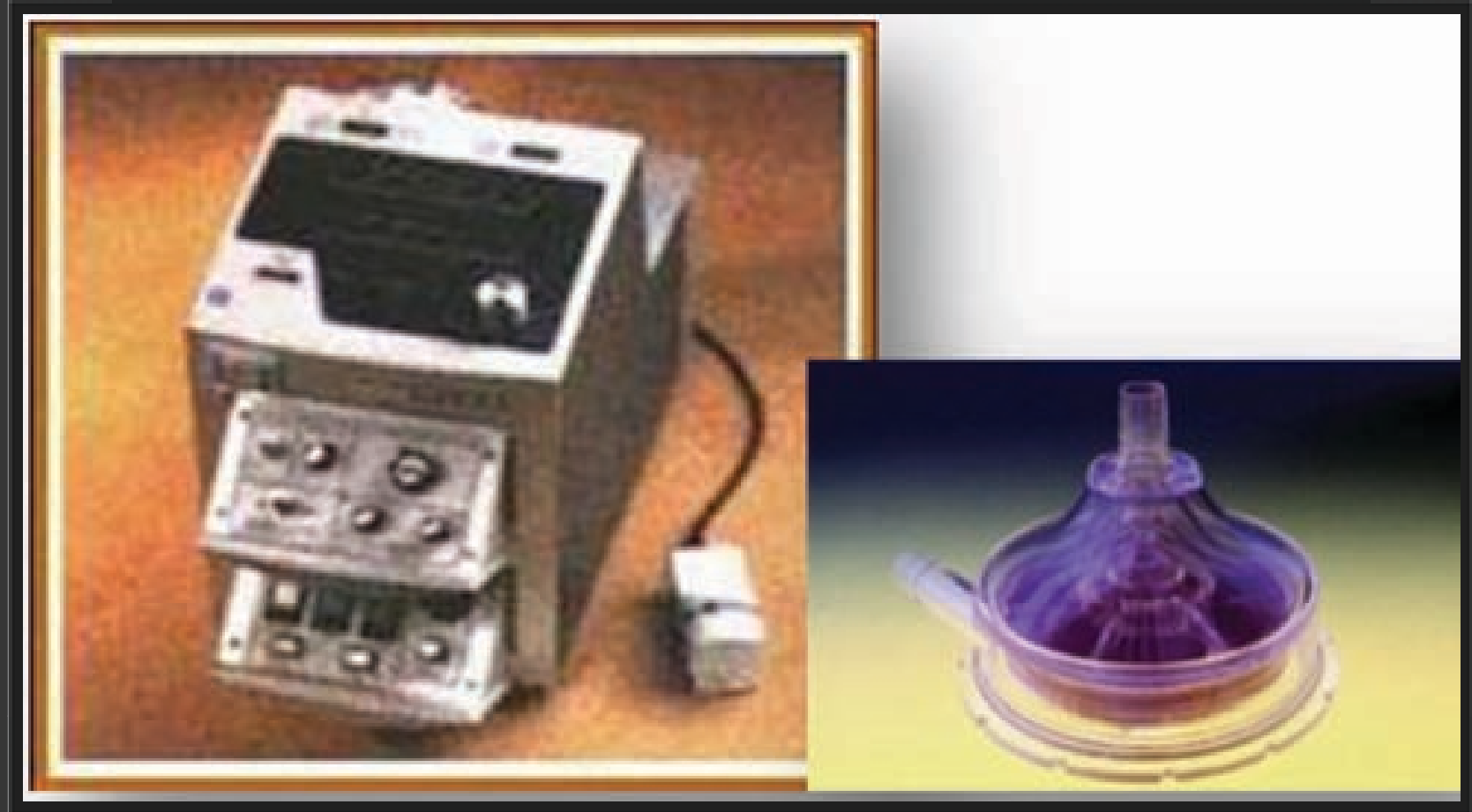

Figura 17: Bomba centrifuga (biopump) com bobina.

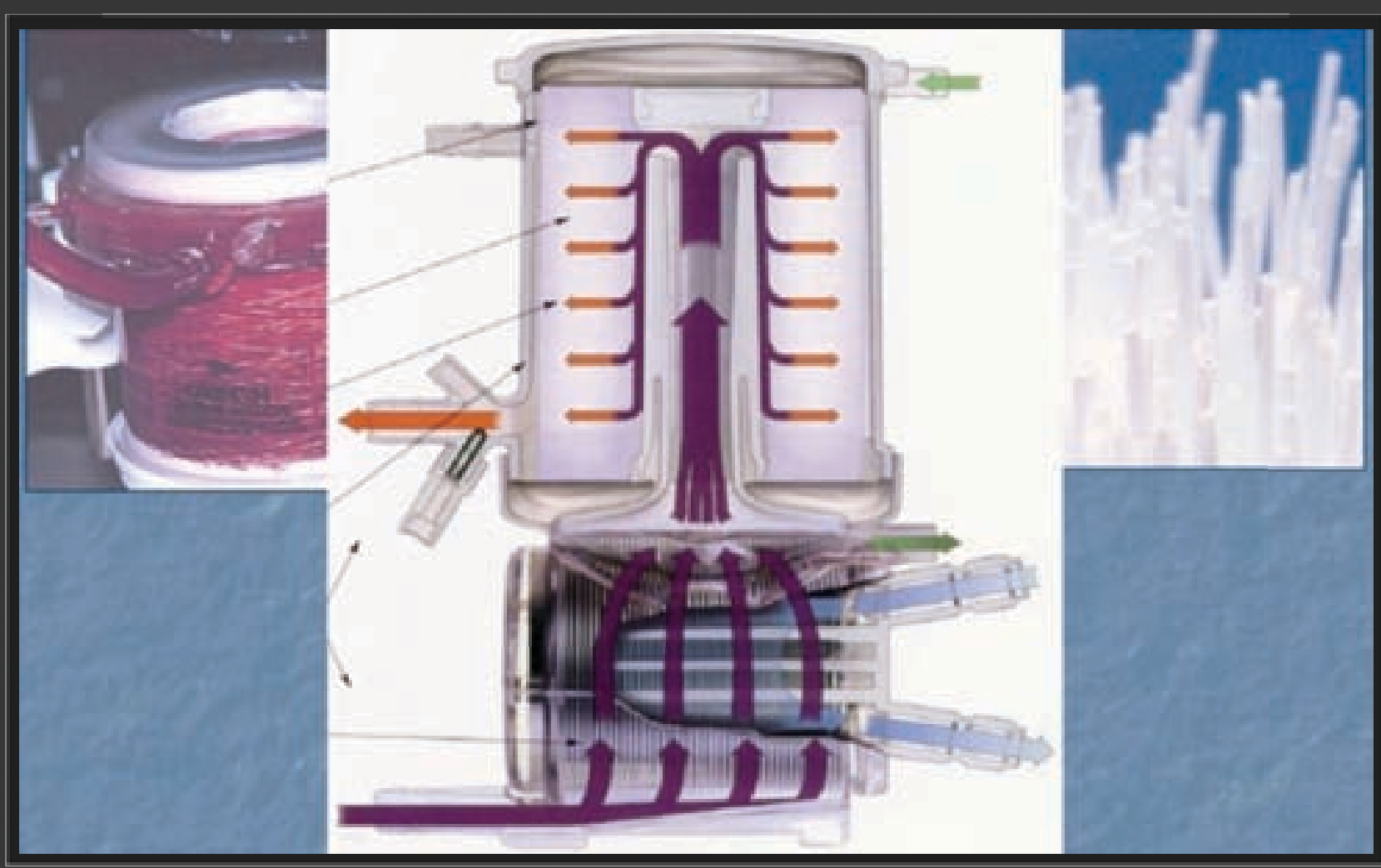

Figura 18: Oxigenador de membranas adulto. 


\subsection{Objetivo da circulação extracorpórea}

O objetivo da circulação extracorpórea é a substituição temporária das atividades cardiopulmonares (Figura 19) através da utilização de um conjunto de técnicas e equipamentos capazes de realizar as funções de bombeamento e oxigenação do sangue, garantindo a perfusão dos tecidos, a manutenção do metabolismo e a integridade celular.

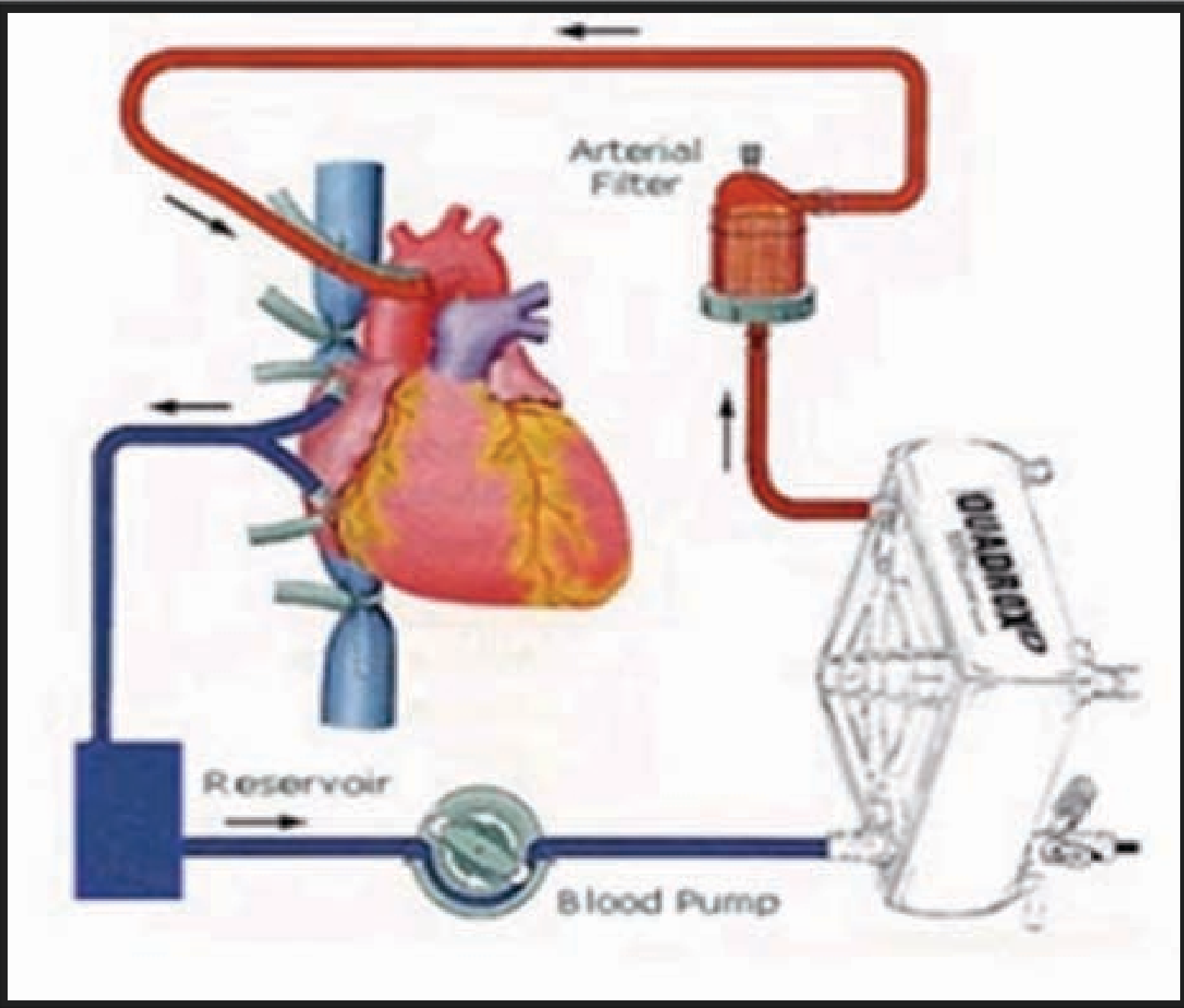

Figura 19: Esquema da perfusão.

\section{Circuito de circulação extracorpórea}

\subsection{Bandeja}

Definido como um conjunto de tubos e conectores que fazem a interligação entre o oxigenador, bombas propulsoras e o paciente (Figura 20).

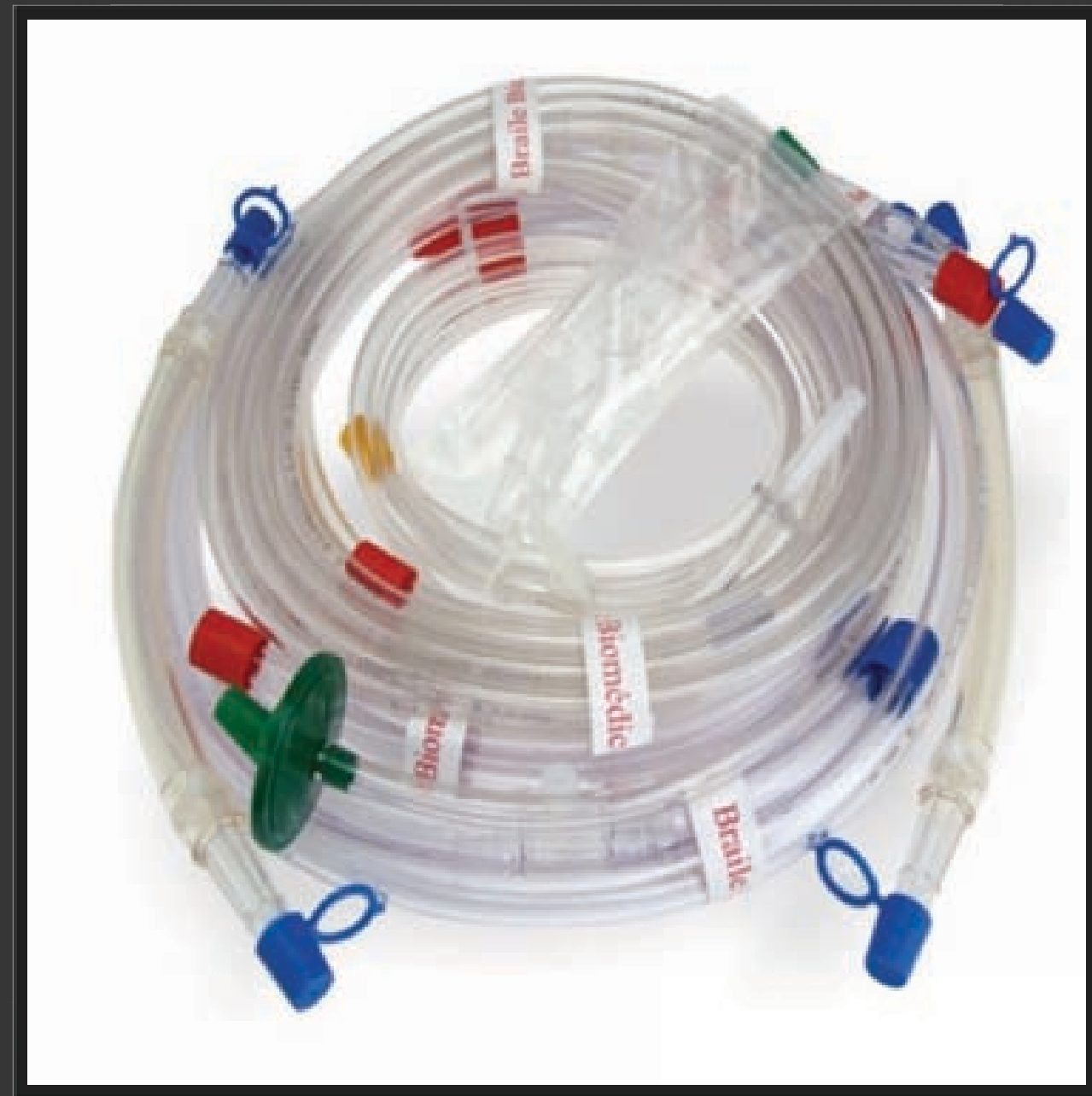

Figura 20: Conjunto de tubos para CEC. 


\subsection{Cânulas}

São responsáveis por drenar o sangue do paciente para a bomba coração-pulmão e infundir o sangue já oxigenado. Podem ser aramadas ou não.

\subsubsection{Cânula Arterial}

Esta cânula é responsável por levar o sangue oxigenado para a aorta do paciente (Figura 21). A seguir temos a posição anatômica da canulação arterial na porção ascendente (Figura 22).

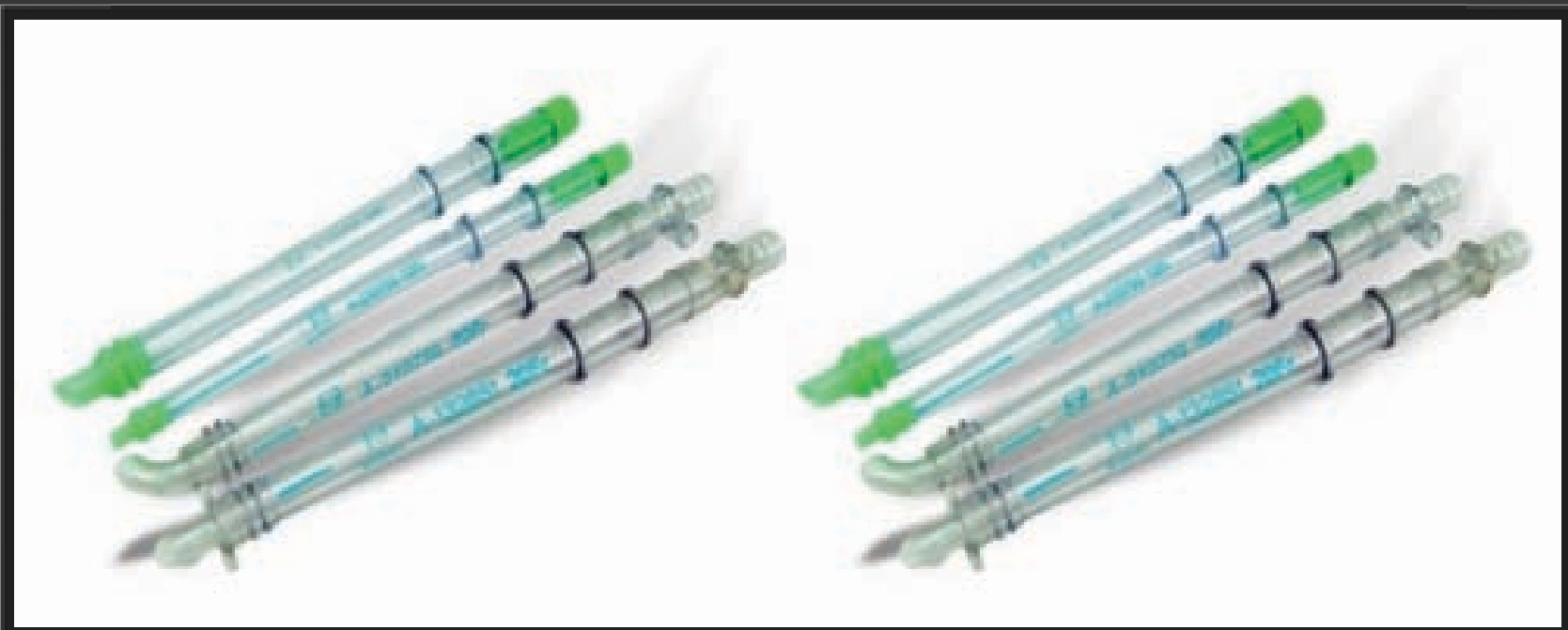

Figura 21: Conjunto de cânulas arteriais aramadas e não aramadas.

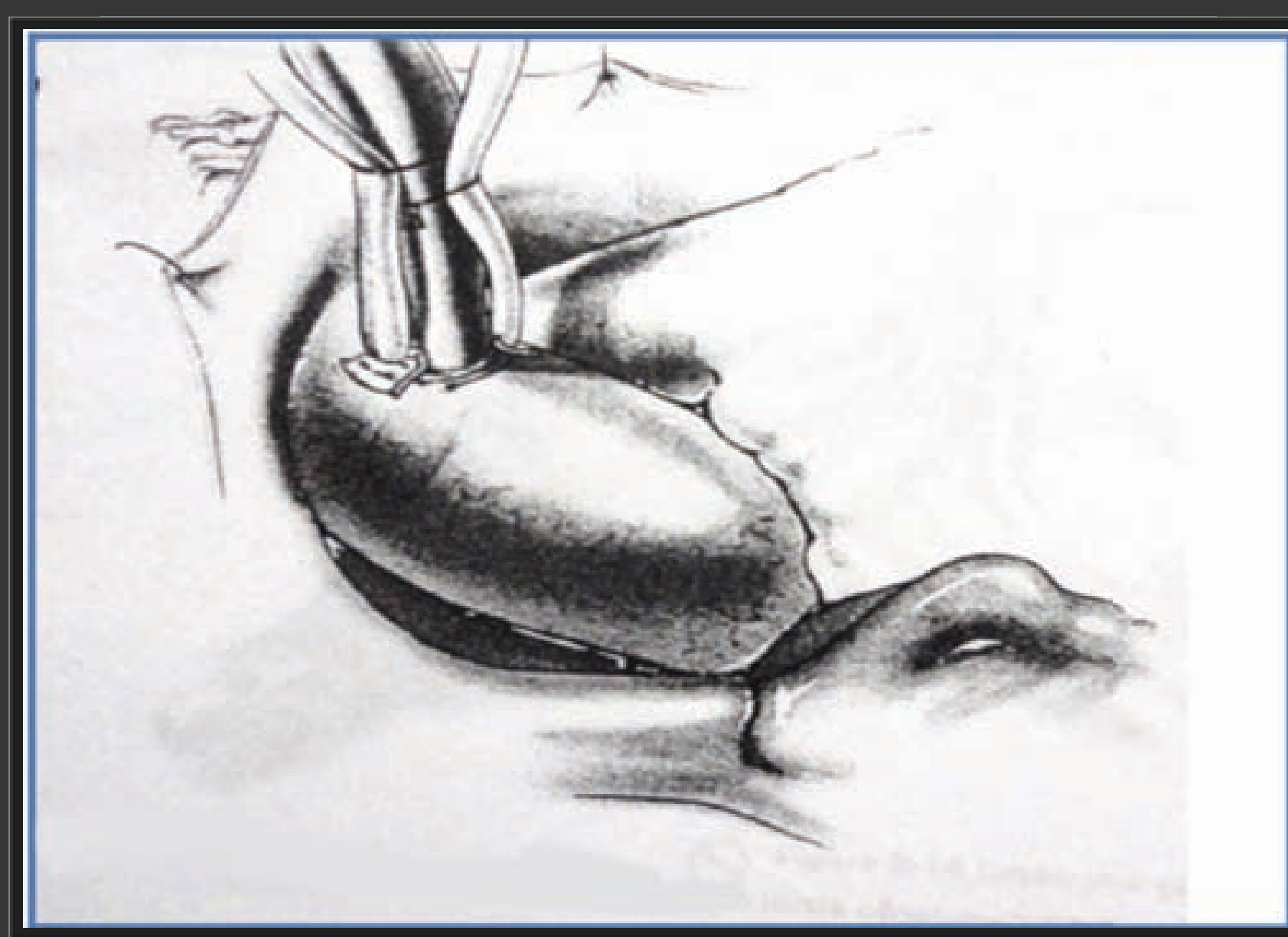

Figura 22: Posicionamento da cânula arterial na aorta.

\subsubsection{Cânulas Venosas}

São responsáveis por drenar o sangue venoso do paciente para o reservatório venoso, podendo ser uma única cânula colocada no átrio direito ou duas cânulas, uma na veia cava superior e outra na veia cava inferior (Figuras 23 e 24). 


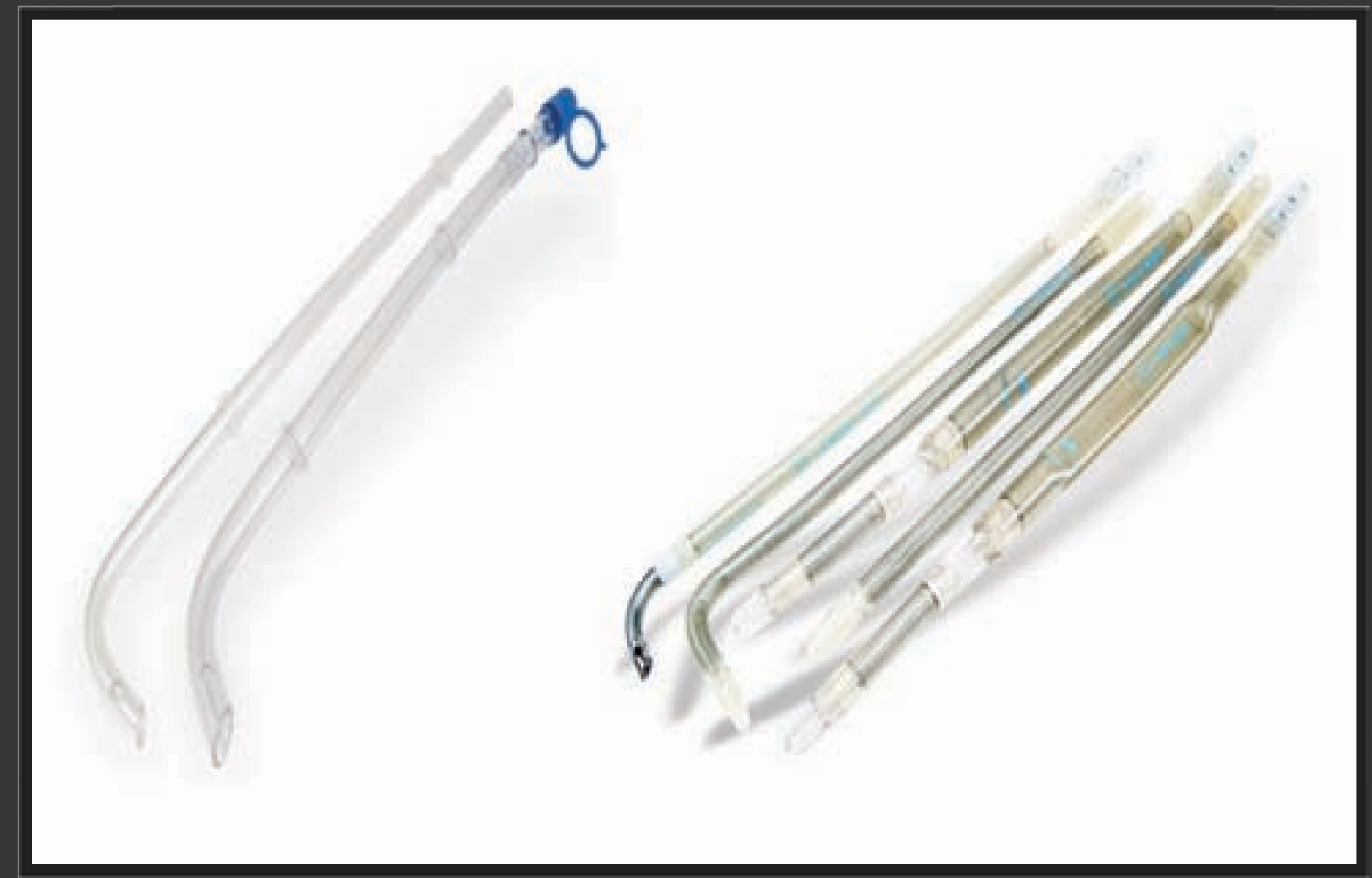

Figura 23: Conjunto de cânulas venosas aramadas e não aramadas.

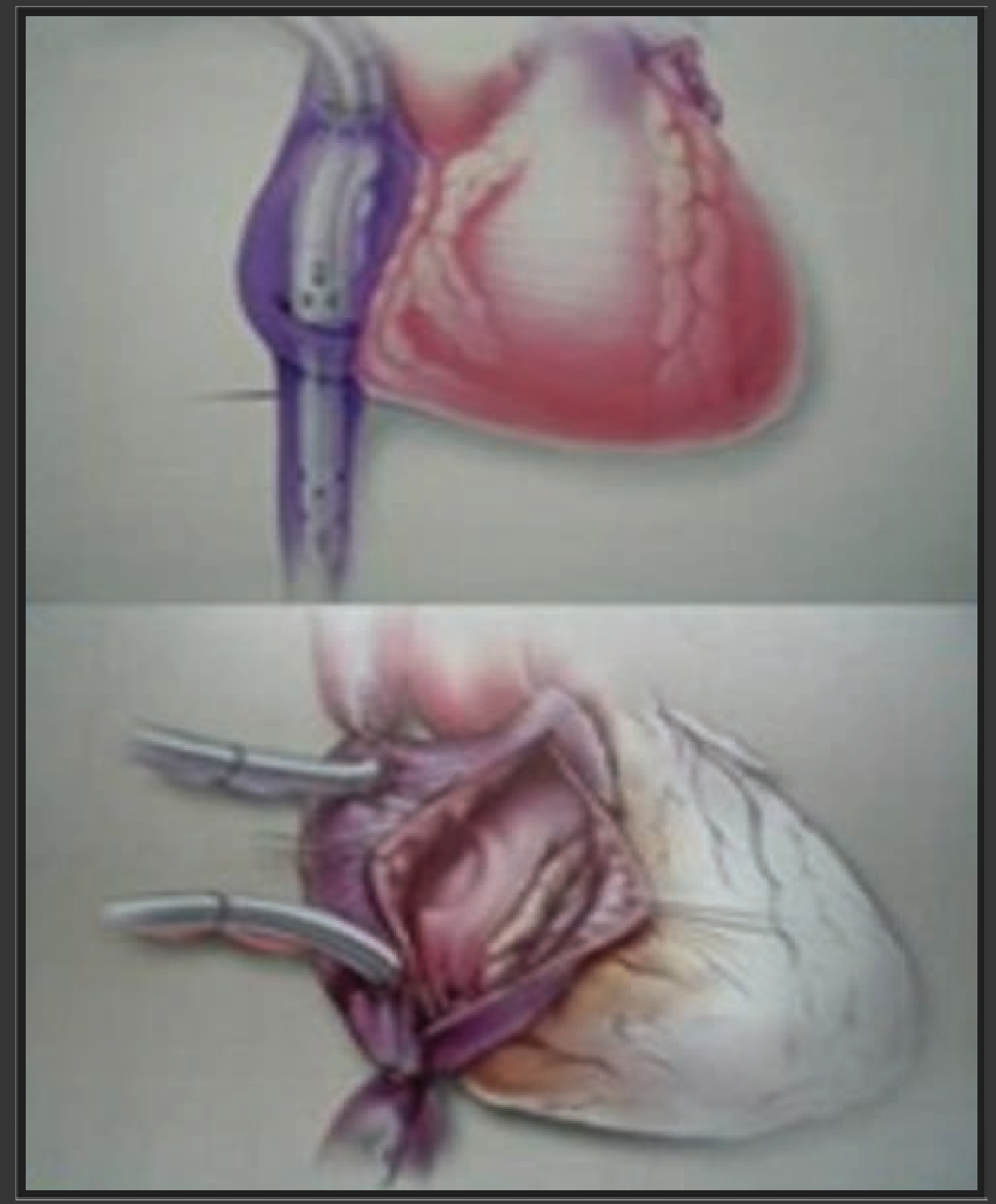

Figura 24: Posicionamento das cânulas venosas no átrio direto e nas veias cavas. 


\subsection{Filtro Arterial}

Este dispositivo é responsável por remover partículas, microagregados plaquetários e microbolhas gasosas do sangue arterializado no oxigenador, antes de sua infusão no paciente (Figura 25). Este deve ser o último elemento da linha arterial para o paciente.

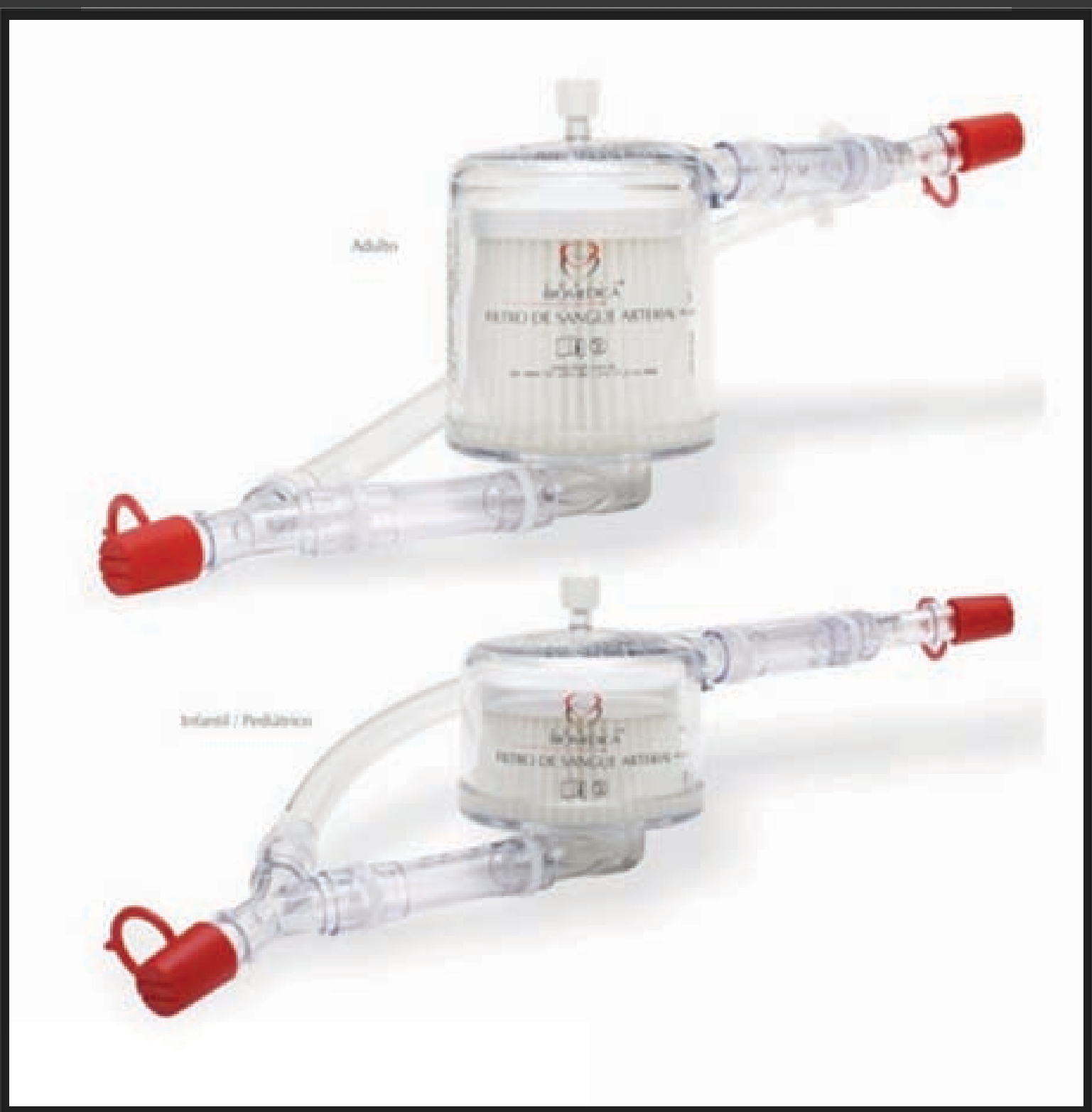

Figura 25: Filtro arterial adulto e infantil.

\subsection{Hemoconcentrador}

Este dispositivo é responsável por aumentar a concentração de hemoglobina e reverter a hemodiluição excessiva do sangue durante a circulação extracorpórea, removendo água, eletrólitos e substâncias de baixo peso molecular como algumas medicações e, também as escórias nitrogenadas (uréia, creatinina) (Figura 26).

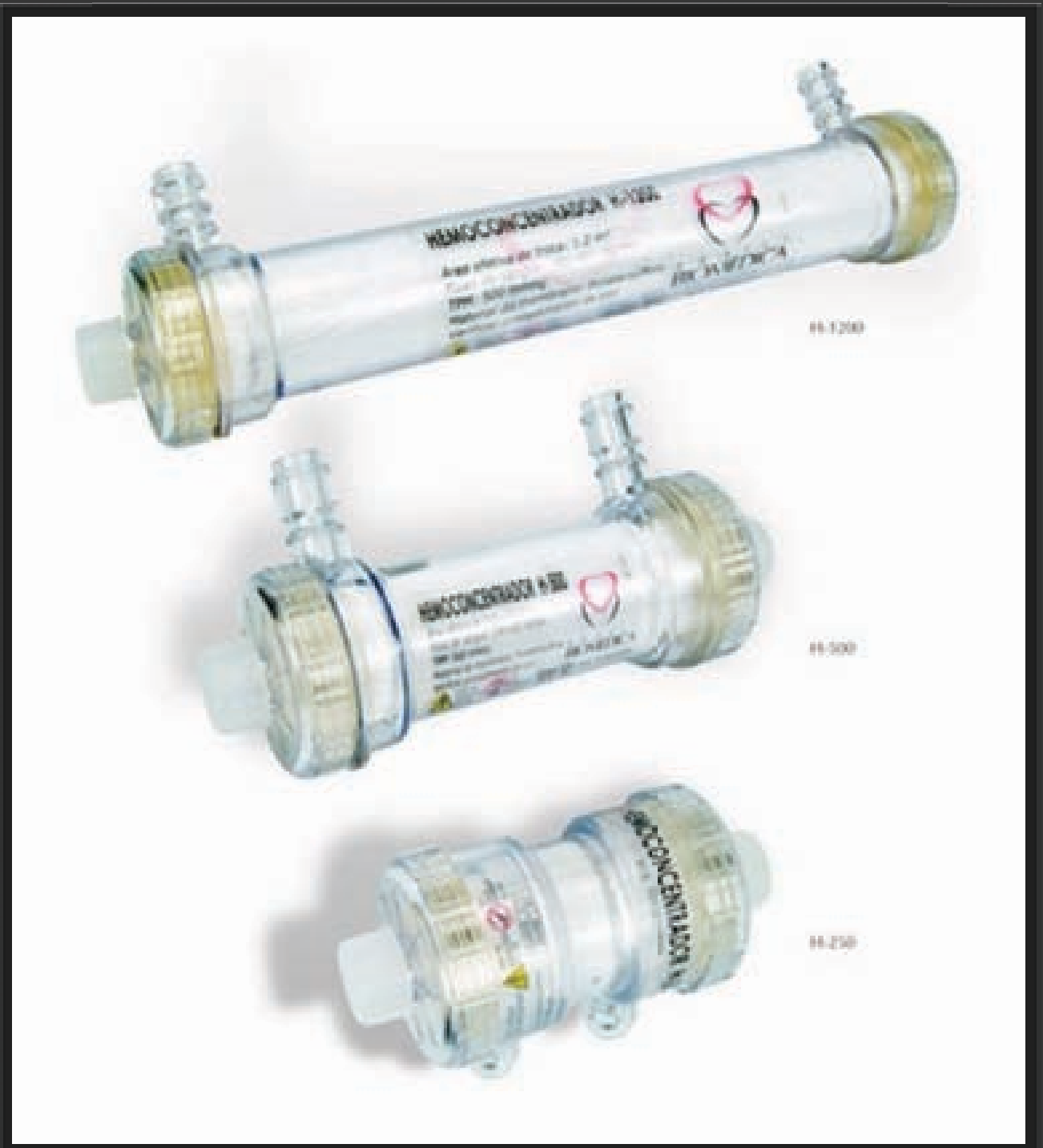

Figura 26: Hemoconcentrador adulto, infantil e neonatal. 


\subsection{Reservatório venoso e oxigenador}

O reservatório venoso pode ser flácido ou rígido e é responsável por coletar o sangue venoso drenado do paciente, podendo armazenar volume de reserva ou de segurança (Figura 27).

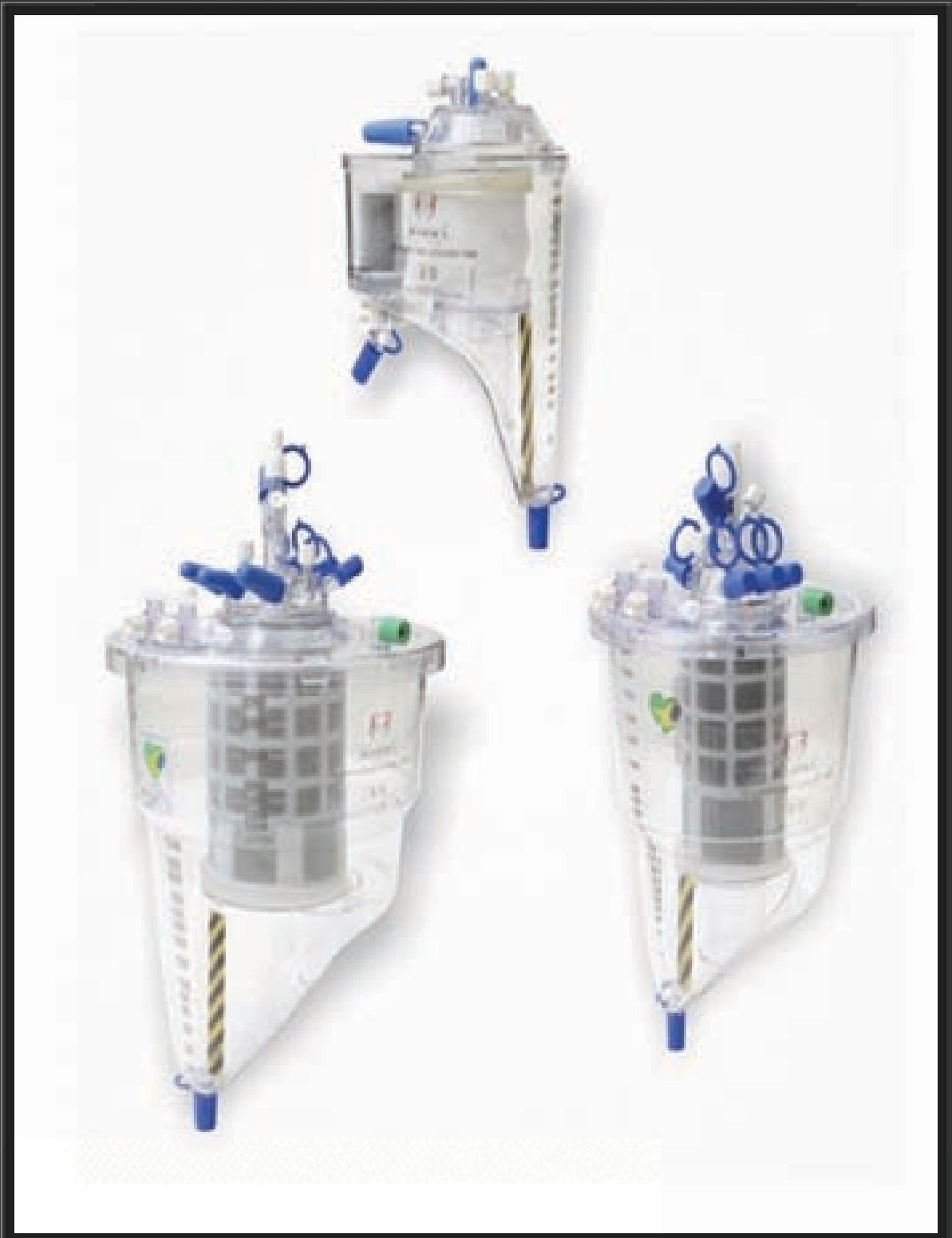

Figura 27: Modelos de reservatório venoso.
Os oxigenadores de membrana (Figura 28) são responsáveis por realizar as trocas gasosas, ou seja, introduzir o oxigênio no sangue e eliminar gás carbônico. Têm capacidade de oxigenar até seis litros de sangue por minuto. São construídos também de materiais atóxicos, biocompatíveis e resistentes a choques acidentais.

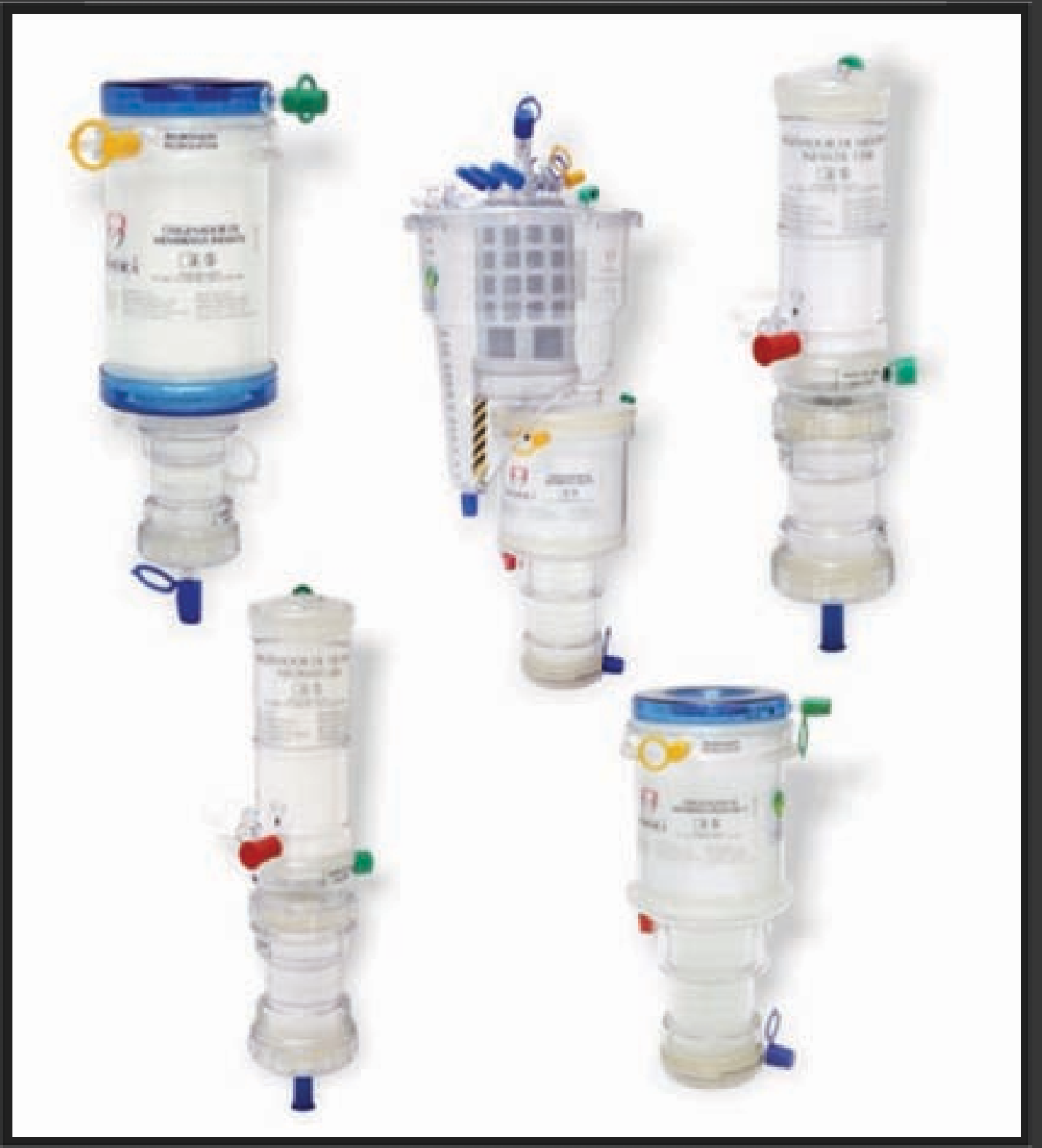

Figura 28: Oxigenadores de membrana neonato, infantil e adulto. 


\subsubsection{Adulto}

Utilizado para pacientes acima de 41 kg. Volume máximo de 4.000 ml.

\subsubsection{Pediátrico}

Utilizado para crianças de $23 \mathrm{~kg}$ a $40 \mathrm{~kg}$.

\subsubsection{Infantil}

Utilizado para crianças de $3 \mathrm{~kg}$ a $25 \mathrm{~kg}$.

\subsubsection{Neonato}

Utilizado para crianças até $3 \mathrm{~kg}$.

\subsection{Reservatório de cardioplegia}

É um sistema (Figura 29) para coleta de sangue oxigenado do paciente ou solução cristaloide específica destinada para proteção do miocárdio.

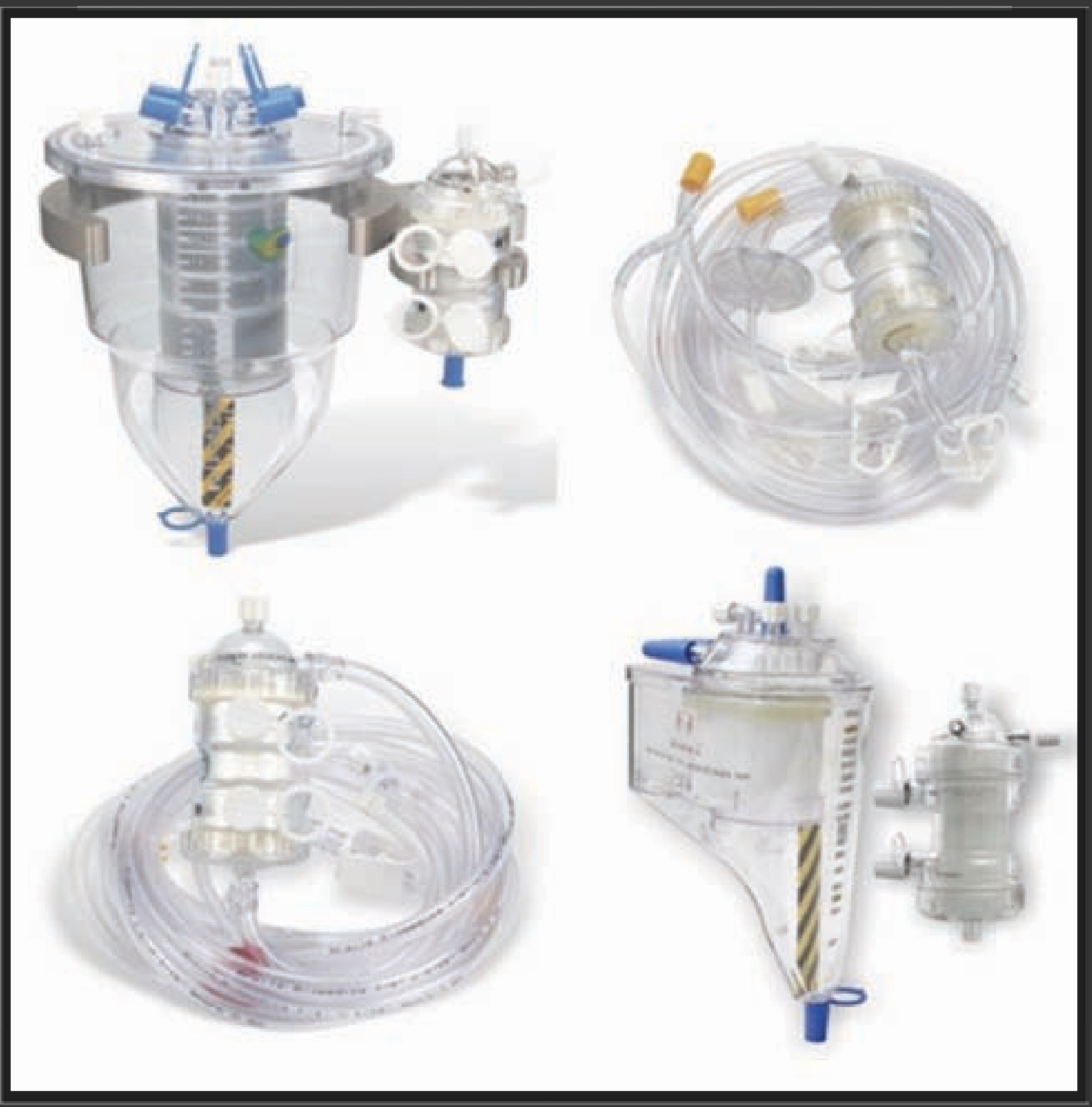

Figura 29: Sistema de cardioplegia adulto e infantil. 


\section{Fisiologia da CEC}

\subsection{Débito cardíaco}

O débito cardíaco é o volume de sangue bombeado pelo coração em um minuto. É igual à frequência cardíaca multiplicada pelo volume sistólico. O débito cardíaco fornecido pela CEC é um fluxo contínuo, laminar, pois não há pulsação cardíaca. Também é um fluxo controlado por meio de cálculos que o perfusionista faz para realizar a perfusão. Portanto, durante a perfusão existe uma simulação do coração fisiológico pelo rolete arterial da máquina de CEC.

Em circulação extracorpórea recomenda-se usar um fluxo arterial correspondente de 2,2 a 2,4l/min/ $\mathrm{m}^{2}$ de superfície corpórea, sendo o valor maior utilizado na perfusão infantil. Podemos correlacionar o fluxo arterial também com o peso do paciente (Tabela 1)

\section{Tabela 1- Peso e fluxo utilizados em CEC.}

\begin{tabular}{l|}
\hline Peso $(\mathrm{Kg})$ \\
\hline$<5$ \\
6 a 10 \\
11 a 20 \\
21 a 40 \\
$>41$
\end{tabular}

\begin{tabular}{|l|l}
\hline Fluxo arterial $\left(1 / \mathrm{min} / \mathrm{m}^{2}\right)$ \\
\hline 150 a 200 \\
100 a 150 \\
80 a 100 \\
60 a 80 \\
40 a 60 \\
\hline
\end{tabular}

Tabela 1: Peso e fluxo utilizados em CEC.

\subsection{Perfusato ou solução priming}

É a solução utilizada para a remoção de todo ar no circuito da circulação extracorpórea preenchendo a conexão artério- venosa. Esta solução pode ser cristaloide (solução de cloreto de sódio a 0,9\%, ringer com lactato, ringer simples, com a adição de manitol) ou coloide (com adição de concentrado de hemácias, plasma fresco congelado, albumina, colóides semi-sintéticos) dependendo das características do paciente como idade, peso, condições e estado geral, doenças associadas e o tipo do procedimento a ser realizado.

O perfusato também confere à CEC a característica da hemodiluição sanguínea, fator importante durante o procedimento.

\subsection{Anticoagulação e reversão}

É essencial que a coagulação do sangue seja inibida para impedir a formação de trombos durante os procedimentos com circulação extracorpórea. A anticoagulação sanguínea se faz necessária, pois o sangue estará circulando em tubos e conectores que não possuem endotélio. Para se inibir a coagulação do sangue nos procedimentos com circulação extracorpórea, usa-se uma medicação anticoagulante, a heparina sódica. Ela é a droga escolhida para essa finalidade porque tem poucos efeitos colaterais, é bem tolerada pelo organismo, pode ser usada com poucos inconvenientes, por longos períodos e existe um antídoto específico disponível. O controle da anticoagulação é feito pelo procedimento do tempo de coagulação ativado (TCA), e espera-se que ele es- 
teja acima de 480 segundos após a administração. Ao final da perfusão, neutraliza-se o efeito anticoagulante da heparina com outra medicação, o cloridrato de protamina. A dose da heparina depende da equipe cirúrgica e varia de 2 a 8 mg/kg de peso, e é revertida na proporção de 1:1, ou seja, para cada $1 \mathrm{ml}$ de heparina administrada revertese com 1 ampola de protamina. O TCA normal deve estar entre 80 e 120 segundos após a neutralização da heparina.

\subsection{Temperaturas em CEC}

A hipotermia ajuda a diminuir necessidades metabólicas do organismo. Este método durante a CEC gera maior segurança e flexibilidade no procedimento, possibilitando a redução dos fluxos de perfusão e de oxigênio sem causar anóxia tecidual, promove maior proteção metabólica e, em relação a acidentes e falhas na bomba coração- pulmão, promove proteção cerebral ao paciente.

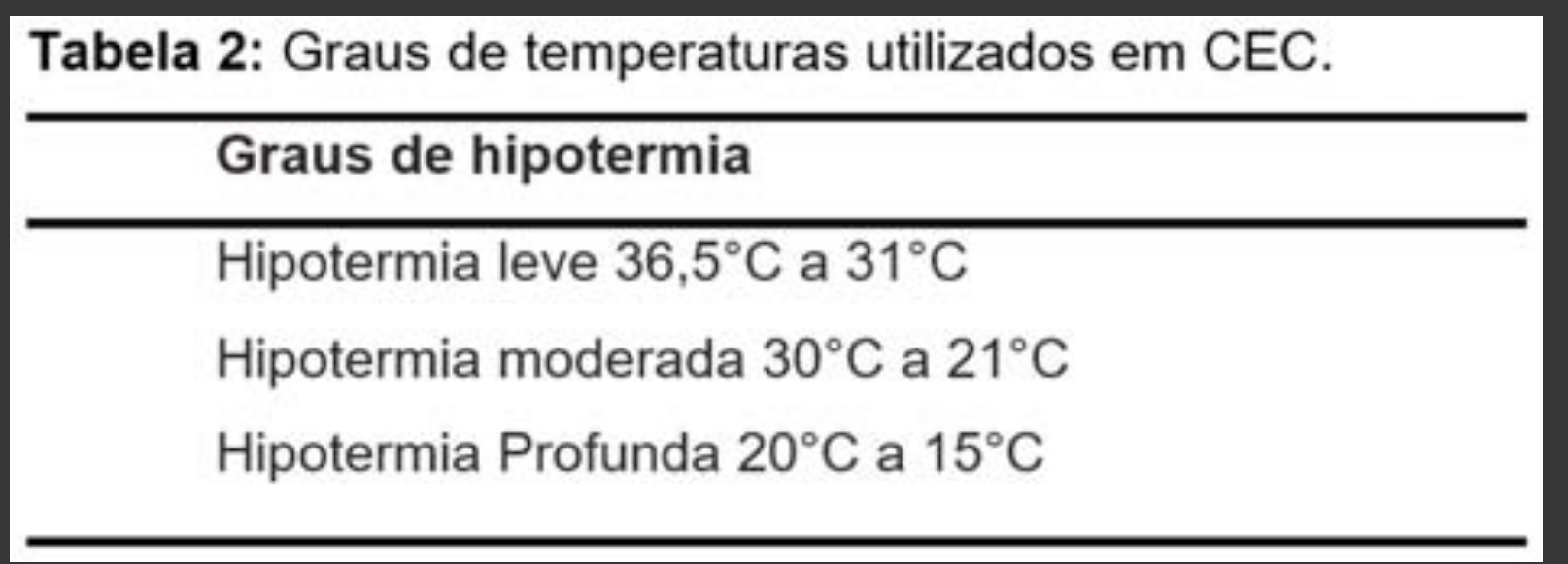

Tabela 2: Temperaturas utilizadas em CEC.

\subsection{Proteção miocárdica}

O metabolismo cardíaco é tão elevado quanto o metabolismo cerebral. O simples fato de o cirurgião realizar o pinçamento transverso da aorta promoverá a interrupção do fluxo sanguíneo para as artérias coronárias tornando o coração imóvel, relaxado e exangue, facilitando as correções cirúrgicas. Entretanto, não conferirá proteção ao tecido miocárdico em relação à isquemia trazendo como conseqüência desde uma ligeira redução na contração até uma situação irreversível como o infarto do miocárdio agudo ocorrido em cirurgia.

A solução cardioplégica deve proteger o coração ao invés de lesá-lo, distribuir-se homogeneamente por todo o miocárdio em quantidades suficientes para produzir o benefício desejado e ter o seu efeito mantido pelo tempo em que durar o pinçamento aórtico.

A composição da cardioplegia contém cloreto de potássio a 19,1\% (promoverá a assistolia cardíaca), sulfato de magnésio, lidocaína a $2 \%$ sem vasoconstritor, glutamato e aspartato. Existem soluções prontas no comércio, mas dependendo da equipe cirúrgica podem ser acrescentadas substâncias separadamente. Essas medicações serão colocadas no reservatório de cardioplegia e serão misturados ao sangue oxigenado do paciente (cardioplegia sanguínea) ou ao cloreto de sódio 0,9\% (cardioplegia cristaloide).

A cardioplegia pode ser administrada por via anterógrada, ou seja, na raiz da aorta ou diretamente nos óstios coronarianos. Nesta via a solução cardioplégica percorre a circulação coronariana no sentido normal do fluxo sanguíneo. Alternativamente, a cardioplegia poderá ser admi- 
nistrada por via retrógrada, ou seja, no óstio do seio coronário do átrio direito e percorrendo a circulação coronariana no sentido inverso, sendo recolhida na raiz da aorta. Em casos mais graves de revascularização do miocárdio e de estenose valvar aórtica, a cardioplegia poderá ser realizada tanto anterógrada quanto retrógrada. A cardioplegia ainda pode ser administrada com temperatura ambiente (normotérmica) ou fria (hipotérmica).

\section{Condução da circulação extracorpórea}

O débito cardíaco por meio do fluxo arterial de perfusão pode ser calculado pelo peso corpóreo ou pela superfície corporal do paciente de acordo com a tabela abaixo (Tabela 3):

\section{Tabela 3: Fluxo de perfusão de acordo com o peso.}

\begin{tabular}{l|l}
\hline Peso & Fluxo de perfusão \\
\hline Até $5 \mathrm{Kg}$ & $150 \mathrm{ml} / \mathrm{Kg} / \mathrm{min}$ \\
5 a $10 \mathrm{Kg}$ & 100 a $120 \mathrm{ml} / \mathrm{Kg} / \mathrm{min}$ \\
11 a $20 \mathrm{Kg}$ & 80 a $100 \mathrm{ml} / \mathrm{Kg} / \mathrm{min}$ \\
21 a $40 \mathrm{Kg}$ & 60 a $80 \mathrm{ml} / \mathrm{Kg} / \mathrm{min}$ \\
$>41 \mathrm{Kg}$ & 40 a $60 \mathrm{ml} / \mathrm{Kg} / \mathrm{min}$ \\
\hline
\end{tabular}

O perfusionista deve saber tudo o quanto for possível sobre o paciente que será submetido a uma cirurgia cardiovascular com CEC. A identificação e os dados antropométricos são de suma importância. Exames laboratoriais como hemograma, coagulograma, bioquímicos e sorologias são indispensáveis. Deve- se saber sobre o uso prévio de anti- agregantes e/ ou heparina. A cineangiocoronariografia com ventriculografia nos coronarianos ou idade superior a 40 anos é fundamental, bem como o ecocardiograma e dúplex de carótidas (para pacientes selecionados). Todos estes dados ajudarão na condução de uma perfusão segura e eficiente.

O perfusionista deve realizar a CEC (Figura 30) com uma drenagem venosa inicial controlada, a fim de evitar uma hipovolemia aguda do paciente, resultando em estímulo simpático intenso. A condução da perfusão deve ser com fluxo arterial adequado, controle rigoroso da resistência vascular sistêmica, controle da hemodiluição não permitindo níveis de hematócrito inferiores de $25 \%$ e controles criteriosos da oxigenação e do equilíbrio ácido-base.

Tabela 3: Fluxo de perfusão de acordo com o peso. 


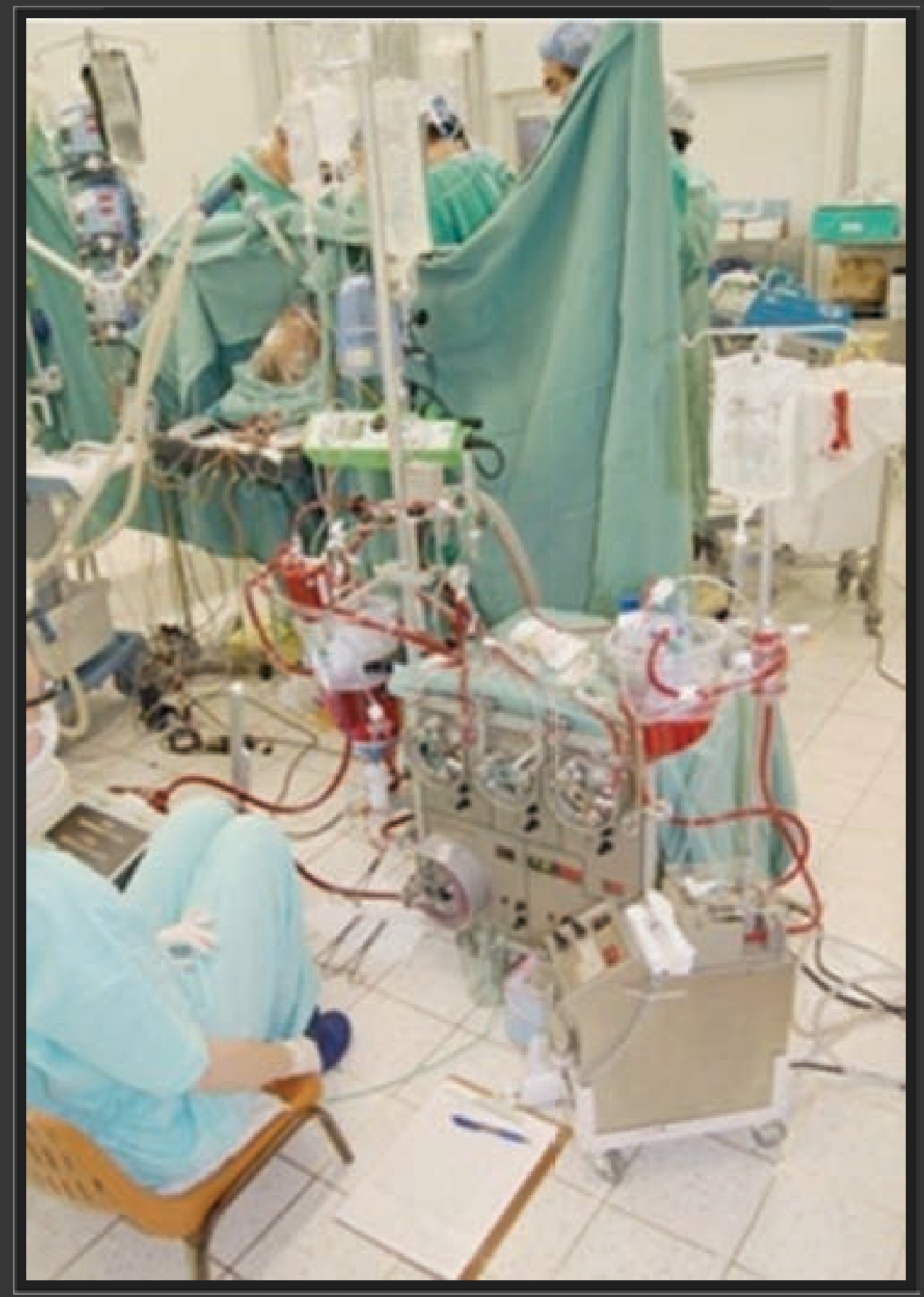

Figura 30: Em CEC.
Para isso, existe uma ficha na qual o perfusionista realiza as suas anotações de controle durante a CEC, como por exemplo: os horários, os valores do fluxo, da pressão arterial média (PAM), da temperatura nasoesofágica, os controles de gases (oxigênio e gás carbônico), valores do tempo de coagulação ativado (TCA) e da gasometria arterial e venosa, administração de drogas, além das anotações gerais e das intercorrências.

O ajuste da perfusão deve ser ditado pelo comportamento das respostas do paciente. Por isso, o exame de gasometria arterial é fundamental para o perfusionista por mostrar a real situação hemodinâmica. As alterações observadas devem ser compreendidas, analisadas e corrigidas rapidamente. Quando em CEC, o paciente é considerado como se estivesse em choque cardiogênico, como politrauma ou em parada cardiorrespiratória. Logo a importância do controle periódico e rigoroso.

A saída da perfusão é o período mais crítico e delicado, em que a comunicação entre cirurgião e perfusionista é de extrema importância. Neste momento, os pulmões e o coração retornam as suas funções e é necessário que ocorra um período de "assistência" destes órgãos. $\mathrm{O}$ coração retoma seus batimentos devagar e as áreas de atelectasias pulmonares são removidas. Também neste período podem ser administradas medicações necessárias ao equilíbrio do paciente como drogas vasoativas e inotrópicas. Portanto, a saída de CEC deve ser lenta e gradativa, com reposição lenta do volume do reservatório venoso de acordo com o pedido do cirurgião e com as respostas do paciente. 


\section{Complicações da circulação extracorpórea}

Apesar de seus benefícios significativos, a CEC pode desencadear a síndrome pós-perfusão, em que mediadores bioquímicos se expressam clinicamente desencadeando coagulopatias pela ação do sistema complemento, disfunção de ventrículo esquerdo e isquemia miocárdica pela ação das interleucinas 6 e 8, fibrinólise pela ação de radicais livres, vasoplegia pela ação de cininas, necrose celular pela ação do fator de necrose alfa (TNFa) e liberação de espécies reativas de oxigênio pela isquemia e reperfusão. Tudo isto pode levar a maior suscetibilidade à infecção, a um quadro mais crítico de insuficiência múltipla de órgãos e até à morte. Mesmo em períodos curtos de CEC a resposta inflamatória induz reações imunológicas que são desencadeadas imediatamente.

A CEC pode ainda produzir hemólise devido à má calibração da bomba arterial e dos aspiradores ou devido à duração do procedimento em si. Com o rompimento das hemácias, o seu conteúdo e os restos celulares permanecem na corrente sanguínea induzindo uma resposta inflamatória aguda através da ativação de mediadores inflamatórios do sistema complemento e por meio do estímulo da secreção das interleucinas $1 \beta$ e 6 e também do TNFa.

A relevância da correlação entre resposta inflamatória e hemólise de pacientes submetidos à cirurgia cardiovascular com CEC no pós-operatório se deve ao fato da possibilidade de surgimento de complica- ções em vários sistemas, pode influenciar no tempo de ventilação mecânica e de internação na UTI.

O trauma da CEC induz uma resposta inflamatória com graus variados de severidade. O contato do sangue com superfície não endotelizada é um dos principais fatores que a desencadeiam e dentre suas potenciais consequências estão insuficiência cardíaca, lesões cerebrais, vasoplegia, coagulopatia, insuficiências renal e respiratória e isquemia mesentérica.

A CEC age como agente agressor devido ao desvio de sangue para um circuito artificial. Existem outros fatores lesivos como, por exemplo: heparinização sistêmica do paciente, mudança do regime de fluxo sanguíneo de pulsátil para contínuo, tendência a acidose metabólica, hipotermia controlada, stress mecânico sob os elementos figurados do sangue, hemodiluição sanguínea e a consequente redução dos fatores de coagulação e, por vezes, a necessidade de transfusão sanguínea maciça.

Para minimizar a resposta inflamatória da CEC algumas medidas (Tabela 4) podem ser tomadas já que ajudam na busca do equilíbrio do organismo do paciente. 
Tabela 4: medidas para amenizar a inflamação durante a CEC

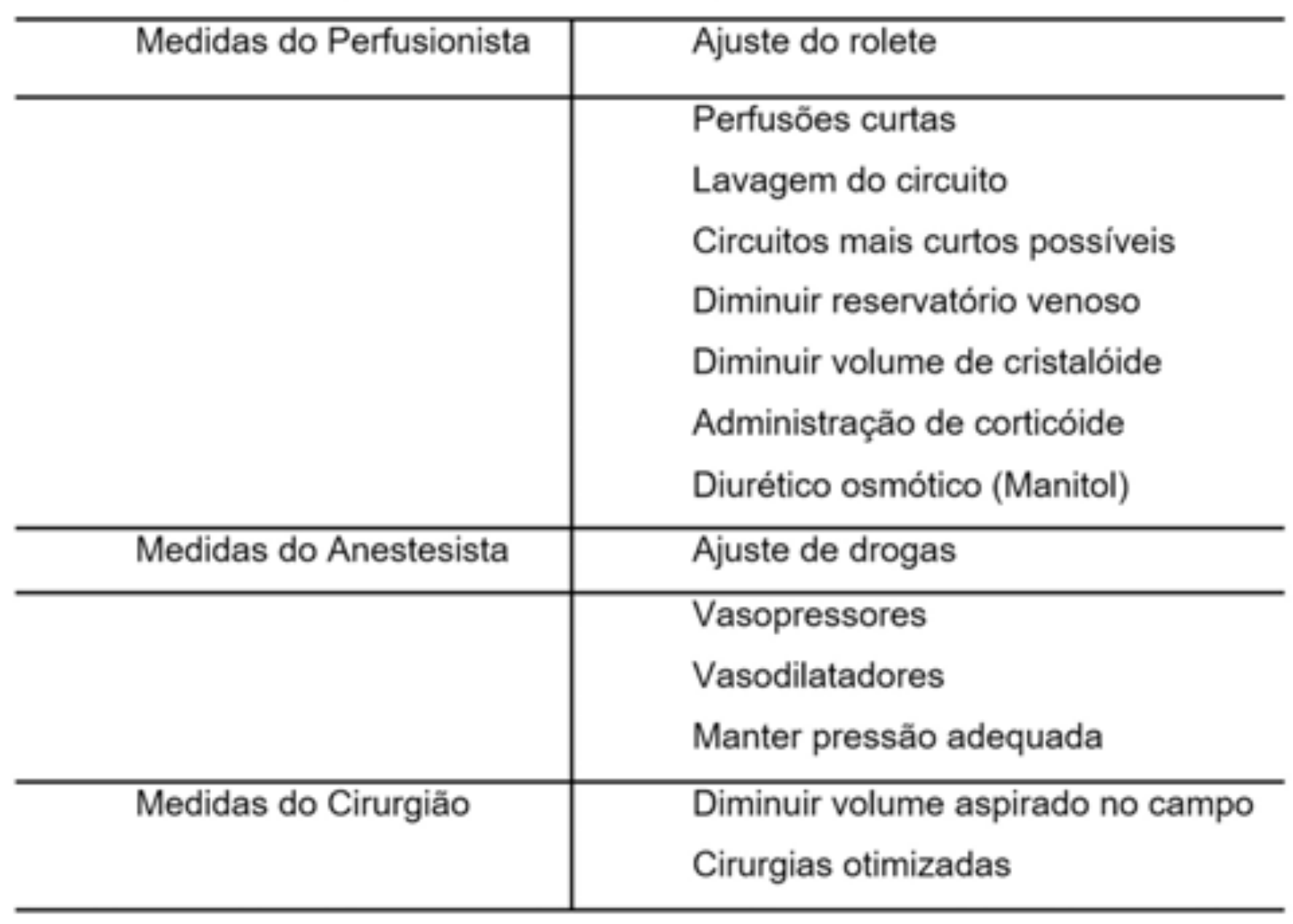

Tabela 4: Medidas para amenizar a inflamação durante a CEC.

\section{Perfusionista e Perfusões especiais}

O Perfusionista é um profissional que possui registro pela CBO (Classificação Brasileira de Ocupações) do Ministério do Trabalho e Emprego, no qual estão descritas suas atividades e a formação básica para exercício dessa ocupação. Tal caracterização confirma que esta especialidade é assegurada apenas para profissionais que tenham formação em curso superior na área da saúde e das ciências biológicas e que sejam certificados pela única instituição que fornece o Título de Especialista em Perfusão no Brasil, a Sociedade Brasileira de Circulação Extracorpórea (SBCEC).

O profissional habilitado em perfusão pode atuar nas cirurgias cardiovasculares adultas e pediátricas. Existem protocolos especiais para gestantes, idosos, neonatos inclusive de baixo peso, hepatopatas, renais crônicos, portadores de coagulopatias e hemoglobinopatias e obesos. A CEC também é necessária para alguns casos de transplantes hepáticos, transplantes cardiopulmonares, quimioterapias intra-abdominais hipertérmicas e de membros isolados e de correção de aneurismas aórticos tóraco-abdominais. Este profissional pode participar de pesquisa em cirurgia animal, participar de gestão de banco de dados cirúrgicos e representação técnica e científica de empresas fornecedoras de materiais.

\section{Bibliografia}

Braz JRC, Auler Júnior JOC, Gomes do Amaral JL, Coriat P. O sistema cardiovascular e a anestesia. In: Duval Neto GF, Gomes do Amaral JL. Circulação extracorpórea. Porto Alegre: Artes Médicas; 1997. p. 14762. 
Galantier J. Particularidades da circulação extracorpórea. In: Auler Junior JOC, Oliveira SA. Pós-operatório de cirurgia torácica e cardiovascular. São Paulo: Artmed; 2004. p. 153-7.

Gomes OM. Interpretação clínica das alterações ácido-básicas e distúrbios da oxigenação. In: Gomes OM, Gomes ES. Equilíbrio ácido-básico e parâmetros de oxigenação em circulação extracorpórea. Belo Horizonte: Coração; 1997. p. 227-39.

Passaroni CP, Silva MAM, Yoshida WB. Cardiopulmonary bypass: development of John Gibbon's heart-lung machine. Rev Bras Cir Cardiovasc. $2015 ; 30(2): 235-45$.

Souza MHL, Elias DO. Fundamentos da circulação extracorpórea. 2a ed. Rio de Janeiro: Centro Editorial Alfa Rio; 2006. 800 p.

Teixeira Filho GF, Batista G. Temas atuais de circulação extracorpórea. Porto Alegre: Sociedade Brasileira de Circulação Extra Corpórea; 1997. $301 \mathrm{p}$. 


\section{BALÃO INTRA-AÓRTICO}

Aline Andrea Teodoro dos Santos

Andréia Cristina Passaroni

Tassya Bueno Takeda 


\section{Histórico}

Em 1958 Harken descreveu o princípio da contrapulsação, que consistia em remover uma quantidade de sangue pela artéria femoral, durante a sístole para a injeção rápida durante a diástole, com o objetivo de aumentar a pressão de perfusão coronariana. Baseado nisso, a primeira aplicação clínica do balão intra-aórtico (BIA) foi em 1968 em pacientes com choque cardiogênico. O primeiro console foi criado em 1970. Em 1979 a terapia foi aprimorada com o desenvolvimento do balão intra-aórtico percutâneo. O primeiro cateter com membrana dobrada foi criado em 1985. Em 2015 foi o dispositivo mais utilizado para assistência ventricular mecânica (Figura 1).

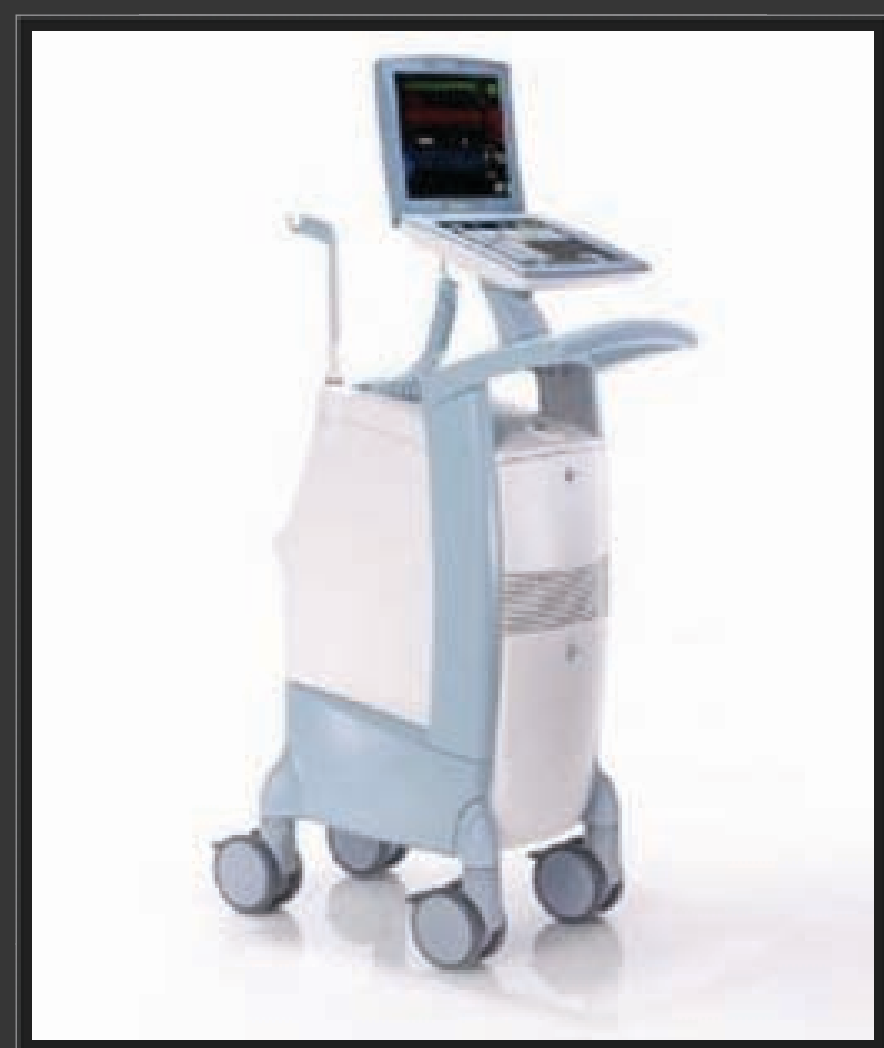

Figura 1: Dispositivo mecânico - console (Balão Intra-aórtico).

\section{Introdução}

\subsection{Conceito}

O balão intra-aórtico é uma modalidade de assistência circulatória mecânica temporária. Consiste em uma terapia de contrapulsação, ocorrendo a inflação do balão durante a diástole e desinflação antes do início da sístole cardíaca (Figura 2). O cateter balão é introduzido pela artéria femoral e posicionado na aorta torácica descendente, imediatamente inferior à artéria subclávia esquerda, inflando e desinflando em sincronismo com o ciclo cardíaco.

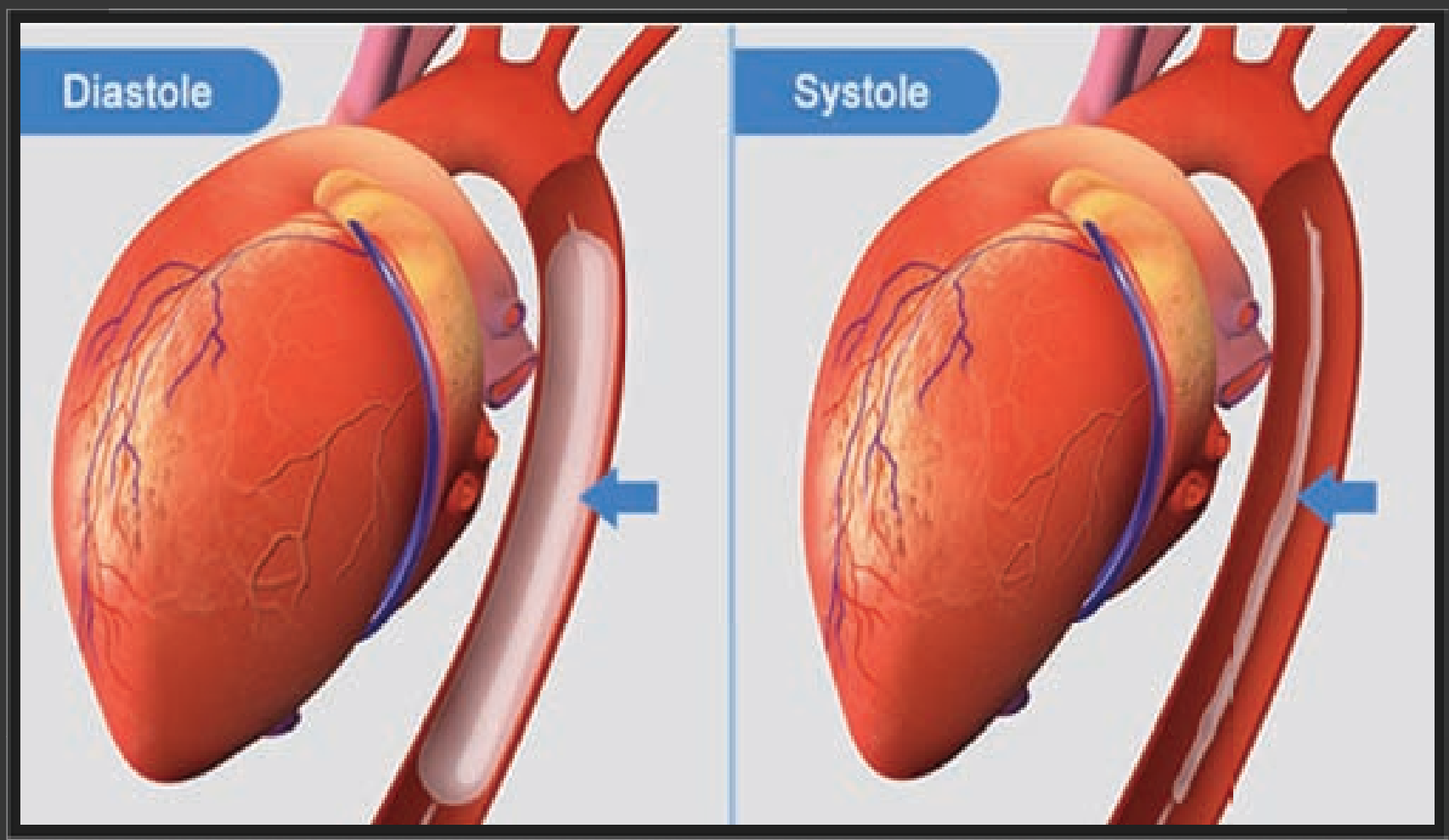

Figura 2: Cateter balão na sístole e diástole cardíaca. 


\subsection{Objetivos}

\subsubsection{Primários}

Tabela 1- Objetivos primários do balão intra-aórtico

\section{Diástole}

Aumento da perfusão coronariana:

Tabela 1- Objetivos primários do balão intra-aórtico.

\subsubsection{Secundários}

\section{Tabela 2- Objetivos secundários do balão intra-aórtico}

Diminuição do trabalho cardíaco;

Diminuição do consumo de oxigênio pelo miocárdio;

Aumento do débito cardíaco;

Tabela 2- Objetivos secundário do balão intra-aórtico.

\section{Indicações}

Pode ser utilizado para o choque cardiogênico refratário à terapia medicamentosa, infarto agudo do miocárdio e suas complicações mecânicas agudas (insuficiência mitral e comunicação interventricular), suporte pré-operatório de cirurgia cardíaca, suporte para procedimentos per- cutâneos e diagnósticos (cateterismo cardíaco e angioplastia coronária), desmame da circulação extracorpórea durante cirurgias cardíacas.

\section{Contra- indicações}

Não deve ser utilizado na insuficiência aórtica grave, aneurismas de aorta, suspeitas de dissecção de aorta, coagulopatias, sepse grave e doença arterial periférica.

\section{Materiais}

São necessários os seguintes materiais: cateter, transdutor de pressão, cabo de eletrocardiograma, cabo do transdutor (Figura 3).

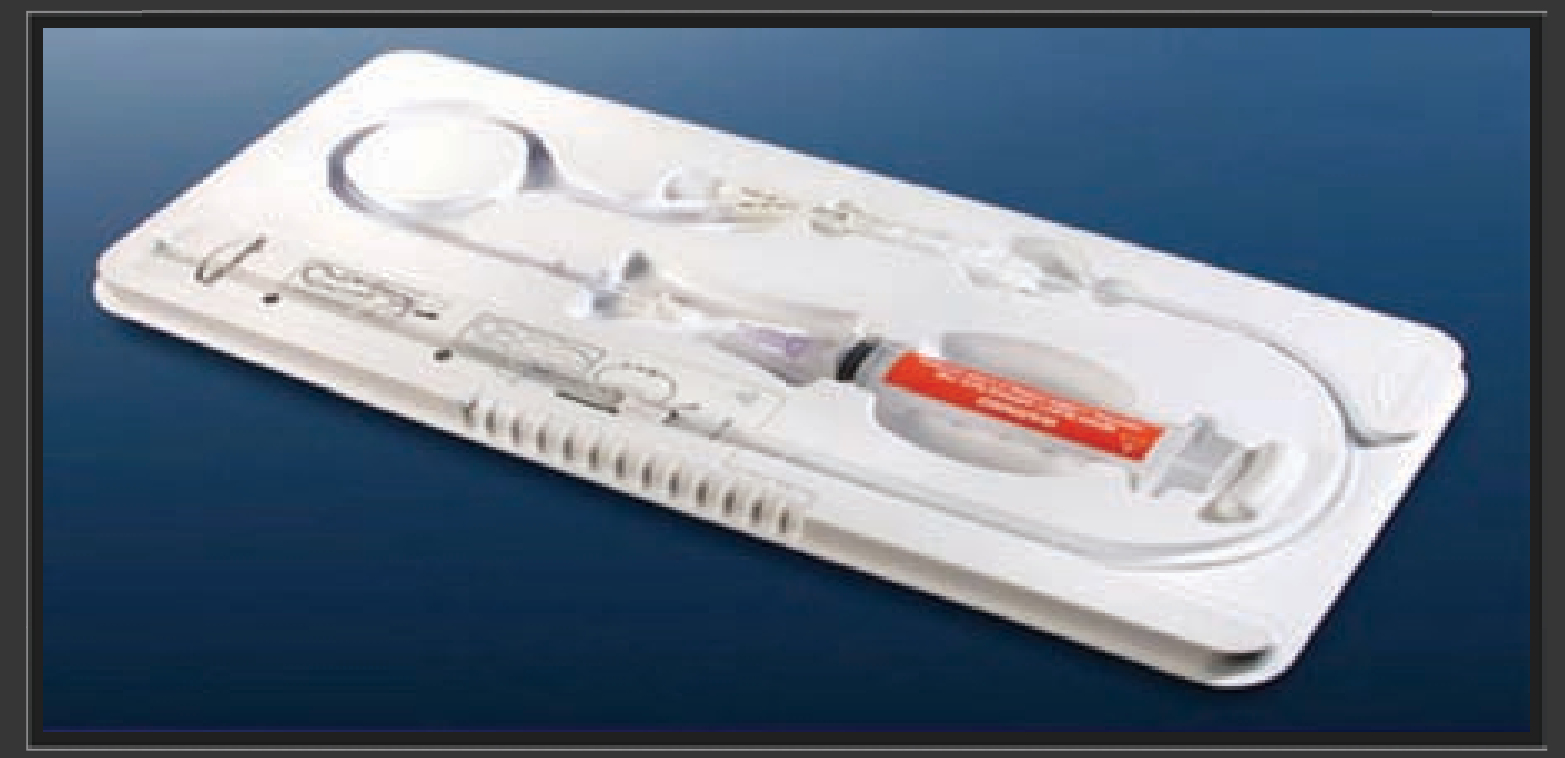

Figura 3: Kit materiais para o Balão Intra-aórtico. 


\section{Console}

O console é composto por monitor, seção pneumática, software, tanque do gás hélio e duas baterias acopladas. (Figura 4).

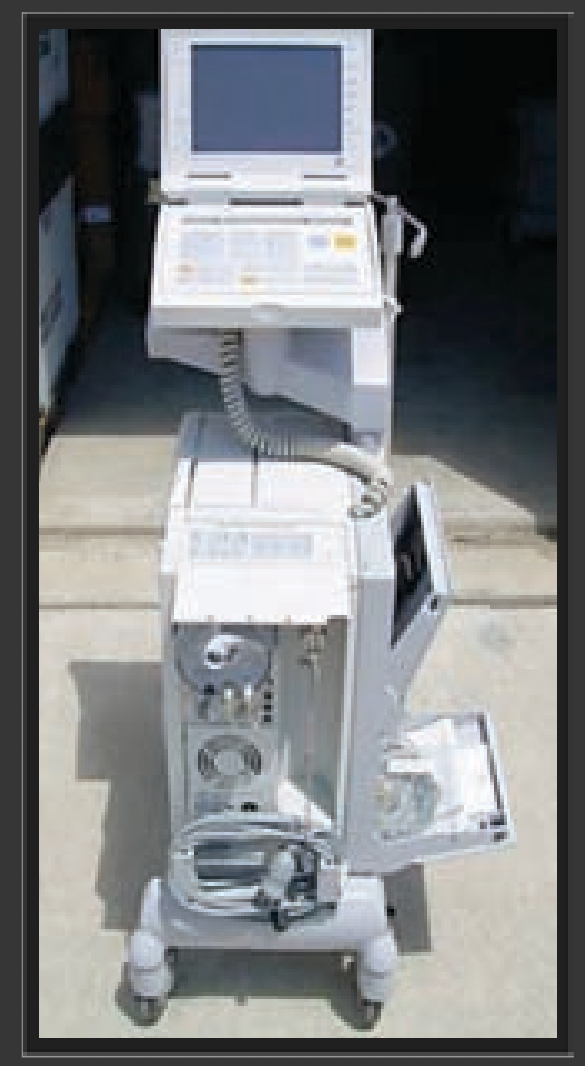

Figura 4: Console do Balão Intra- aórtico.

\section{Procedimento para inserção do cateter balão}

O console do BIA pode ser levado à beira do leito, ao lado da mesa cirúrgica ou mesmo da mesa da sala de hemodinâmica. Este é facilmente transportável podendo ser colocado inclusive em aeronaves.
Logo após a colocação do cabo do eletrocardiograma específico para o BIA, o console deverá ser ligado. Este cabo é blindado e, devido a este detalhe, ele suporta cardioversão/ desfibrilação do paciente caso haja necessidade e, por isso, não poderá ser trocado por outro cabo, pois o console sofrerá um curto circuito. Este cabo pode ser colocado no tórax do paciente, respeitando as cores que estão descritas (Figura 5).

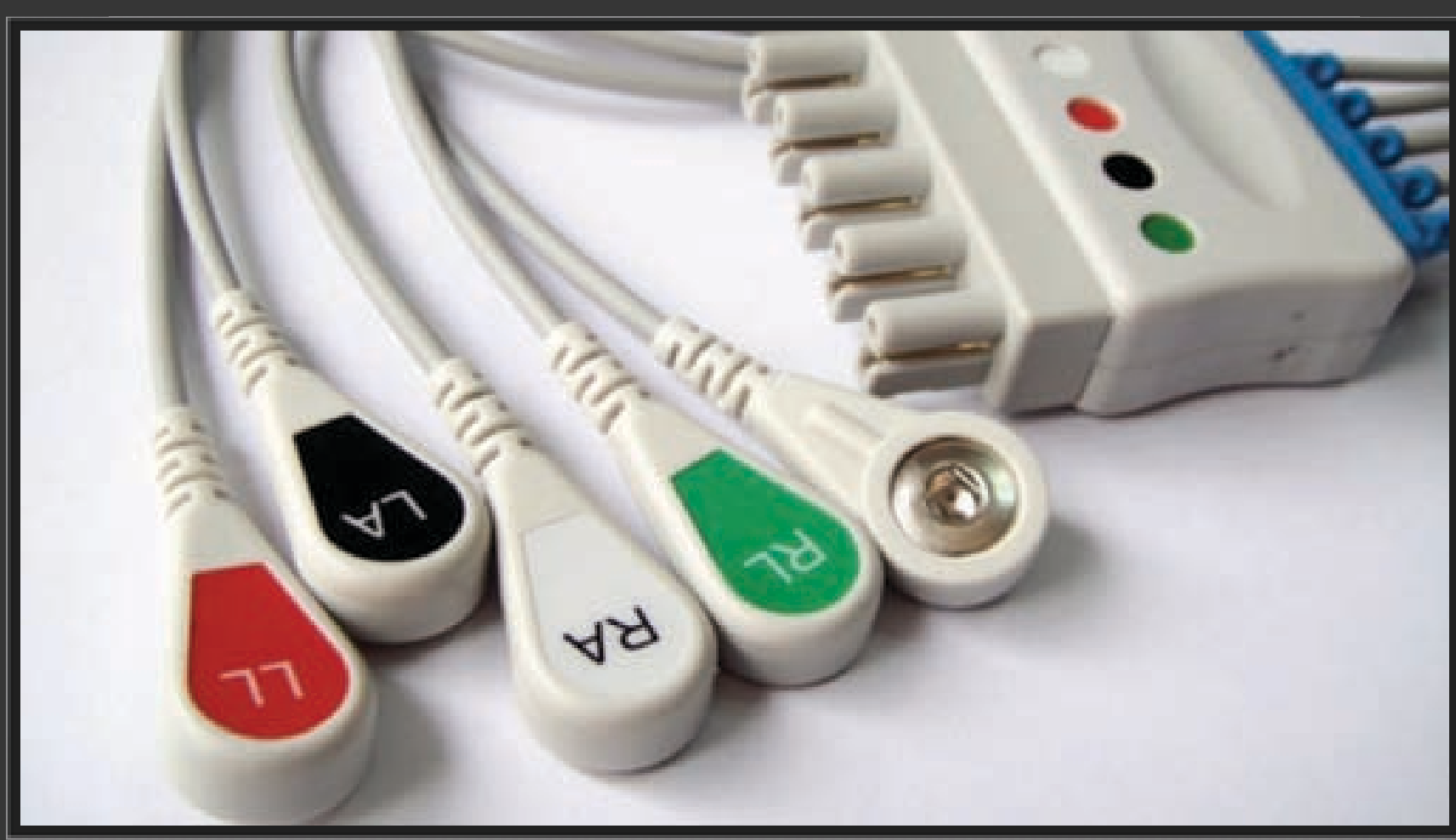

Figura 5: Cabo do eletro blindado do Bia.

Para a lavagem do cateter balão é necessária uma solução de cloreto de sódio a 0,9\% com heparina sódica. Este deverá ser acoplado em 
um equipo com transdutor de pressão compatível com o cabo pressórico do BIA.

A seguir, temos a sequência do procedimento para a inserção do BIA.

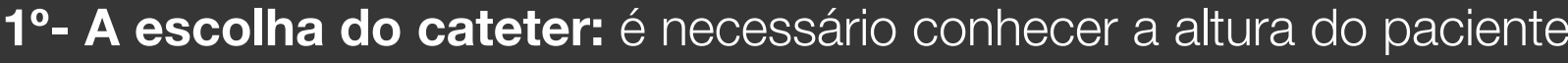
para a escolha adequada do cateter balão (Figura 6).

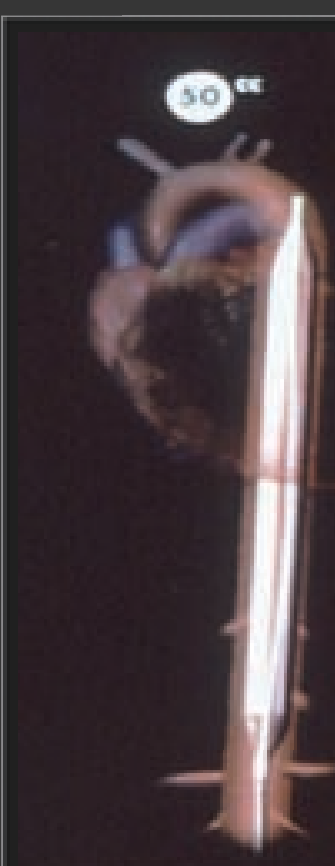

$>182 \mathrm{~cm}$

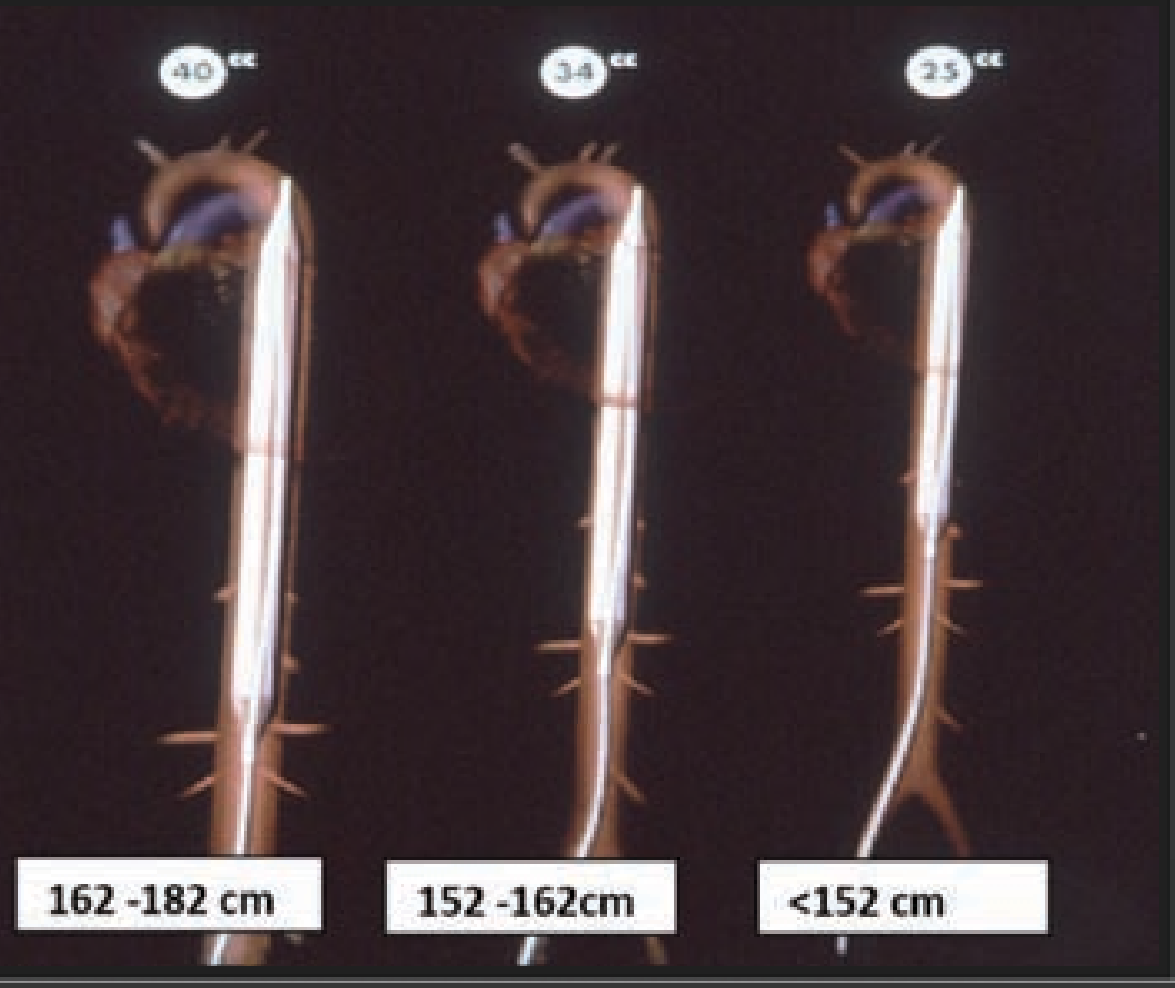

Figura 6: Cateteres balão e tamanhos.

$2^{\circ}$ - Montagem do transdutor da pressão arterial: o transdutor de pressão deve ser posicionado na linha axilar média e conectado ao cateter balão por uma extensão transparente inclusa no kit. A solução com heparina é mantida em bolsa pressurizada em 300 mmHg e 90 cm acima do transdutor. O cabo da pressão arterial média (PAM) conecta-se do transdutor ao console (Figura 7).

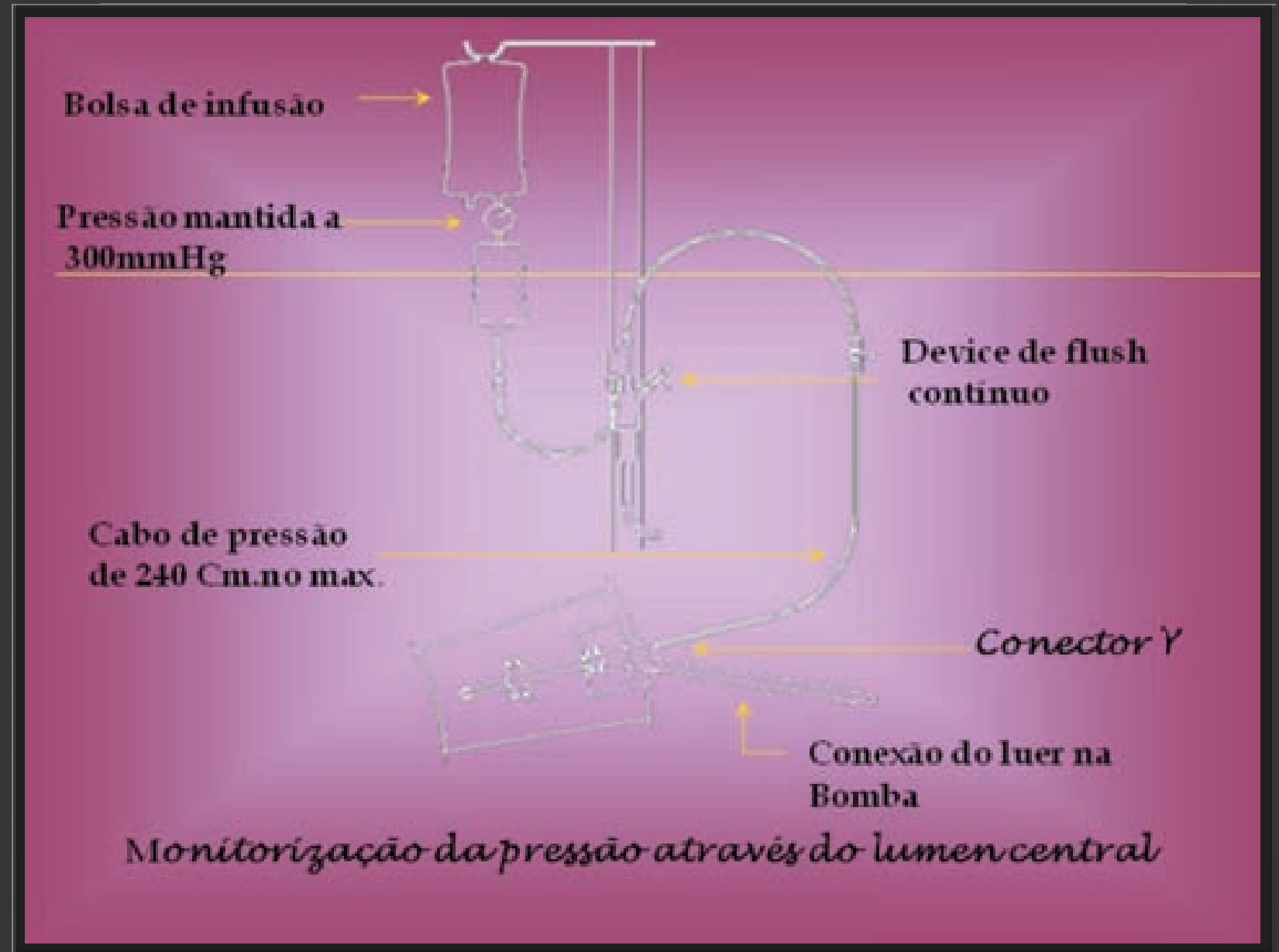

Figura 7: Transdutor da pressão arterial.

$3^{\circ}$ - Conexão com transdutor de pressão arterial: posicionar os eletrodos de acordo com a instrução do próprio cabo do ECG, e a seguir, liga-se o cabo ao console. 
$4^{\circ}$ - Inserção do cateter balão (material para o procedimento vem no kit do cateter balão): o médico cardiologista, intensivista ou cirurgião cardiovascular deve realizar as preparações usuais para o procedimento de cateterização percutânea, e a seguir realizar a técnica de Seldinger para a inserção do cateter na circulação arterial. (Figuras 8a, 8b, 8c, 8d, 8e, 8f, 8g).

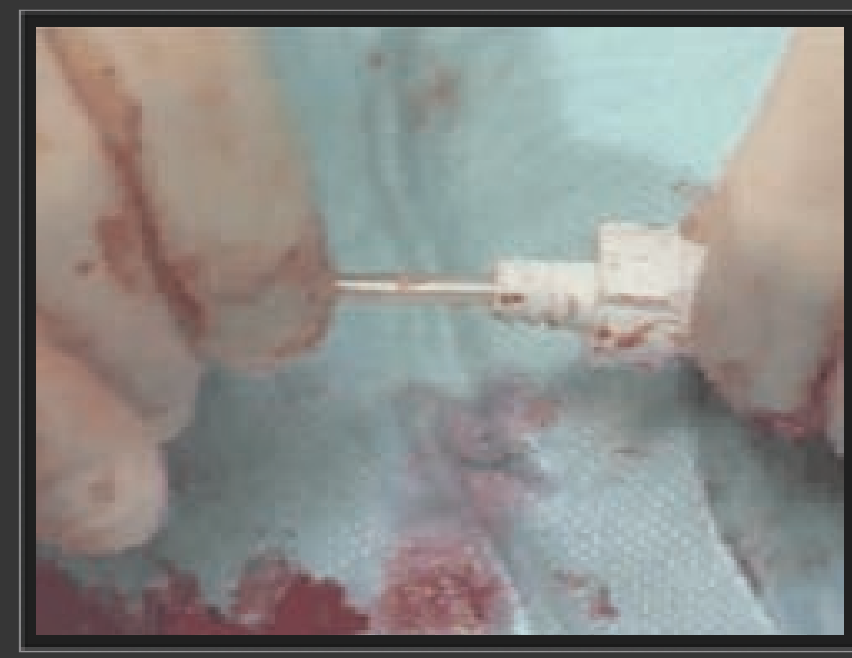

Figura 8e: Passagem do cateter balão já previamente medido.

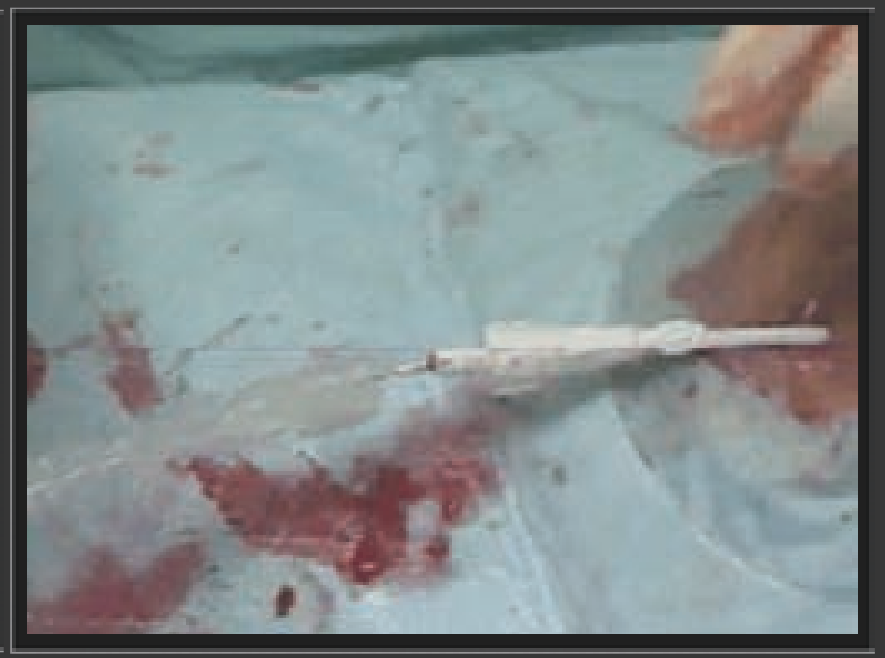

Figura 8f: Cateter balão introduzido.

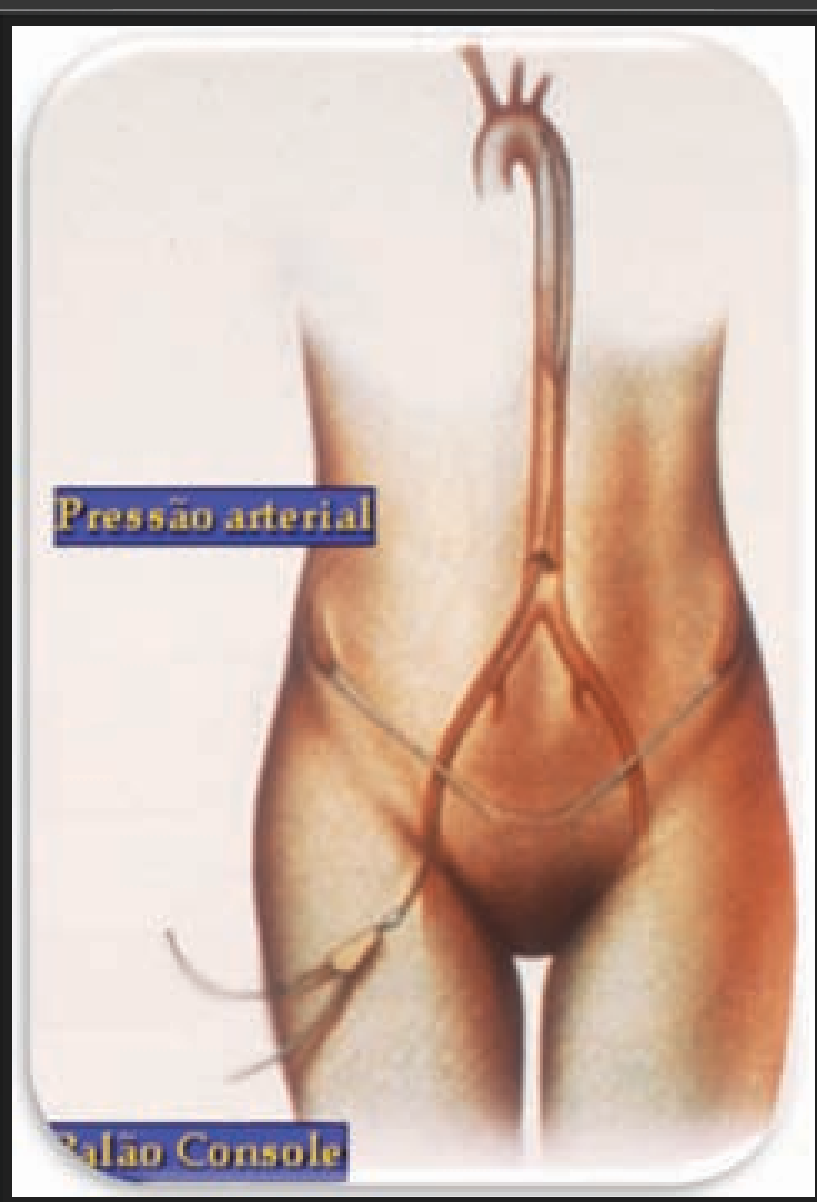

Figura 8g: Inserção do cateter balão.

Figura 8c: Uso do dilatador.
Figura 8b: Introdução de fio-guia.

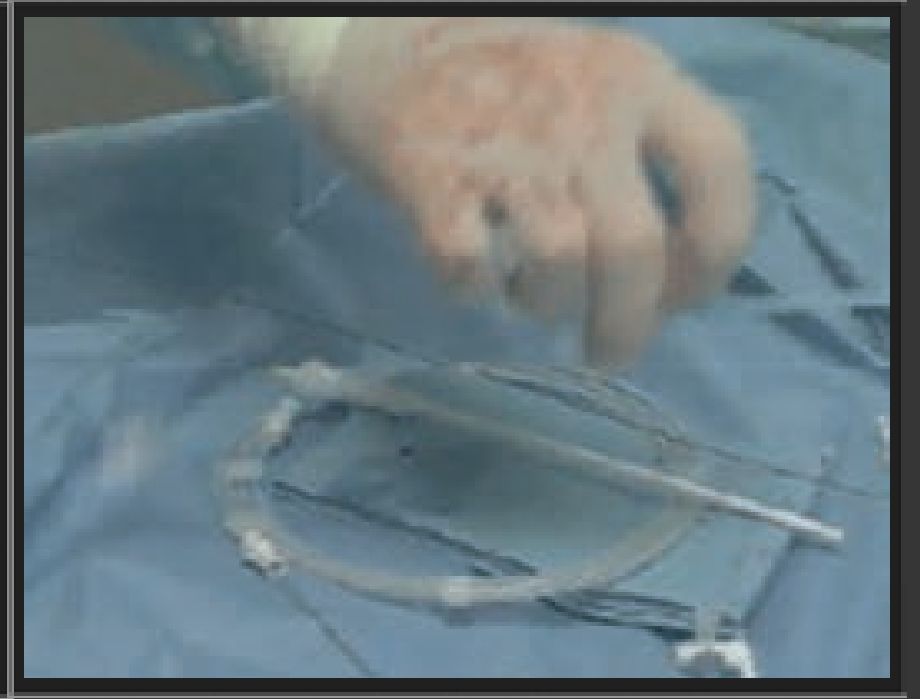

Figura 8d: Materiais do conjunto do cateter-balão 
Para retirar o cateter balão da caixa deve-se acoplar a seringa de 50 $\mathrm{mL}$ inclusa no kit ao cateter balão e, aplicando uma pressão negativa no cateter, torná-lo murcho, removendo-o da caixa com facilidade.

Lembrando que o cateter deverá ficar locado inferiormente à artéria subclávia esquerda e superiormente à artéria renal esquerda, geralmente entre o segundo ou terceiro e quinto ou sexto espaço intercostal. Após a inserção do cateter é necessária a realização da checagem dos pulsos dos membros inferiores e do raio $X$ de tórax (Figura 9).

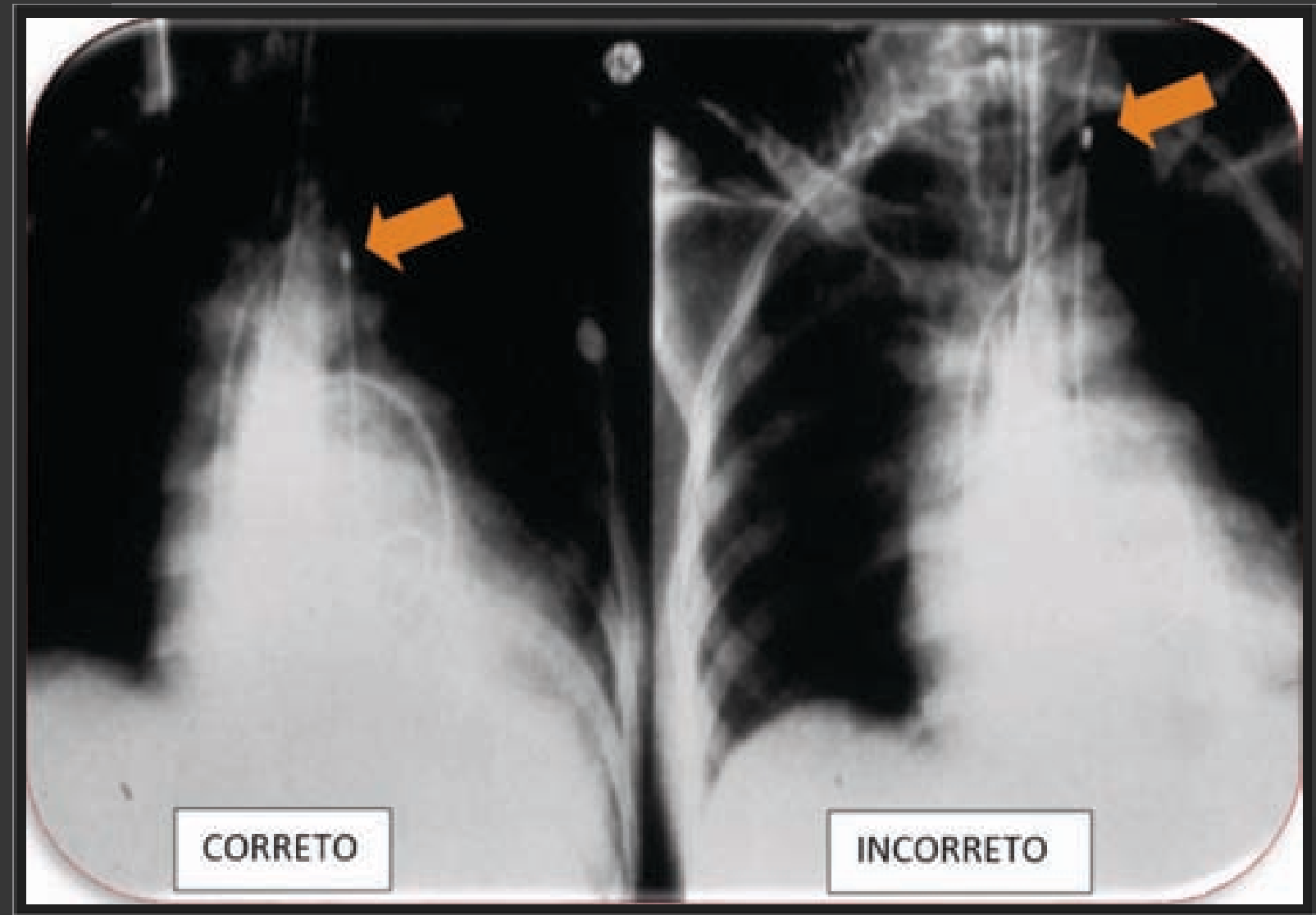

Figura 9: Raio X do tórax após inserção do cateter balão. $5^{\circ}$ - Conexão do cateter ao console: conectar o cateter puncionado ao console, através da extensão transparente já inclusa no kit do cateter balão.

\section{$6^{\circ}$ - Calibrar o transdutor de pressão e iniciar a contrapulsação:}

para calibrar a pressão arterial, deve-se abrir a torneirinha do transdutor para o ambiente e, no console segurar o botão "zerar pressão" por dois segundos. Após o aparecimento do número zero no monitor, abrir a torneirinha para o paciente e pressionar o botão "iniciar".

\section{Recapitulando:}

$1^{\circ}$ - Escolha do cateter adequado;

$2^{\circ}$ - Inserção do cateter no paciente;

3- Conexão com transdutor de pressão arterial;

4- Montagem do ECG;

50- Conexão do cateter ao console,

60- Zerar a pressão

$7^{\circ}$ Iniciar a contra-pulsação. 


\section{Assistência do cateter balão: contrapulsação}

O cateter balão é introduzido pela artéria femoral e fica localizado na aorta descendente, insuflando e desinsuflando, sincronizado com o ciclo cardíaco. Infla no início da diástole (Figura 10), promovendo aumento da perfusão coronariana e desinfla no final da diástole diminuindo a pós-carga (Figura 11).

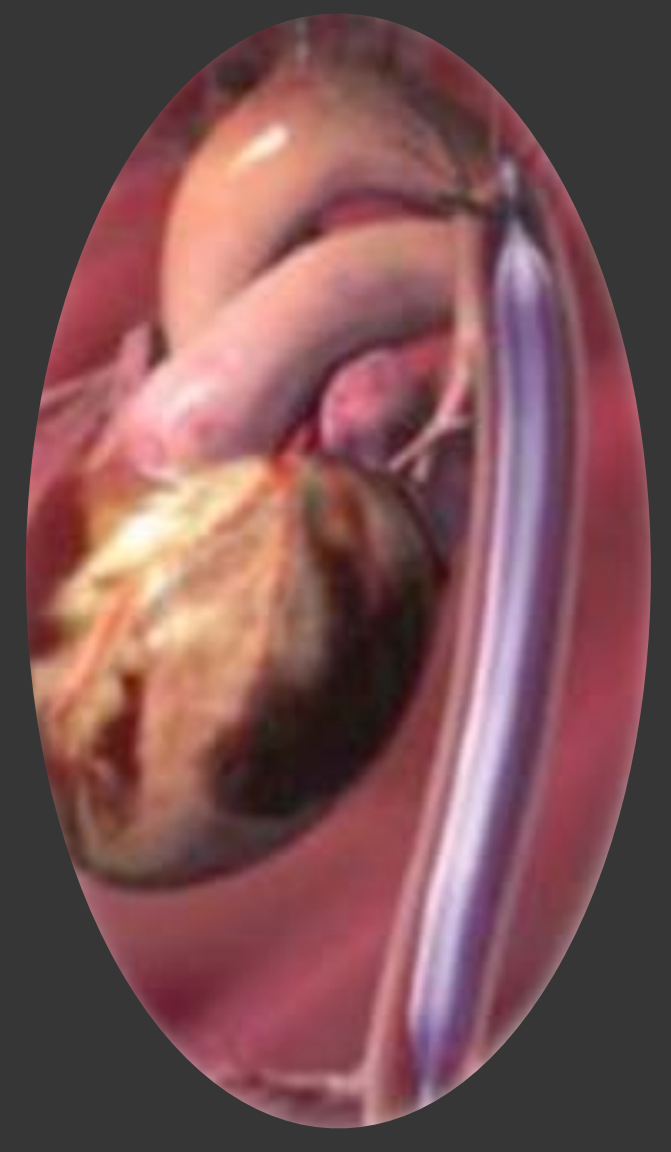

Figura 10: Inflação do cateter balão no inicio da diástole.

O sangue que permaneceu entre a valva aórtica fechada e o balão inflado é direcionado aos óstios coronarianos, aumentando a perfusão do miocárdio. Este pequeno volume de sangue arterial nutre e oxigena todo o miocárdio melhorando a sua condição de bomba muscular devido ao aumento da perfusão coronariana com redução da isquemia.

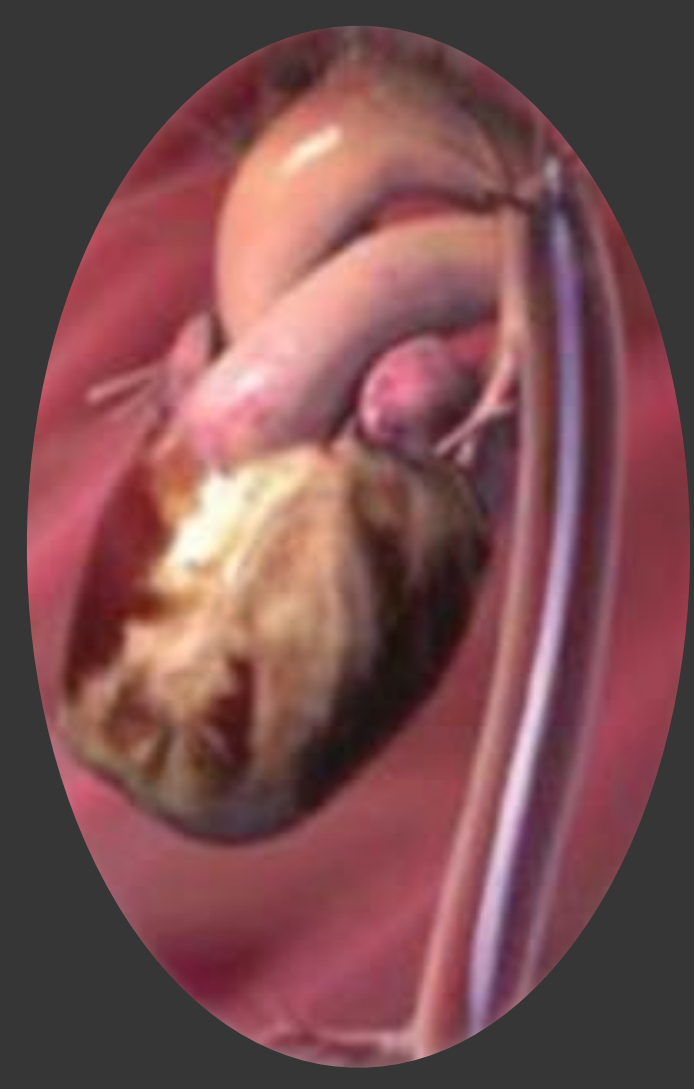

Figura 11: Desinflação do cateter balão no final da diástole.

Já na sístole ventricular, com o balão desinflado, ocorre a diminuição do trabalho cardíaco (mais precisamente do ventrículo esquerdo), diminuição no consumo de oxigênio pelo miocárdio, diminuição na pressão aórtica diastólica final, diminuição da pós-carga, melhora da contratilidade, aumento do fluxo anterógrado durante a sístole, aumento da eficiência do trabalho ventricular esquerdo (demanda de oxigênio diminuída) e aumento do débito cardíaco promovendo uma melhor perfusão sistêmica. Isso acontece devido à força de vácuo que o próprio balão faz ao desinflar dentro da aorta, facilitando a saída do sangue arterial 
do ventrículo esquerdo e fazendo com que o mesmo realize uma força menor de contração para ejetar o sangue pela aorta.

Portanto, a contrapulsação nada mais é do que a assistência do próprio balão sincronizado aos batimentos cardíacos: na sístole ventricular o balão estará desinflado, na diástole ventricular o balão estará inflado (Figura 12).

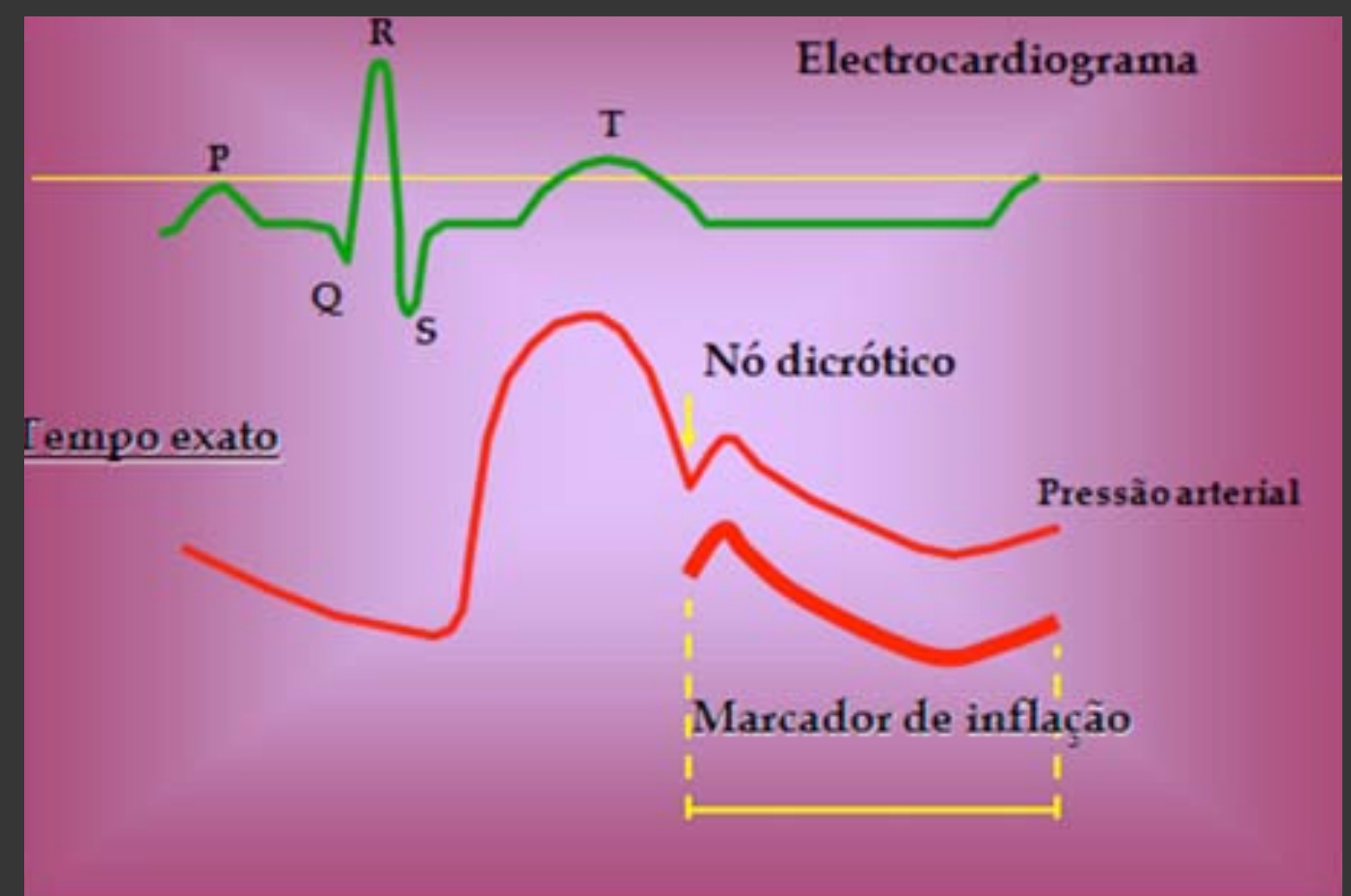

Figura 12: Comparação do eletrocardiograma e a onda de pressão do cateter balão.

O BIA deve inflar e desinflar em perfeita sincronia com o ciclo cardíaco, o qual pode ser descrito como uma seqüência de cinco eventos:

a) enchimento ventricular, quando os ventrículos encontram-se "relaxados" recebendo passivamente o sangue proveniente dos átrios; b) sístole atrial: quando os átrios se contraem e completam o enchimento ventricular (dois terços do enchimento ventricular ocorrem de maneira passiva e apenas o terço final do volume atrial é impulsionado com a contração atrial);

c) contração isovolumétrica: quando se inicia a contração ventricular com as valvas semilunares fechadas; o aumento da pressão intraventricular gerado pela contração leva ao fechamento das valvas atrioventriculares; com a continuidade da contração ventricular, a pressão intracavitária continua se elevando até que supera a pressão existente na raiz da aorta; nesse momento abrem-se as valvas semilunares e inicia-se outro evento do ciclo cardíaco;

d) ejeção ventricular: quando ocorre a propulsão propriamente dita do sangue;

e) relaxamento isovolumétrico ventricular: em que a pressão na raiz da aorta é maior que a existente no interior dos ventrículos, ocorrendo o fechamento das valvas semilunares e a abertura das atrioventriculares, pois a pressão existente no interior dos átrios é superior também à pressão intraventricular, levando à passagem do sangue dos átrios para os ventrículos, reiniciando assim o ciclo.

A programação apropriada requer coordenação da insuflação e desinsuflação do balão com o ciclo cardíaco do paciente. A onda R do ECG, espículas de marcapasso no ECG, ou a pressão sistólica arterial são usadas para identificar os ciclos cardíacos individuais. Todos agem como sinais para o console do BIA discriminar a sístole da diástole. A onda $\mathrm{R}$ assinala o início da despolarização elétrica que precede a sísto- 
le mecânica. Quaisquer delas podem ser usadas como um ponto de referência para determinar quando a desinsuflação do balão deve ocorrer. Uma curva arterial de pressão é necessária para determinar o início da diástole e da sístole mecânica. A diástole começa quando o nó dicrótico aparece na curva arterial. A insuflação do balão é programada para ocorrer neste ponto no ciclo cardíaco. O ponto de desinsuflação pode ser ajustado de forma ideal observando- se a queda diastólica final na pressão criada pela insuflação do balão. O objetivo é criar a maior queda possível de pressão das curvas pressóricas na raiz da aorta.

Para avaliar a programação de assistência é estabelecida a frequência de trabalho em 1:2, o que significa que o balão está assistindo em ciclos cardíacos alternados. Dessa forma, o observador pode comparar o efeito da insuflação e desinsuflação do balão com batimentos não assistidos.

Então tem-se (Figuras 13 e 14):

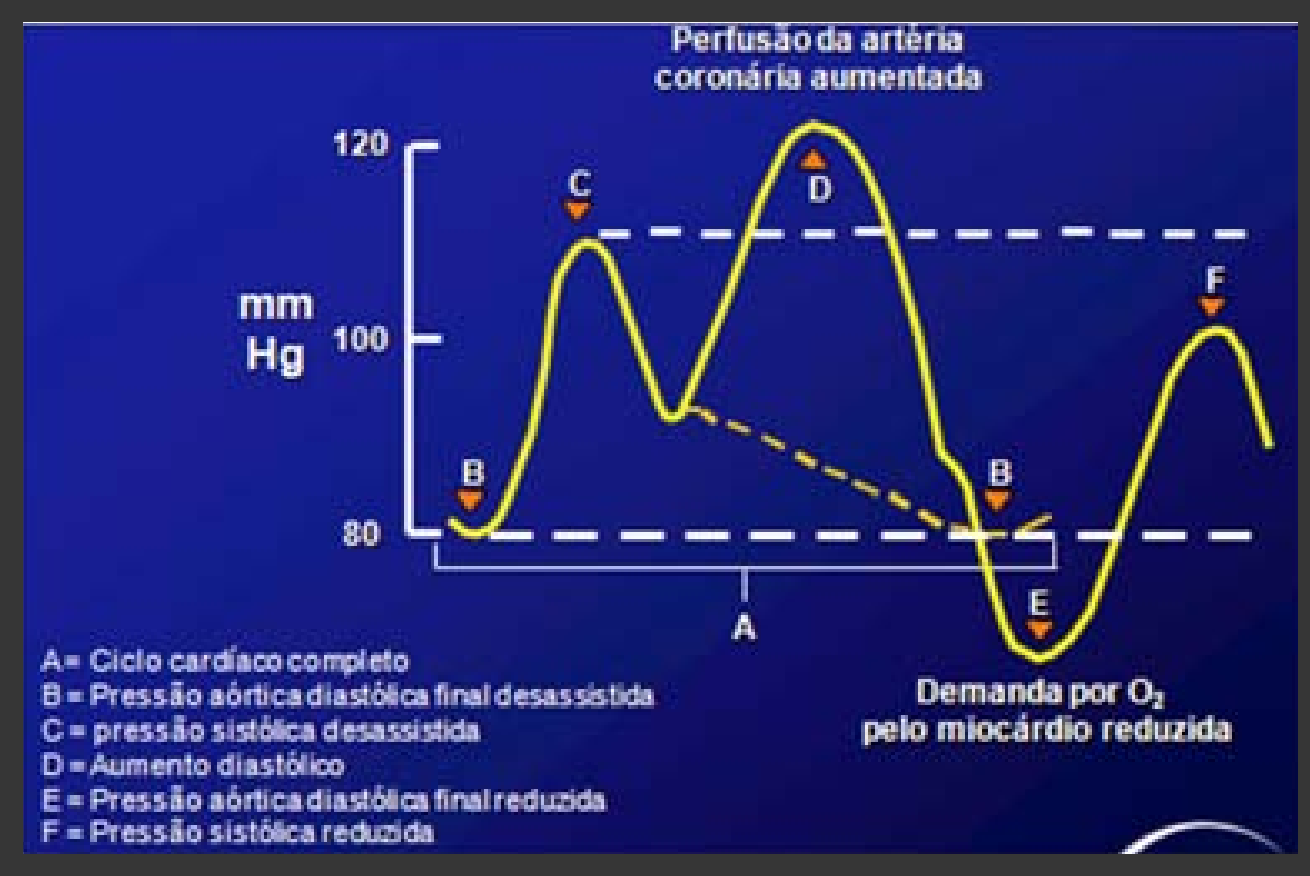

Figura 13: Explicação para as ondas do BIA.

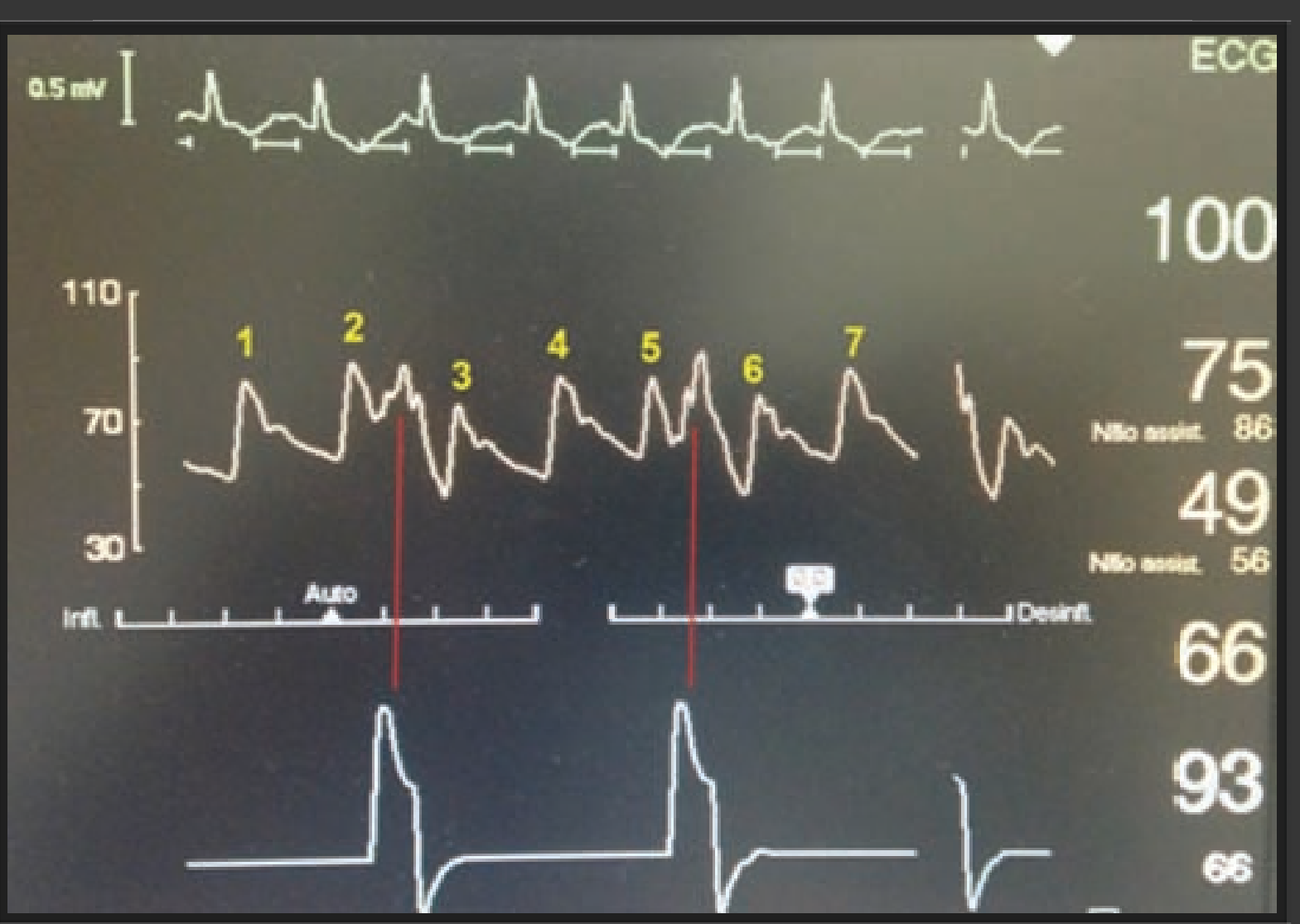

Figura 14: Comparação das ondas do ECG, PAM e BIA, pelo monitor do console.

\section{Desmame do BIA e sua remoção}

O manejo do processo de desmame da assistência circulatória e o encerramento da contrapulsação podem ser realizados de acordo com a necessidade do paciente frente às suas condições hemodinâmicas.

Deve-se reduzir progressivamente a frequência de 1:1 para 1:2 e, então 1:3 (Figura 15), sendo que o primeiro algarismo da relação de frequência ajustada mostra a ação do BIA e o segundo o(s) batimento(s) cardíaco(s) do paciente. É também possível uma redução 
progressiva do volume de fornecimento do gás hélio que enche o cateter- balão (Figura 16). Os métodos de desmame descritos podem ser combinados. Já os intervalos para o desmame variam de horas a dias, de acordo com aspectos clínicos durante a evolução do paciente.

\section{Desmame}

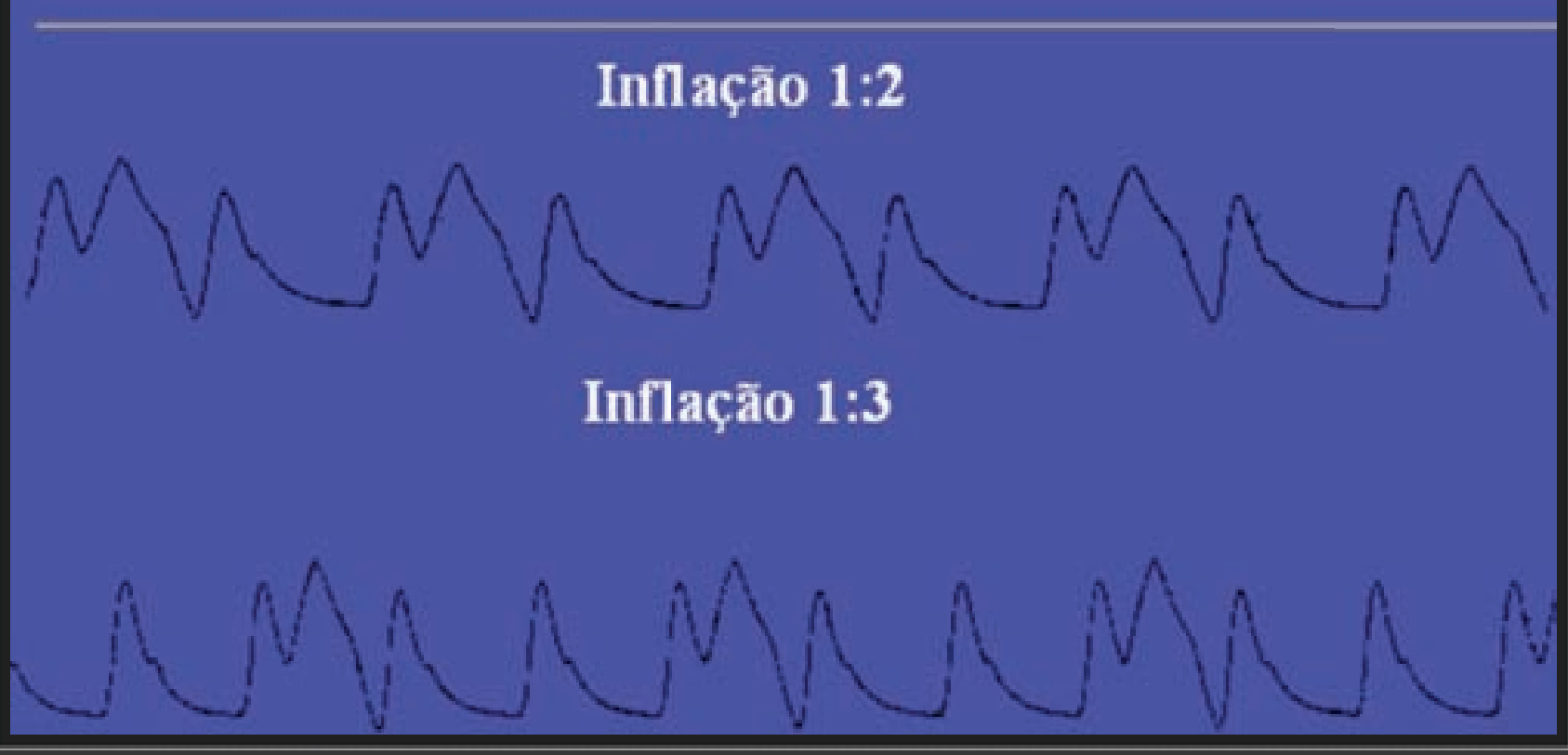

Figura 15: Desmame pela frequência do BIA. Ondas de pressão.

\section{Desmame}

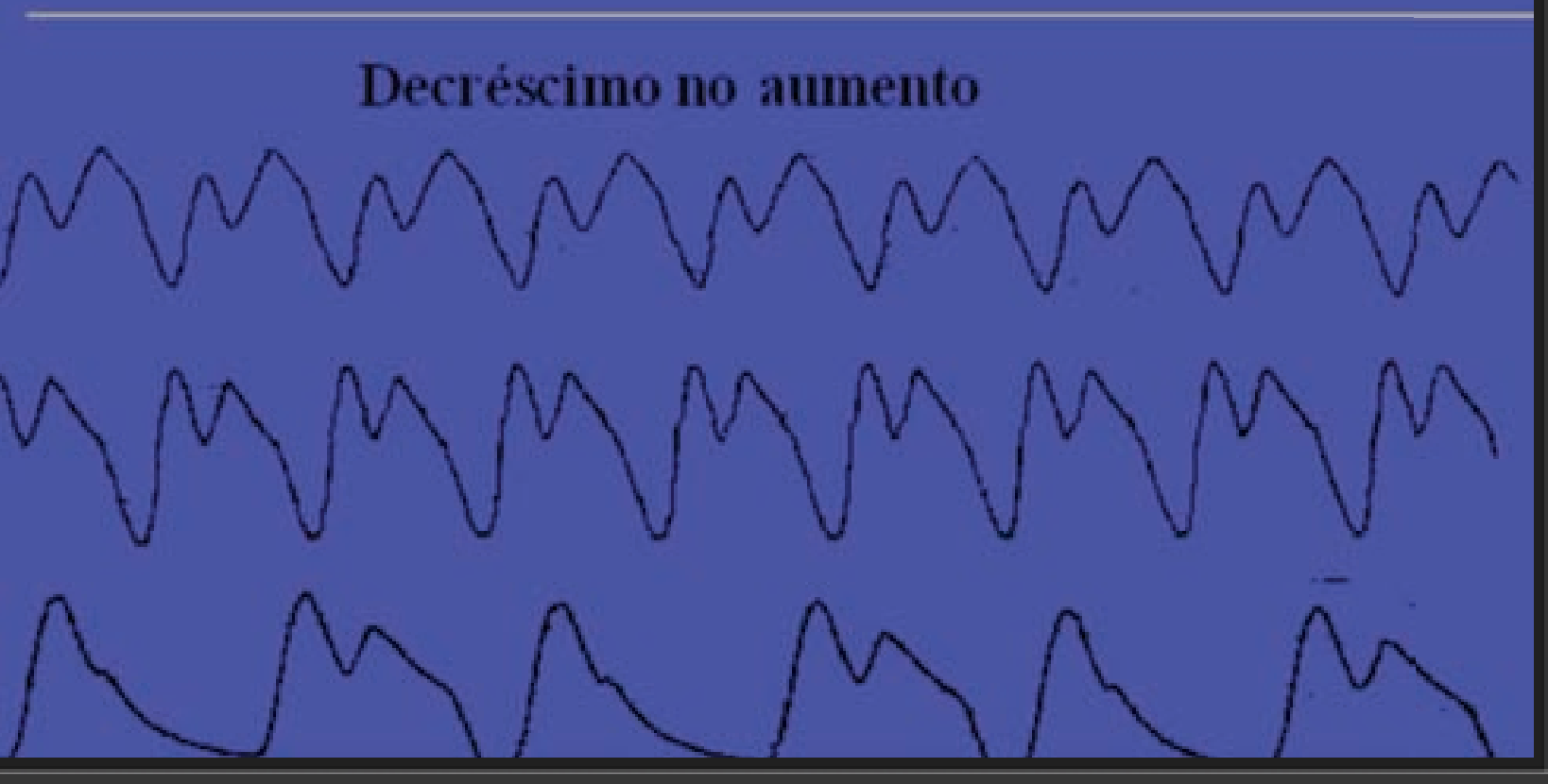

Figura 16: Desmame pelo decréscimo do aumento do BIA.

Com o paciente estável, desmamado do BIA de forma adequada, inicia-se o procedimento para a remoção do cateter- balão:

* Interrompe-se a contrapulsação;

* O cilindro de gás hélio no console é fechado;

* Desconecta- se o cateter do console, deixando que o balão expulse todo o gás do seu interior;

* Retiram-se todos os pontos de sutura que fixam o cateter à pele;

* Retira-se o cateter- balão; 
* Pressione com os dedos o ponto de punção durante a extração do cateter balão (deixe que o sangue flua livremente na parte proximal durante poucos segundos);

* Estabeleça a hemostasia aplicando pressão no local de inserção por aproximadamente 30 minutos;

* Examine cuidadosamente o membro na parte distal da inserção para checar e perfusão (se necessário pode- se usar o aparelho de duplex acoplado ao console);

* Retire a extensão, eletrodos e cabos do paciente, assim como o transdutor de pressão;

* Leve o equipamento ao local de armazenamento e conecte o cabo na fonte de energia mais próxima.

\section{Possiveis efétos colaterais e complicações do B/A}

\section{a) Isquemia:}

Varia desde perda de pulso, cianose e dor até a perda de membro, mas é uma complicação rara. Fatores de risco: mulheres, diabéticos e doença vascular periférica.

Podemos prevenir a isquemia com o posicionamento correto do BIA, usando o menor balão compatível para o paciente e o membro com o melhor pulso e perfusão distais.
O tratamento consiste em trocar o BIA para o outro membro e se possível não usar a bainha durante a inserção. Pode ser necessária uma avaliação especializada nos casos de oclusão arterial aguda.

A isquemia renal também é uma possível complicação, ocorre quando o BIA está locado muito abaixo do seu correto posicionamento na aorta descendente, causando a oclusão das artérias renais.

\section{b) Sangramento no local de inserção:}

Devemos observar o local de inserção antes e após a remoção do BIA para averiguar o eventual surgimento de hematoma ou pseudoaneurismas.

A prevenção consiste na técnica de inserção cuidadosa, monitorização do uso de anticoagulantes, prevenção da movimentação do cateter no local de inserção.

O tratamento é feito com pressão manual, monitorização do pulso distal e reparo cirúrgico de pseudoaneurismas.

\section{c) Trombocitopenia :}

Avaliação feita com contagem periódica de plaquetas no hemograma.

Prevenção evitando o uso excessivo de heparina.

Tratamento de acordo com a repercussão clínica. 


\section{d) Trombose:}

O BIA não deve permanecer inativo por mais de 30 minutos a fim de evitarmos trombose sanguínea na sua superfície.

Caso se observe a inoperância do sistema, devemos desconectar o BIA da sua extensão e usando uma seringa específica que acompanha o cateter e uma torneira de 3 vias insuflar e desinsuflar o balão manualmente.

\section{e) Vazamento do balão:}

A única prova definitiva é o aparecimento de sangue no cateter balão ou na sua extensão (devido à ruptura do balão); alarmes freqüentes (por aumento baixo, perda de gás) podem indicar a possibilidade de vazamento de gás no BIA, mesmo sem a presença de sangue no cateter ou na sua extensão.

No caso de presença de sangue no BIA ou na extensão, recomendase a remoção do cateter.

\section{f) Infecção:}

Devemos observar atentamente o local de inserção do cateter.

Deve- se usar técnicas assépticas durante a inserção e trocar os curativos de acordo com o protocolo de prevenção de infecções do hospital.

\section{g) Dissecção aórtica:}

Também é uma complicação rara, porém não desprezível. Para diminuirmos o seu risco devemos inserir o BIA sobre o fio- guia tendo certeza que o mesmo está dentro da circulação arterial.

\section{Cuidados com o paciente que se en- contra com a assistência do BIA}

O paciente deverá ser mantido em repouso absoluto no leito. O encosto do leito não deve ser inclinado a mais de $45^{\circ}$. A perna onde está inserido o cateter balão não poderá ser dobrada, nem realizada a dorsiflexão do pé da perna envolvida.

\section{Bibliografia}

Rabischoffsk A. Suporte circulatório: balão de contrapulsação aórtico (B.I.A.). Rev SOCER J. 1997;10(3):152-56.

Souza MHL, Elias DO. Fundamentos da circulação extracorpórea. 2a ed. Rio de Janeiro: Centro Editorial Alfa Rio; 2006. 800 p.

Teixeira Filho GF, Batista G. Temas atuais de circulação extracorpórea. Porto Alegre: Sociedade Brasileira de Circulação Extra Corpórea; 1997. $301 \mathrm{p}$. 


\section{DISSECÇÃO DE AORTA}

André Monti Garzesi

Leonardo Rufino Garcia

Marcello Laneza Felicio

Nelson Leonardo K. Leite de Campos 


\section{Anatomia da aorta}

A aorta é a maior artéria do corpo humano e em adultos saudáveis geralmente o diâmetro não excede $4 \mathrm{~cm}$. Vale lembrar que ocorre aumen-

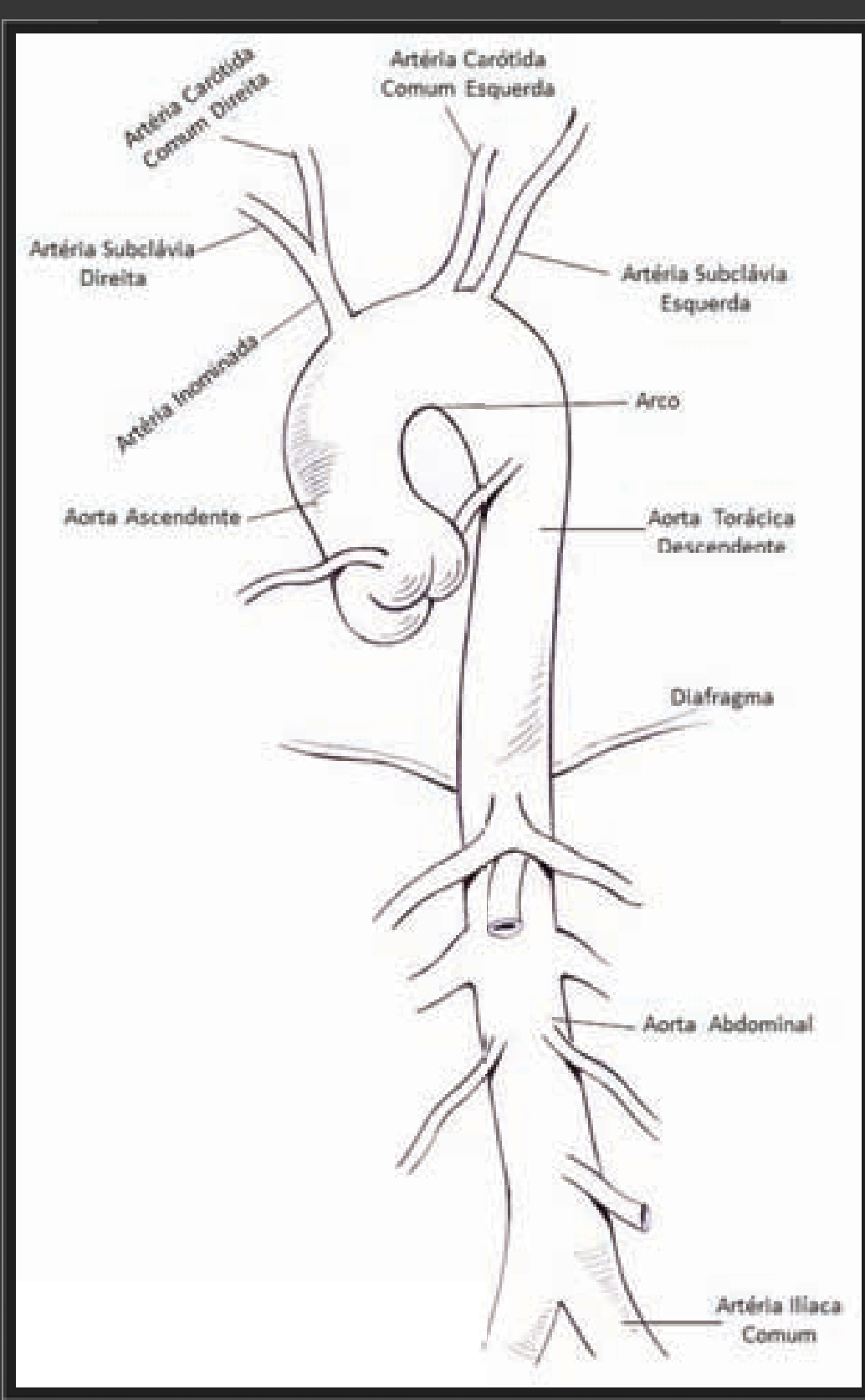

to do diâmetro durante a vida $(0,9 \mathrm{~mm}$ a cada década para homens e $0,7 \mathrm{~mm}$ para mulheres).

Anatomicamente é dividida em aorta torácica e aorta abdominal. É responsável por transportar cerca de 200 miIhões de litros de sangue para o corpo durante toda a vida de um ser humano (Figura 1).
Histologicamente a aorta é dividida em três camadas: a túnica íntima a mais interna e fina revestida pelo endotélio; a túnica média - espessa, composta por fibras musculares lisas, dispostas concentricamente, com fibras elásticas e de colágeno; a túnica adventícia - tecido conjuntivo, rico em colágeno, nesta camada estão presentes os vasa vasorum e os vasos linfáticos (Figura 2).

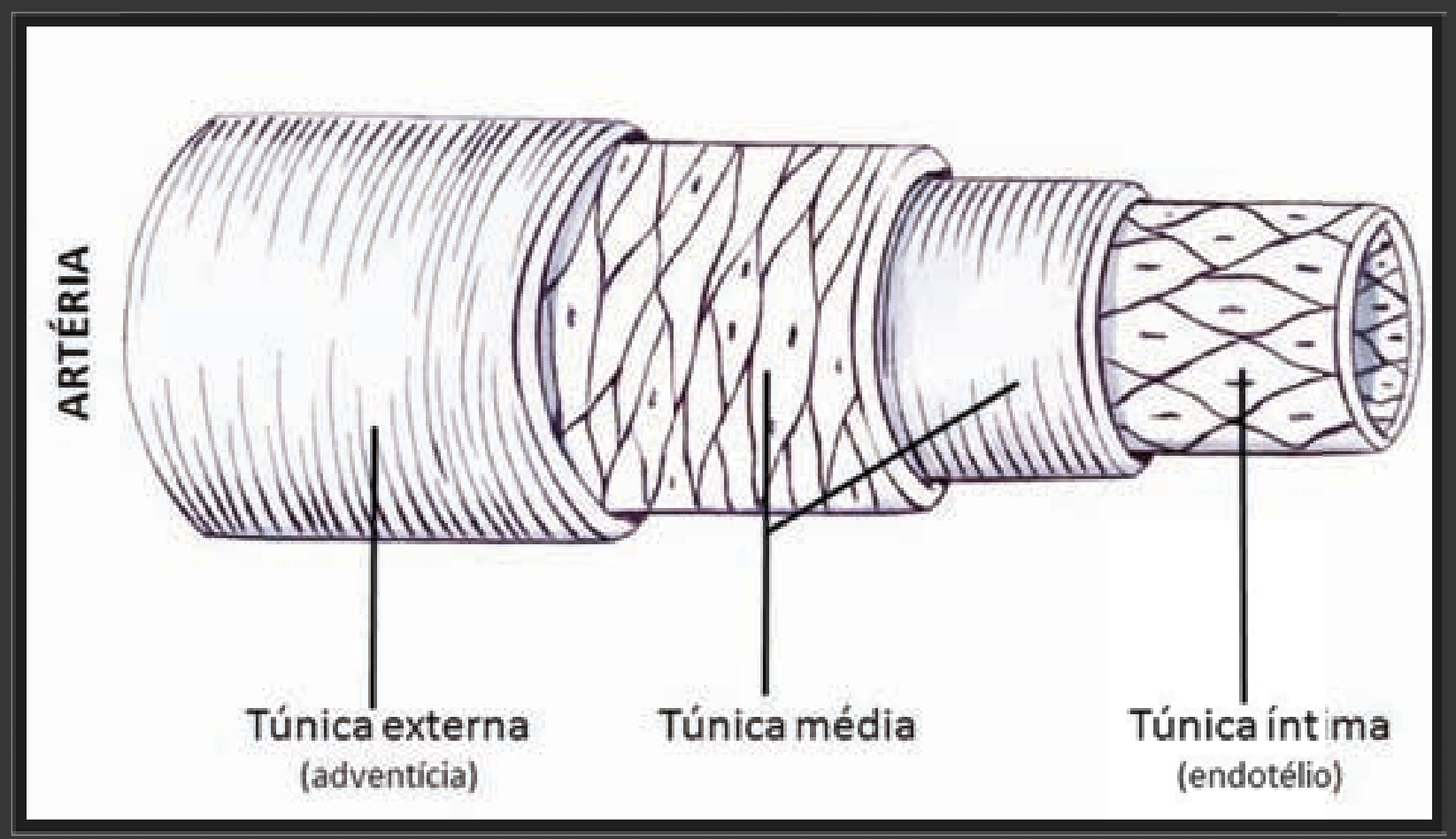

Figura 2 - Camadas da aorta

A aorta também possui um importante papel no controle da resistência vascular sistêmica, frequência cardíaca e na manutenção do fluxo sanguíneo mesmo durante a diástole (efeito de Windkessel).

Figura 1 - Anatomia da aorta 


\section{Deffinição}

A dissecção aguda da aorta é um evento súbito que consiste no extravasamento do sangue do lúmen aórtico normal através de um ponto de saída na túnica intima para o espaço intramural, resultando na separação das camadas mais internas da parede da aorta, formando o lúmen falso, que pode ter ou não comunicação com o lúmen verdadeiro (Figura 3). Entretanto a dissecção da camada média pode ocorrer na ausência de lesão da túnica intima, podendo ser secundária a sangramentos dos vasa vasorum (Figura 4).

A presença de sangue no espaço intramural leva a uma resposta inflamatória que pode causar dilatação e ruptura da aorta.

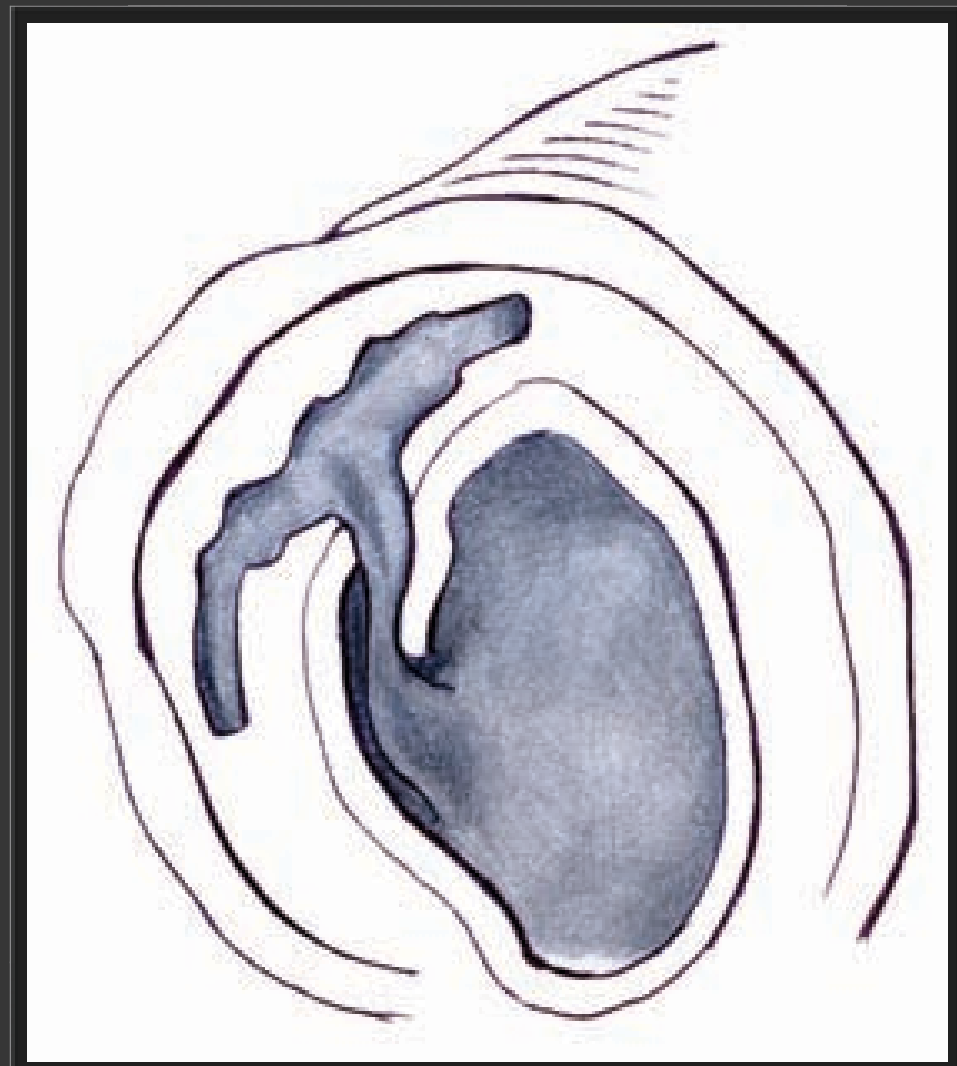

Figura 3 - Dissecção com rotura da intima

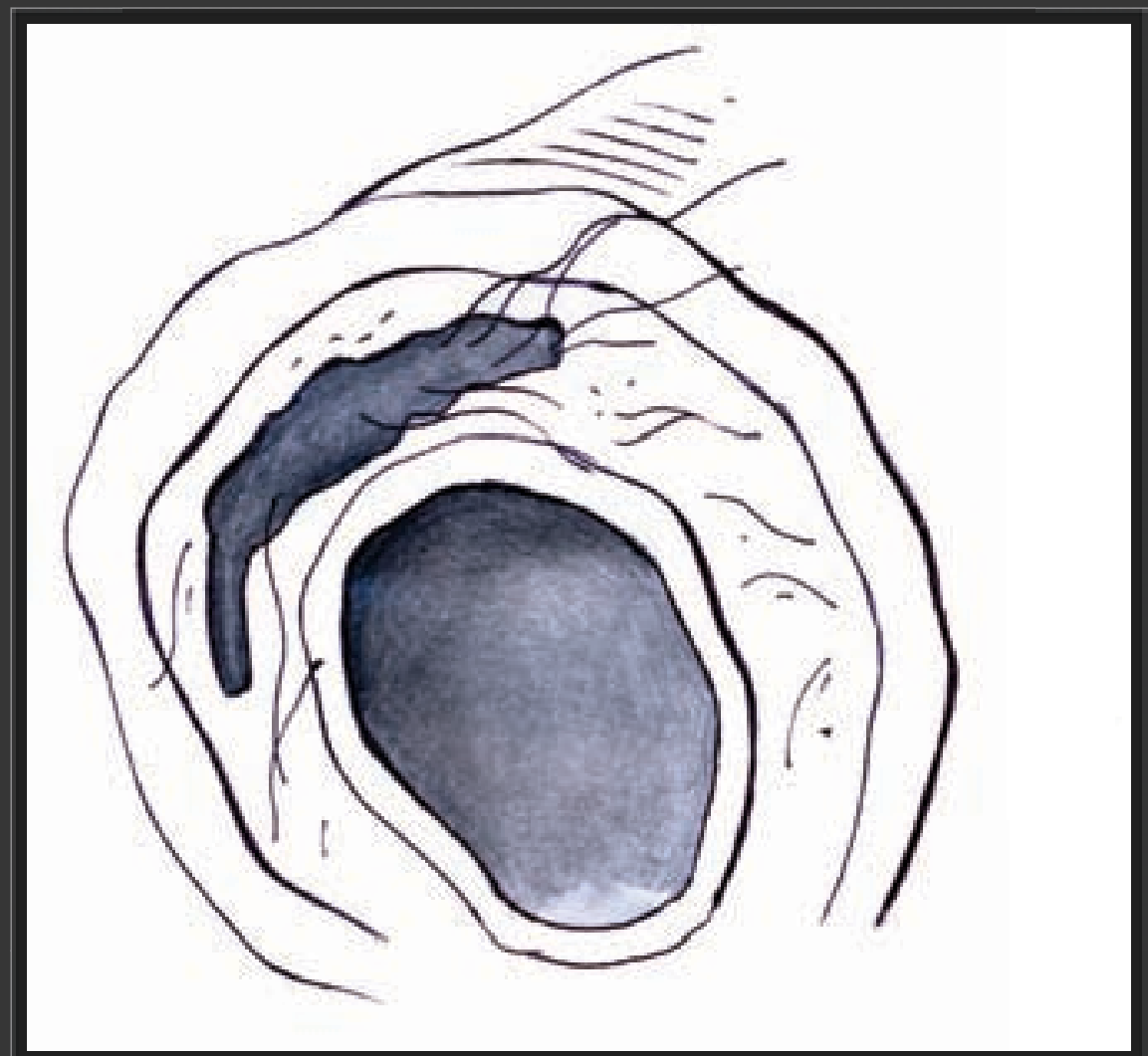

Figura 4 - Dissecção sem rotura da intima

\section{Epidemiologia}

No "Oxford Vascular Study" foi estimado que a incidência da dissecção aguda da aorta é de 6 por 100 mil habitantes por ano, é maior em homens e aumenta com a idade. O prognóstico é pior em mulheres devido a sua apresentação atípica e o diagnóstico tardio. O fator de risco mais comum é a hipertensão arterial sistêmica não controlada. São fatores de risco doenças pré existentes da aorta, doenças da válvula aórtica, história familiar de doenças da aorta, cirurgia cardíaca prévia, tabagismo, trauma torácico e o uso de drogas injetáveis (como cocaína e anfetaminas). 


\section{Classificação}

Duas classificações para dissecção de aorta são comumente usadas: De Bakey e Stanford. (Figura 5; Tabela 1)

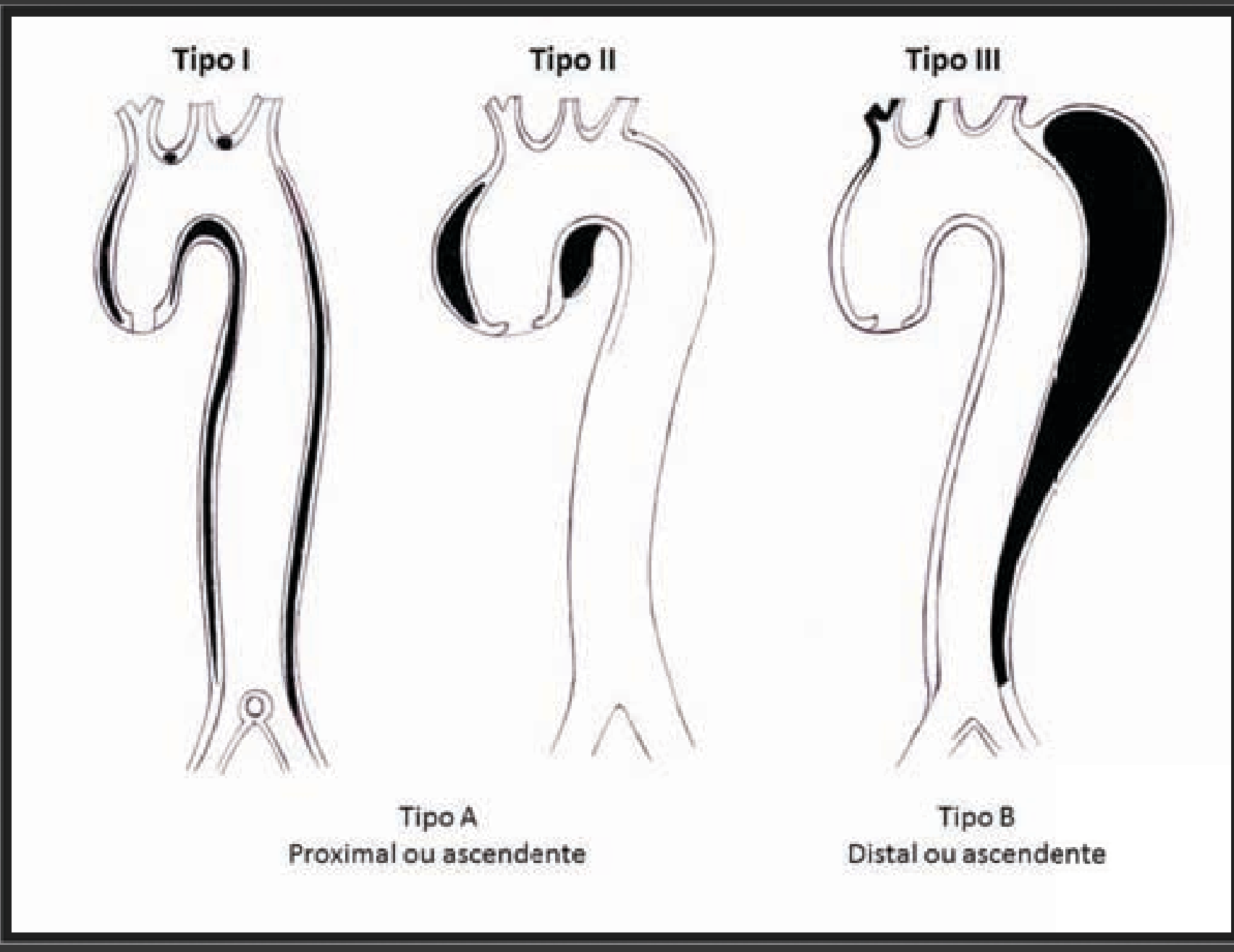

Figura 5 - Classificação da dissecção de aorta por Stanford e De Bakey

As dissecções podem ser divididas em aguda (menos que 14 dias), subaguda (15 a 90 dias) e crônica (mais que 90 dias).
Stanford

Tipo A: Todos os casos em que a aorta ascendente está envolvida, com ou sem o envolvimento do arco e da aorta torácica descendente.

Tipo B: Acomete apenas a aorta torácica descendente; em alguns casos pode ocorrer uma dissecção retrograda da aorta descendente, estendendo para o arco aórtico, mas não a aorta ascendente. Em outros casos a dissecçào fica restrita ao arco aórtico ou se estende anterogradamente, sem acometer a aorta ascendente.

De Bakey

Tipo I: A dissecçào acomete a aorta ascendente e se estende para o arco e asrta descendente.

Tipo II: A disseç̧ão estả restrita a aorta ascendente.

Tipo III: A dissecção pode estar restrita a aorta torácica descendente (tipo IIIa) ou pode se estender para a aorta abdominal e artérias iliacas (tipo IIIb), também pode se estender proximalmente e envolver o arco e a arra ascendente.

Tabela 1 - Classificação da dissecção de aorta

\section{Quadro Clínico}

A dor torácica é o sintoma mais comum, suas características são uma dor de início súbito, de forte intensidade, com ou sem irradiação para o dorso.

Outros possíveis achados clínicos são: 
- Surgimento de regurgitação aórtica, pela perda da sustentação das cúspides, levando a presença de sopro diastólico em foco aórtico;

- Tamponamento cardíaco secundário a sangramento para o mediastino;

- Isquemia miocárdica ou infarto pela compressão ou obstrução dos óstios coronarianos ou ainda a propagação da dissecção para as coronárias;

- Insuficiência cardíaca, geralmente secundária a regurgitação aórtica, isquemia miocárdica, tamponamento, doença pré existente do ventrículo esquerdo ou choque hemorrágico;

- Derrame pleural importante secundário a sangramentos para o espaço pleural (raro, devido à gravidade do quadro, geralmente estes pacientes não chegam com vida ao serviço hospitalar);

- Síncope, geralmente secundária a tamponamento cardíaco ou dissecção dos vasos supra aórticos (vasos da base);

- Déficits neurológicos podem aparecer devido a má perfusão cerebral, hipotensão, tromboembolismo distal ou compressão de nervo periférico;

- Lesão de medula espinhal por oclusão das artérias espinhais;

- Isquemia mesentérica pela compressão mecânica dos ramos aórticos (devido à própria dissecção ou sangramento) e quando o ramo aórtico fica na luz falsa;
- Insuficiência renal aguda, devido à hipoperfusão renal, secundária a hipotensão prolongada ou por isquemia secundária ao envolvimento das artérias renais na dissecção;

- Isquemia de membros inferiores pelo hipofluxo sanguíneo ou mesmo devido ao envolvimento da artérias ilíacas na dissecção (Tabela 2).

\begin{tabular}{|c|c|c|}
\hline Sintomas e Complicações & Tipo A & Tipo B \\
\hline Dor tóracica & $80 \%$ & $70 \%$ \\
\hline Dor dorsal & $40 \%$ & $70 \%$ \\
\hline Inicio súbito da dor & $85 \%$ & $85 \%$ \\
\hline Dor migratória & $<15 \%$ & $20 \%$ \\
\hline Regurgitação aórtica & $40-75 \%$ & $\mathrm{~N} / \mathrm{A}$ \\
\hline Tamponamento cardiaco & $<20 \%$ & $\mathrm{~N} / \mathrm{A}$ \\
\hline Isquemia miocárdica ou Infarto & $10-15 \%$ & $10 \%$ \\
\hline Insuficiência cardiaca & $<10 \%$ & $<5 \%$ \\
\hline Derrame pleural & $15 \%$ & $20 \%$ \\
\hline Sincope & $15 \%$ & $<5 \%$ \\
\hline Déficit neurológico maior (coma / AVE) & $<10 \%$ & $<5 \%$ \\
\hline Lesão da medula espinhal & $<1 \%$ & $\mathbf{S} / \mathbf{R}$ \\
\hline Isquemia mesentérica & $<5 \%$ & $\mathrm{~S} / \mathrm{R}$ \\
\hline Insuficiência renal aguda & $<20 \%$ & $10 \%$ \\
\hline Isquemia de membros inferiores & $<10 \%$ & $<10 \%$ \\
\hline
\end{tabular}

Tabela 2 - Principais sintomas e complicações em pacientes com dissecção aguda da aorta. 


\section{Critério diagnóstico}

\subsection{Diagnóstico laboratorial}

Pacientes admitidos com suspeita de dissecção aguda de aorta devem realizar os seguintes exames laboratoriais, para realizar diagnósticos diferenciais e detectar possíveis complicações:

- Hemograma completo: verificar possíveis sangramentos, infecções e processos inflamatórios (SIRS);

- PCR: verificar possíveis processos inflamatórios;

- Pro-Calcitocina: diagnóstico diferencial entre SIRS e sepse;

- Ureia e creatinina: avaliar função renal;

- CPK, CKMB e Troponina: avaliar isquemia miocárdica;

- Enzimas hepáticas: avaliar possível isquemia hepática;

- Lactato: avaliar isquemia intestinal e distúrbio metabólico;

- Glicose: avaliar glicemia

- Gasometria: avaliar distúrbio metabólico e oxigenação.

\subsection{Diagnóstico por imagem}

Os exames de imagem têm como propósito estudar detalhadamente a aorta, visualizando seu diâmetro nos diferentes segmentos, localizar o local de dissecção e sua extensão, avaliar o envolvimento da válvula aórtica e dos ramos aórticos.

\subsubsection{Raio X:}

Todos os pacientes com suspeita de dissecção de aorta devem realizar um raio x simples de tórax. Raramente será possível realizar o diagnóstico com esse exame, no entanto, a comparação com exames anteriores pode revelar alterações do contorno aórtico aumentando a suspeita de dissecção. O alargamento de mediastino pode ser de difícil visualização devido à qualidade técnica do exame que normalmente é realizado na sala de emergência, com equipamentos portáteis.

Cerca de $20 \%$ dos pacientes com dissecção de aorta possuem raio x de tórax com achados negativos (Figura 6).

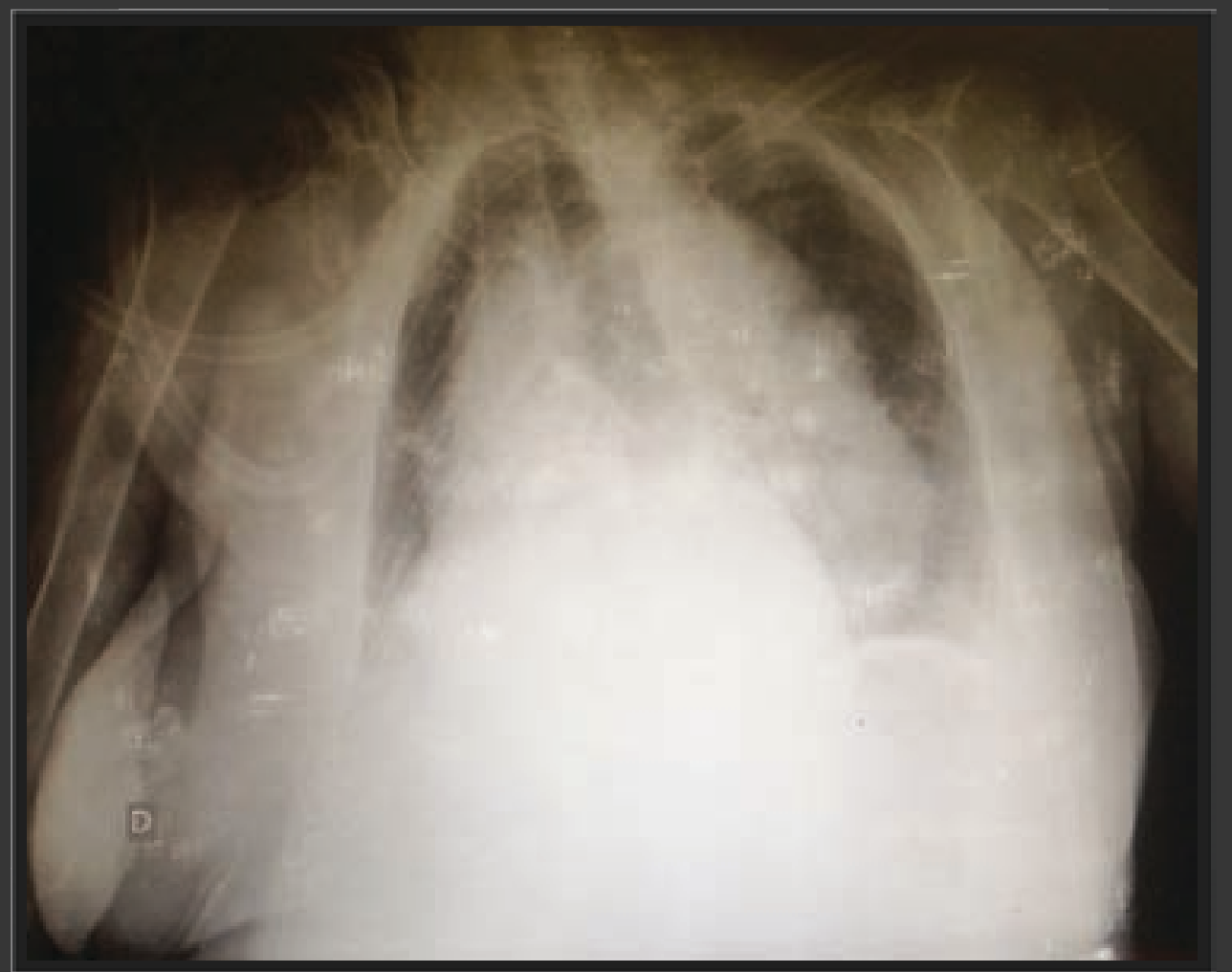

Figura 6 - Exemplo de Rx de tórax evidenciando alargamento de mediastino. 


\subsubsection{Ecocardiograma:}

Baseado na detecção de "flap" intimal na aorta. Possui uma sensibilidade de 77-80\% e especificidade de 93-96\% para a aorta ascendente. A detecção de dissecção distal da aorta torácica é de apenas 70\%.

\subsubsection{Tomografia computadorizada:}

Exame realizado com contraste possibilitando visualizar o "flap" intimal separando os dois lumens (verdadeiro e falso). Com esse método é possível obter medidas precisas da extensão da dissecção, seu comprimento, envolvimento de ramos da aorta, além do diâmetro. Possui uma sensibilidade de mais de 95\% para dissecção de aorta (Figura 7).

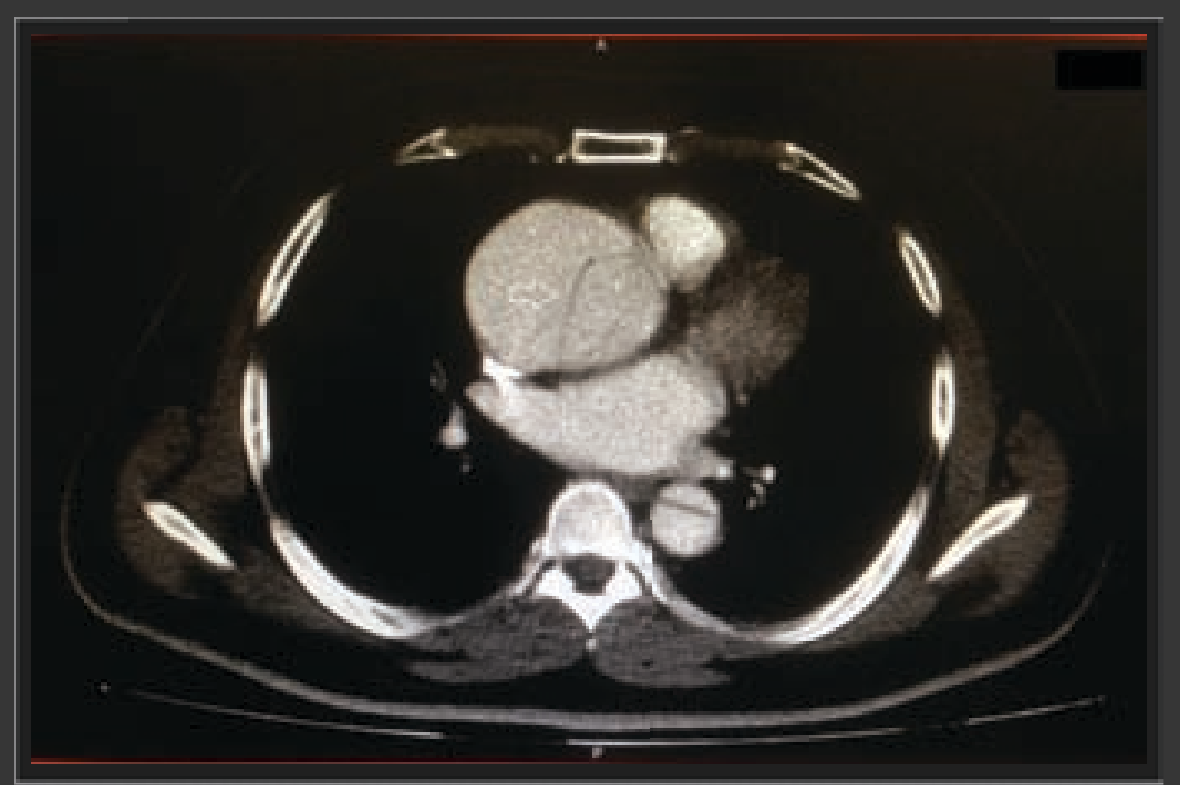

Figura 7 - Tomografia de tórax com dissecção de aorta, iniciando em ascendente, progredindo para descendente. Setas mostrando lâmina de dissecção, separando a luz falsa da verdadeira.

\subsubsection{Ressonância Magnética:}

É o padrão ouro para o diagnóstico de dissecção de aorta, possui sensibilidade e especificidade de $98 \%$.

\section{Tratamento}

\subsection{Tratamento medicamentoso}

O principal objetivo é reduzir os danos na região da aorta doente, diminuindo a pressão arterial e a contratilidade cardíaca. Também é importante tratar a dor do paciente.

Na ausência de contra indicações do uso de $\beta$-bloqueador, esse deve ser introduzido intravenoso com o objetivo de manter uma frequência cardíaca de 60 batimentos/minuto. Para pacientes com contra indicação ao uso de $\beta$-bloqueadores devem ser introduzidos antagonistas de canais de cálcio não- dihidropiridínicos para o controle da frequência cardíaca. Os $\beta$-bloqueadores devem ser utilizados com atenção na presença de regurgitação aórtica, pois irá ocorrer o bloqueio da taquicardia compensatória.

Caso a pressão arterial sistólica se mantenha acima de 120 mmHg mesmo após o controle da frequência cardíaca, deve ser iniciado o uso de inibidores da enzima conversora angiotensina e/ou vasodilatadores de uso intravenoso com o objetivo de reduzir a pressão arterial sistólica, mas mantendo níveis adequados para perfusão de órgãos alvo. 


\subsection{Tratamento cirúrgico}

É o tratamento de escolha para as dissecções do tipo Stanford A. Essas possuem uma mortalidade de $50 \%$ nas primeiras 48 horas quando não operadas. A mortalidade perioperatória é de $25 \%$ e as complicações neurológicas de 18\%. O tratamento cirúrgico reduz a mortalidade em um mês de 90\% para 30\%. É realizado com o auxilio de circulação extracorpórea e, a depender do nível anatômico da dissecção esta pode ser tratada com o uso de um tubo reto de Dácron ou um tubo já com uma valva aórtica com necessidade de reimplante das artérias coronárias (cirurgia de Bentall - De Bono). Nos casos em que há acometimento do arco aórtico os ramos supra-aórticos devem ser reimplantados na prótese tubular utilizada.

As dissecções do tipo Stanford B normalmente possuem uma evolução sem complicações, dessa maneira o paciente pode ser tratado apenas com a terapia medicamentosa, com objetivo de controlar a dor, a frequência cardíaca e a pressão arterial sistêmica.

Para as dissecções do tipo Stanford B com evolução complicada, como dor persistente ou recorrente, hipertensão não controlada, má perfusão de órgãos e sinais de rotura o tratamento de escolha é o reparo endovascular.

A cirurgia aberta é uma opção para os pacientes que possuem doença arterial dos membros inferiores, importante tortuosidade das artérias ilíacas, angulação acentuada do arco aórtico e ausência de colo proximal para fixação da prótese endovascular.

\section{Bibliografia}

Erbel R, Aboyans V, Boileau C, Bossone E, Bartolomeo RD, Eggebrecht H, et al. 2014 ESC guidelines on the diagnosis and treatment of aortic diseases: document covering acute and chronic aortic diseases of the thoracic and abdominal aorta of the adult. The Task Force for the Diagnosis and Treatment of Aortic Diseases of the European Society of Cardiology (ESC). Eur Heart J. 2014;35:2873-926.

Hagan PG, Nienaber CA, Isselbacher EM, Bruckman D, Karavite DJ, Russman PL, et al. The International Registry of Acute Aortic Dissection (IRAD): new insights into an old disease. JAMA. 2000;283:897-903.

Hiratzka LF, Bakris GL, Beckman JA, Bersin RM, Carr VF, Casey DE Jr, et al. 2010 ACCF/AHAVAATS/ACR/ASA/SCA/SCAI/SIR/STS/SVM guidelines for the diagnosis and management of patients with thoracic aortic disease: a report of the American College of Cardiology Foundation/ American Heart Association Task Force on Practice Guidelines, American Association for Thoracic Surgery, American College of Radiology, American Stroke Association, Society of Cardiovascular Anesthesiologists, Society for Cardiovascular Angiography and Interventions, Society of Interventional Radiology, Society of Thoracic Surgeons, and Society for Vascular Medicine. Circulation. 2010;121:1544-79.

Howard DP, Banerjee A, Fairhead JF, Perkins J, Silver LE, Rothwell PM. Population based study of incidence and outcome of acute aortic dissection and premorbid risk factor control: 10-year results from the Oxford Vascular Study. Circulation. 2013;127:2031-7. 
Kirklin JK, Kouchoukos NT, Blackstone EH, Hanley FL, editors. Cardiac surgery. 4th ed. Philadelphia: Elsevier; 2013. Acute aortic dissection; p.

941-72. 


\section{CIRURGIA DE REVASCULARIZ DO MIOCARDIO}

André Monti Garzesi

Antônio Sérgio Martins

Leonardo Rufino Garcia

Marcello Laneza Felicio

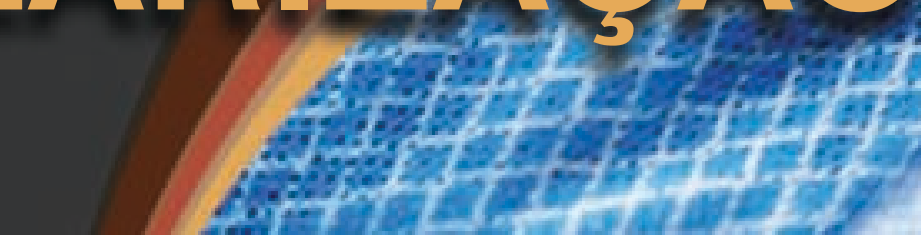




\section{Introdução}

A primeira cirurgia de revascularização do miocárdio (RM) foi realizada em 1964 e desde então o procedimento vem passando por constantes avanços tecnológicos, técnicas cirúrgicas e revisão de vários conceitos relativos à aterosclerose. A RM atualmente é um dos procedimentos cirúrgicos mais realizados em todo o mundo.

Os objetivos da RM são aliviar os sintomas, melhorar a função ventricular, prevenir o infarto, proteger o miocárdio isquêmico, aumentar a expectativa de vida e melhorar sua qualidade.

\section{Anatomia coronariana}

As artérias coronarianas são responsáveis pela irrigação do miocárdio, são os primeiros ramos emergentes da aorta e emergem a cerca de um cm superior às cúspides aórticas. Se situam na superfície epicárdica e dão origem a ramos para o interior do miocárdio (Figura 1).

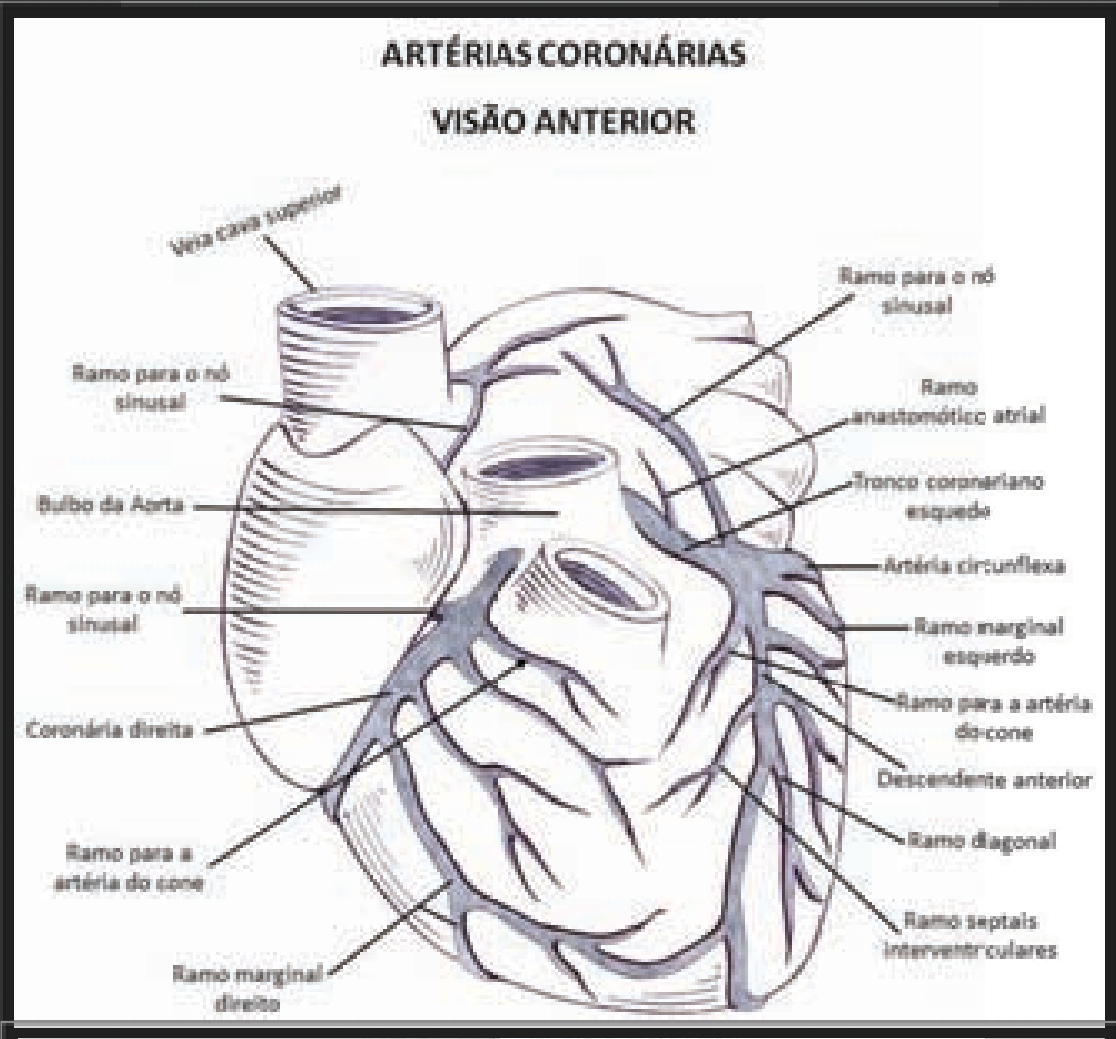

ARTÉRIASCORONÁRIAS VISĀO POSTERIOR

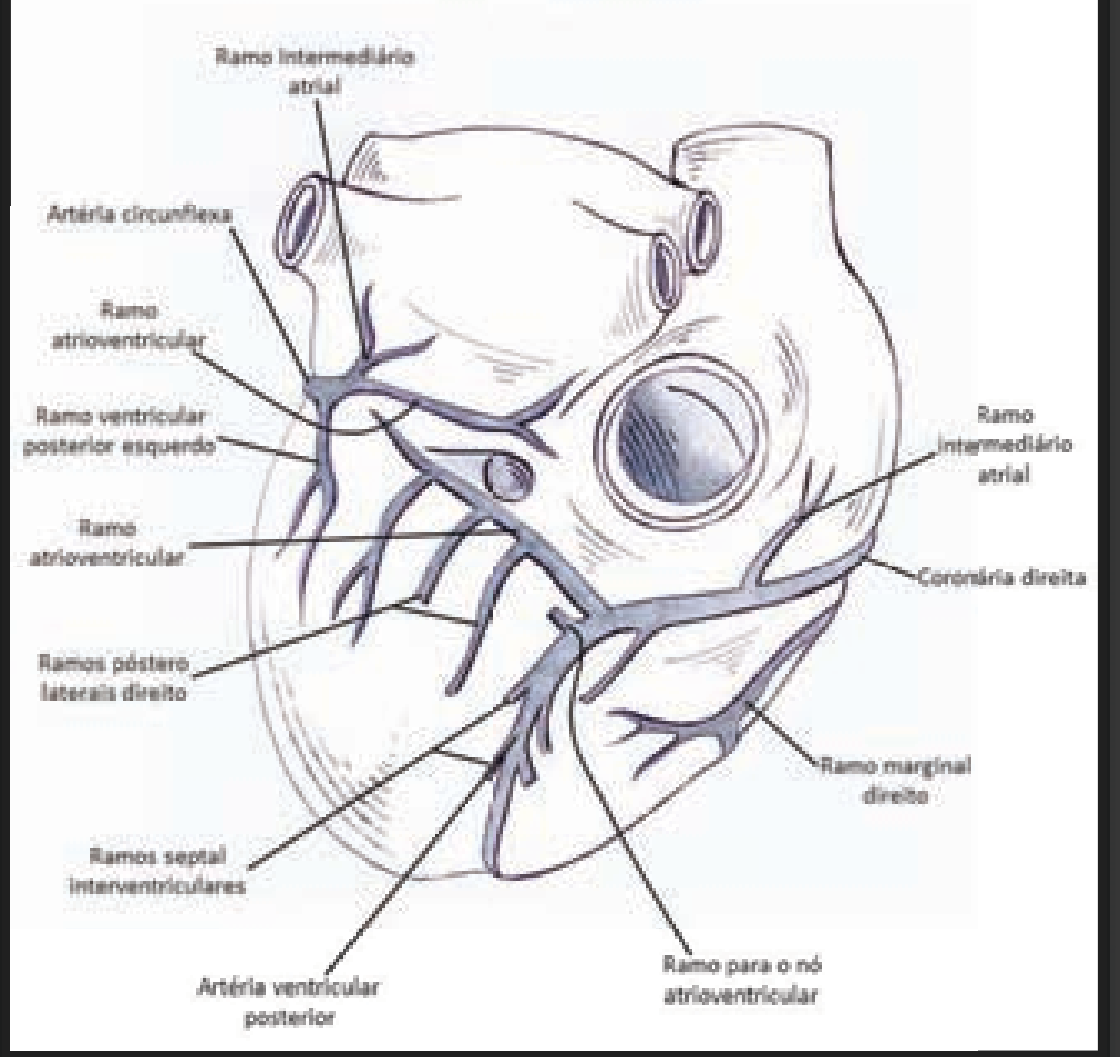

Figura 1 - Anatomia coronariana. 
O sistema arterial coronariano é dividido em artéria coronária direita e esquerda:

Artéria coronária direita (CD): origina-se no seio coronariano direito (97\%), tem seu trajeto entre a via de saída do ventrículo direito e a aurícula direita, acompanhando o sulco atrioventricular direito em direção a Crux Cordis (definida como o ponto de encontro do sulco coronariano com os sulcos interatrial e interventricular).

A CD é responsável por irrigar toda a parede livre do ventrículo direito, terço posterior do septo interventricular, parede inferior do ventrículo esquerdo e todo o átrio direito.

Dá origem a 4-5 ramos ventriculares, a artéria sinusal em cerca 55\% dos casos, a artéria do cone em cerca 50\%, artéria descendente posterior (DP) em cerca $80 \%$ dos casos e artéria ventricular posterior (VP) (Figura 2).
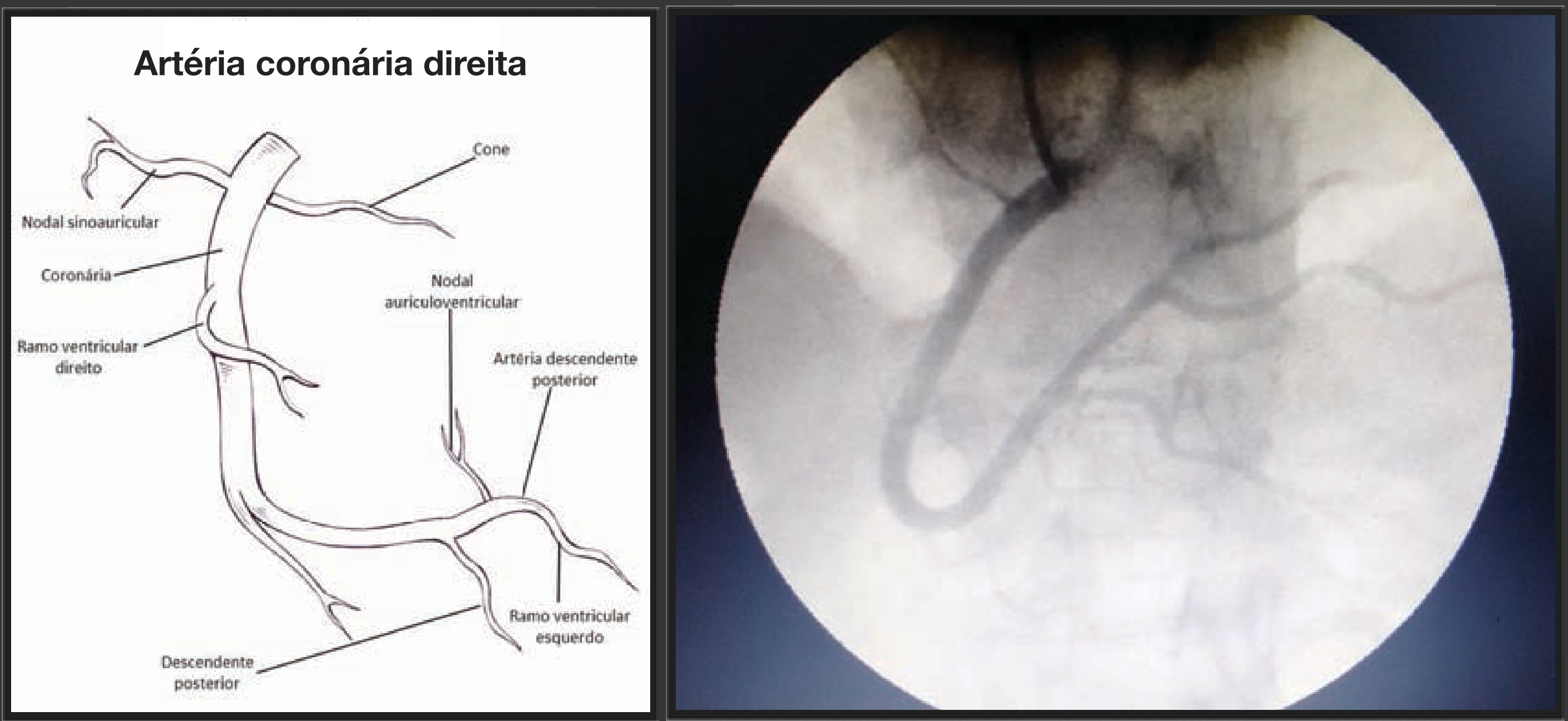

Figura 2 - Desenho esquemático da anatomia da artéria coronária direita e cateterismo. 
Artéria coronária esquerda: origina-se no seio coronariano esquerdo. O seu trajeto inicial é constituído por um pequeno segmento, denominado de tronco coronariano esquerdo (TCE), que se bifurca em artéria descendente anterior (DA) e artéria circunflexa (CX). Em alguns casos o TCE pode ser trifurcado, dando origem também a artéria diagonalis.

A artéria coronária esquerda é responsável por irrigar todo o átrio esquerdo, os dois terços anteriores do septo, a margem esquerda da parede livre do ventrículo direito e a parede anterior e lateral do ventrículo esquerdo.

A DA percorre todo o sulco interventricular anterior até o ápice, dá origem aos ramos septais e aos ramos diagonais que irrigam a parede ântero lateral do ventrículo esquerdo.

A CX tem o trajeto sob a aurícula esquerda, percorrendo o sulco atrioventricular esquerdo, dá origem aos ramos marginais que irrigam a parede lateral do ventrículo esquerdo e ao ramo ventricular posterior esquerdo (VPE) que irriga a parede posterior do ventrículo esquerdo (Figura 3).
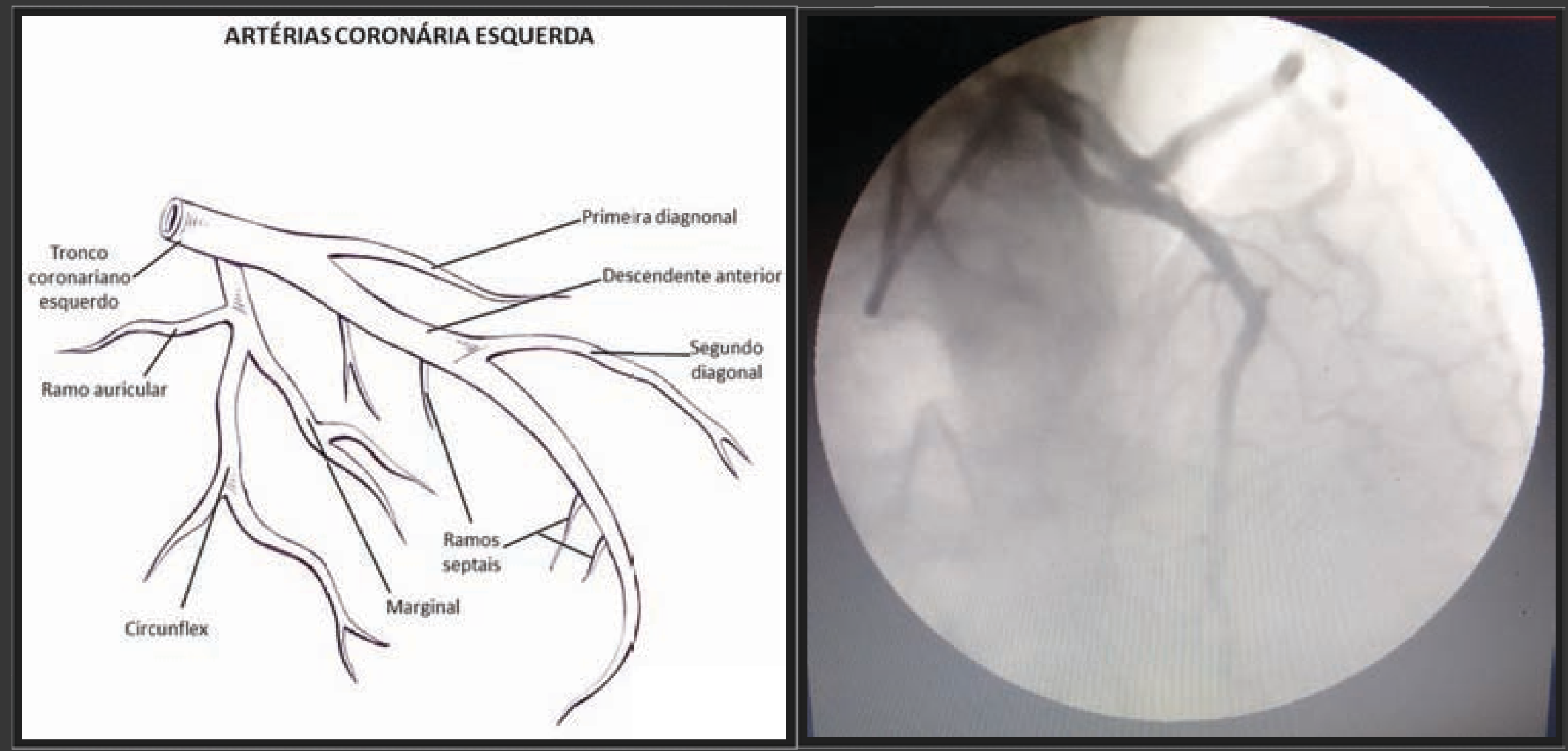

Figura 3 - Desenho esquemático da anatomia da artéria coronária esquerda e cateterismo 
A dominância da coronária direita (cerca de 85\% dos pacientes) ocorre quando esta ultrapassa a Crux Cordis e dá origem a VP e a DP.

A dominância da coronária esquerda (cerca de 8\% dos pacientes) ocorre quando a artéria circunflexa, em sua porção distal, dá origem a artéria DP e as artérias ventriculares posteriores, nesse tipo de dominância a coronária direita não irriga nenhuma porção do ventrículo esquerdo.

A codominância (cerca de $7 \%$ dos pacientes) ocorre quando a artéria circunflexa dá origem a artéria VP (em alguns casos outra DP) e a coronária direita dá origem a artéria DP.

reconhecidas adequadamente e que são determinadas pela extensão da obstrução da luz das artérias coronárias.

\section{As síndromes coronarianas são classicamente definidas como:}

Angina instável: é necessário a internação hospitalar e o uso de medicações intravenosas, nesses casos existe isquemia do miocárdio.

Angina estável: caráter crônico, pode ser tratada com medicações de uso oral.

Choque cardiogênico: é necessário o uso de drogas inotrópicas

\section{Indicação cirúrgica}

A indicação cirúrgica deve levar em consideração o contexto cultural e social do paciente, deverá ter uma interação entre os cardiologistas clínicos, cardiologistas intervencionistas e os cirurgiões cardíacos (o "heart team"), para determinar a melhor opção de tratamento, sempre esclarecendo da melhor maneira possível dúvidas do paciente e de seus familiares e respeitando suas decisões (Figura 4).

A doença arterial coronariana possui manifestações clínicas que devem ser

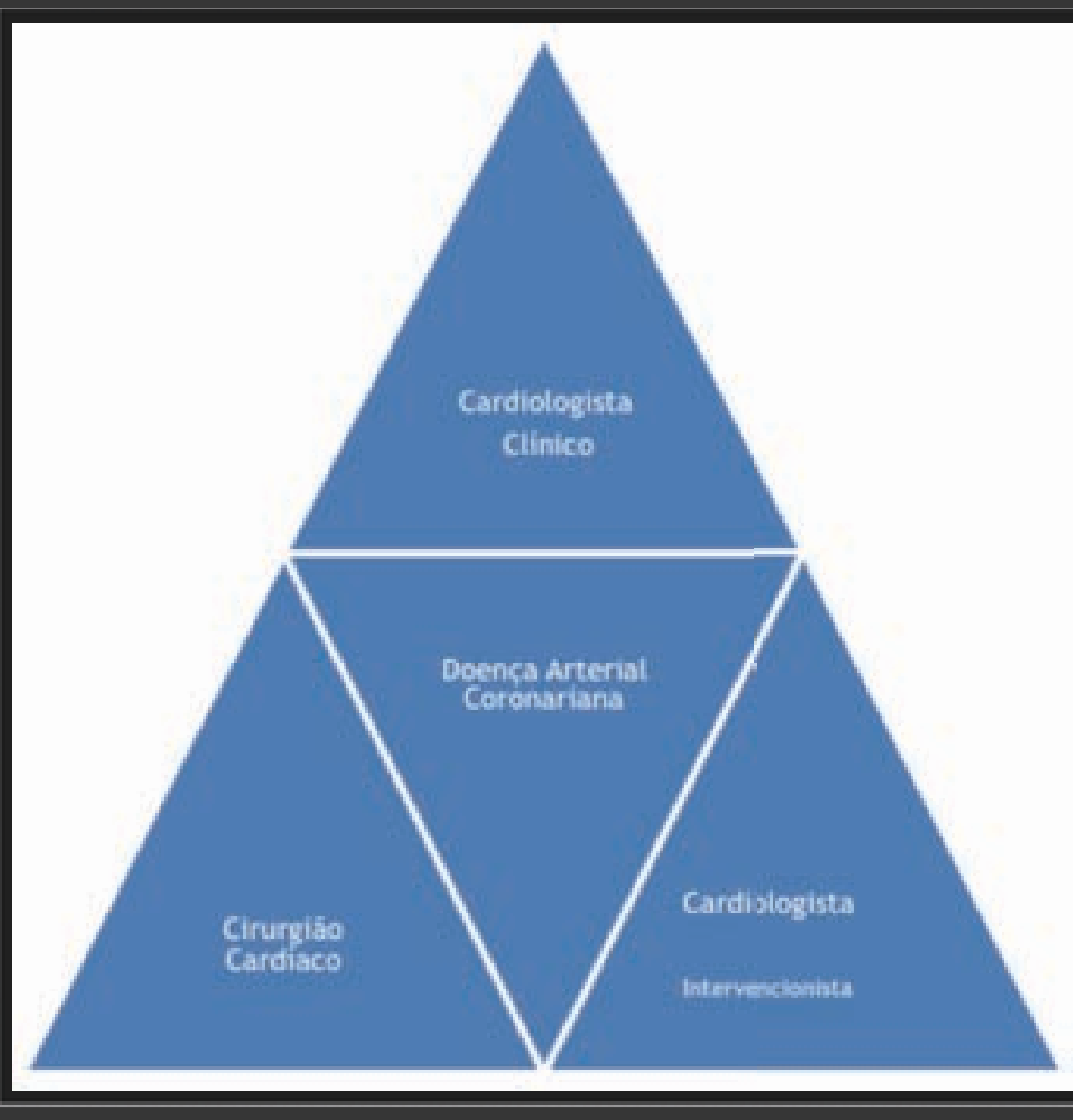

Figura 4 - Heart Team para manter uma pressão sistólica de $90 \mathrm{mmHg}$. Em alguns casos é necessário o uso de balão intra aórtico. É definido pelo índice cardíaco menor que $1,81 / \mathrm{min} / \mathrm{m}^{2}$, PVC maior que $20 \mathrm{mmHg}$, pressão sistólica menor que $90 \mathrm{mmHg}$.

Infarto do miocárdio: o infarto transmural é definido pelo aparecimento de nova onda " $Q$ " em duas ou mais derivações no ECG de 12 canais, já o infarto subendocárdico é definido pelo ECG sem novas ondas "Q", mas com evidencias de necrose miocárdica, como os achados clínicos, as alterações eletrocardiográficas e das enzimas cardíacas (Figura 5). 


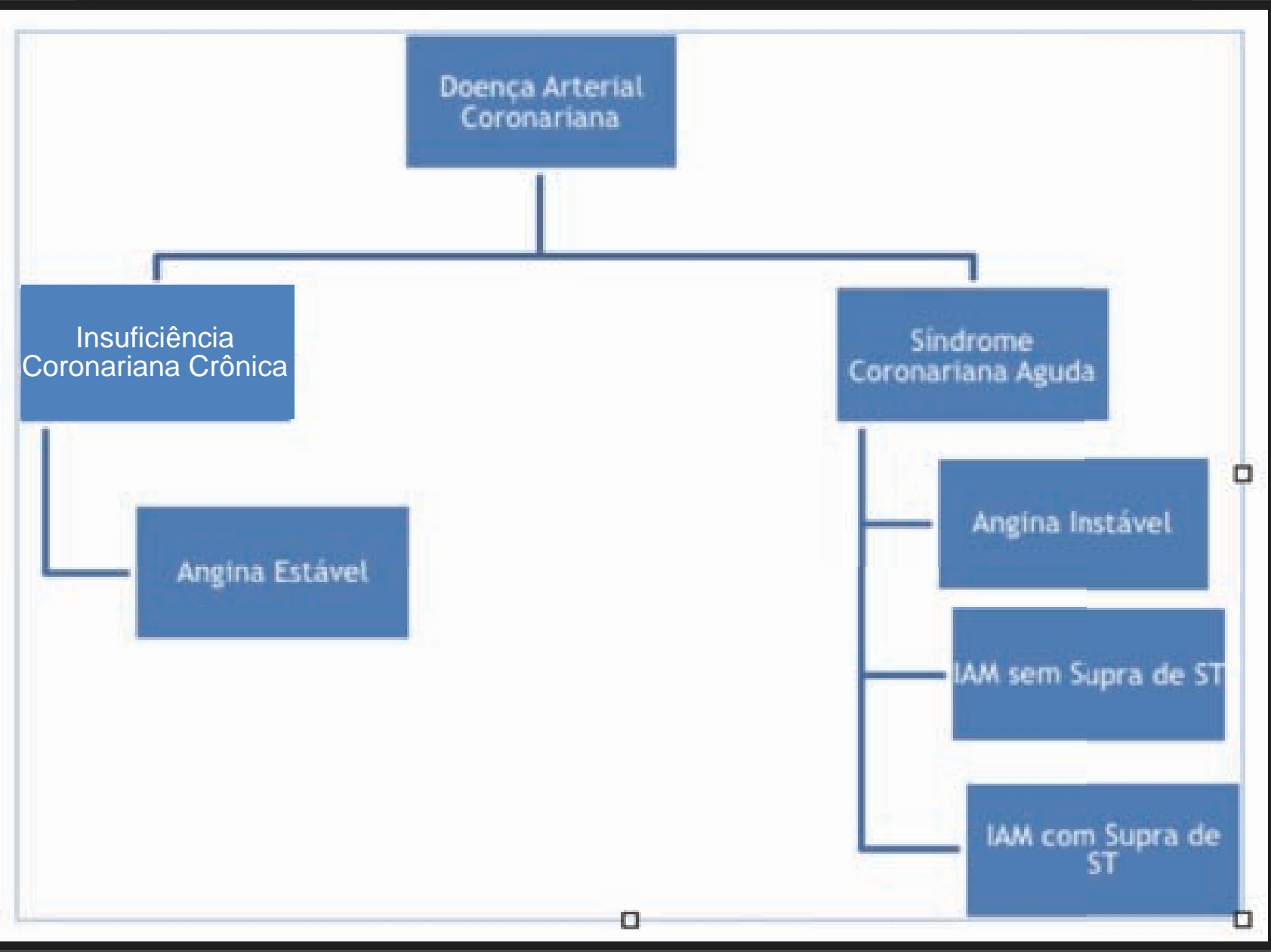

Figura 5- As síndromes coronarianas

As recentes recomendações para a realização de revascularização do miocárdio (cirúrgica ou percutânea) em pacientes com doença coronariana estável estão bem definidas, se dividem levando em consideração o prognóstico e os sintomas do paciente (Tabela 1).

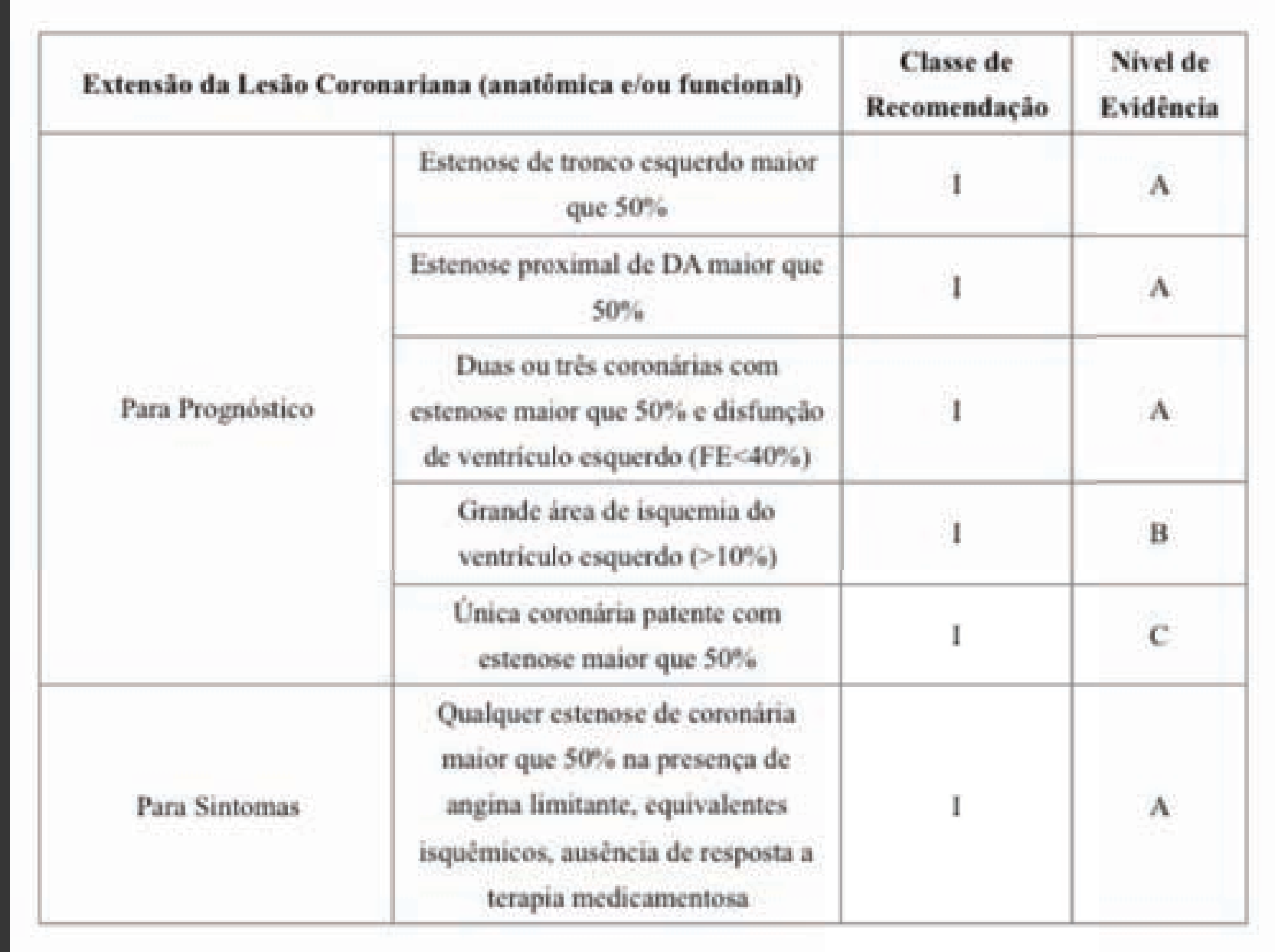

Tabela 1- Indicações para revascularização do miocárdio (cirúrgica ou percutânea)

Para pacientes com angina estável e anatomia coronariana adequada tanto para a intervenção cirúrgica quanto pela percutânea, as recomendações sobre qual método mais adequado a ser utilizado levam em consideração o "SYNTAX score" (método de classificação por pontuação levando em conta a anatomia coronariana do paciente e a localização das lesões). Quanto maior o valor do SYNTAX, mais complexa e grave é a lesão) (Tabela 2; Figuras 6 e 7). 


\begin{tabular}{|c|c|c|c|c|}
\hline \multirow{2}{*}{$\begin{array}{l}\text { Extensão da Lesão } \\
\text { Coronariana }\end{array}$} & \multicolumn{2}{|c|}{ Revascularizacâo do Miocárdio } & \multicolumn{2}{|c|}{ Angioplastia Percutànea } \\
\hline & $\begin{array}{c}\text { Classe de } \\
\text { Recomendaçào }\end{array}$ & $\begin{array}{l}\text { Nivel de } \\
\text { Evidéncia }\end{array}$ & $\begin{array}{c}\text { Classe de } \\
\text { Recomendacão }\end{array}$ & $\begin{array}{l}\text { Nivel de } \\
\text { Evidência }\end{array}$ \\
\hline $\begin{array}{l}\text { Lesáo em uma ou duas } \\
\text { coronárias sem estenose } \\
\text { proximal da DA }\end{array}$ & $\mathrm{Ib}$ & c & 1 & c \\
\hline $\begin{array}{l}\text { Lesảo em uma coronária } \\
\text { com lesśo proximal da } \\
\text { DA }\end{array}$ & 1 & 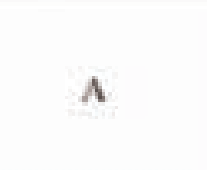 & 1 & A \\
\hline $\begin{array}{l}\text { Lesío em duas } \\
\text { coronárias com lesio } \\
\text { proximal da DA }\end{array}$ & 1 & B & 1 & c \\
\hline $\begin{array}{l}\text { Lessajo em tronco } \\
\text { esquerdo com SYNTAX } \\
\leq 22\end{array}$ & 1 & B & 1 & B \\
\hline $\begin{array}{l}\text { Lesaio em tronco } \\
\text { esquerdo com SYNTAX } \\
\text { entre } 23 \text { e } 32\end{array}$ & 1 & B & $\mathrm{Ha}$ & B \\
\hline $\begin{array}{c}\text { Lesâo em tronco } \\
\text { esquerdo com SYNTAX } \\
>32\end{array}$ & 1 & B & III & B \\
\hline $\begin{array}{l}\text { Lesăo em trứs coronirias } \\
\text { com SYNTAX } \leq 22\end{array}$ & 1 & $\mathbf{A}$ & 1 & B \\
\hline $\begin{array}{l}\text { Lesblo em trís coronárias } \\
\text { com SYNTAX entre } \\
23.32\end{array}$ & I & A & III & B \\
\hline $\begin{array}{l}\text { Lesảo em trús coronárias } \\
\text { com } \text { SYNTAX }>32\end{array}$ & $\mathrm{I}$ & A & III & B \\
\hline
\end{tabular}

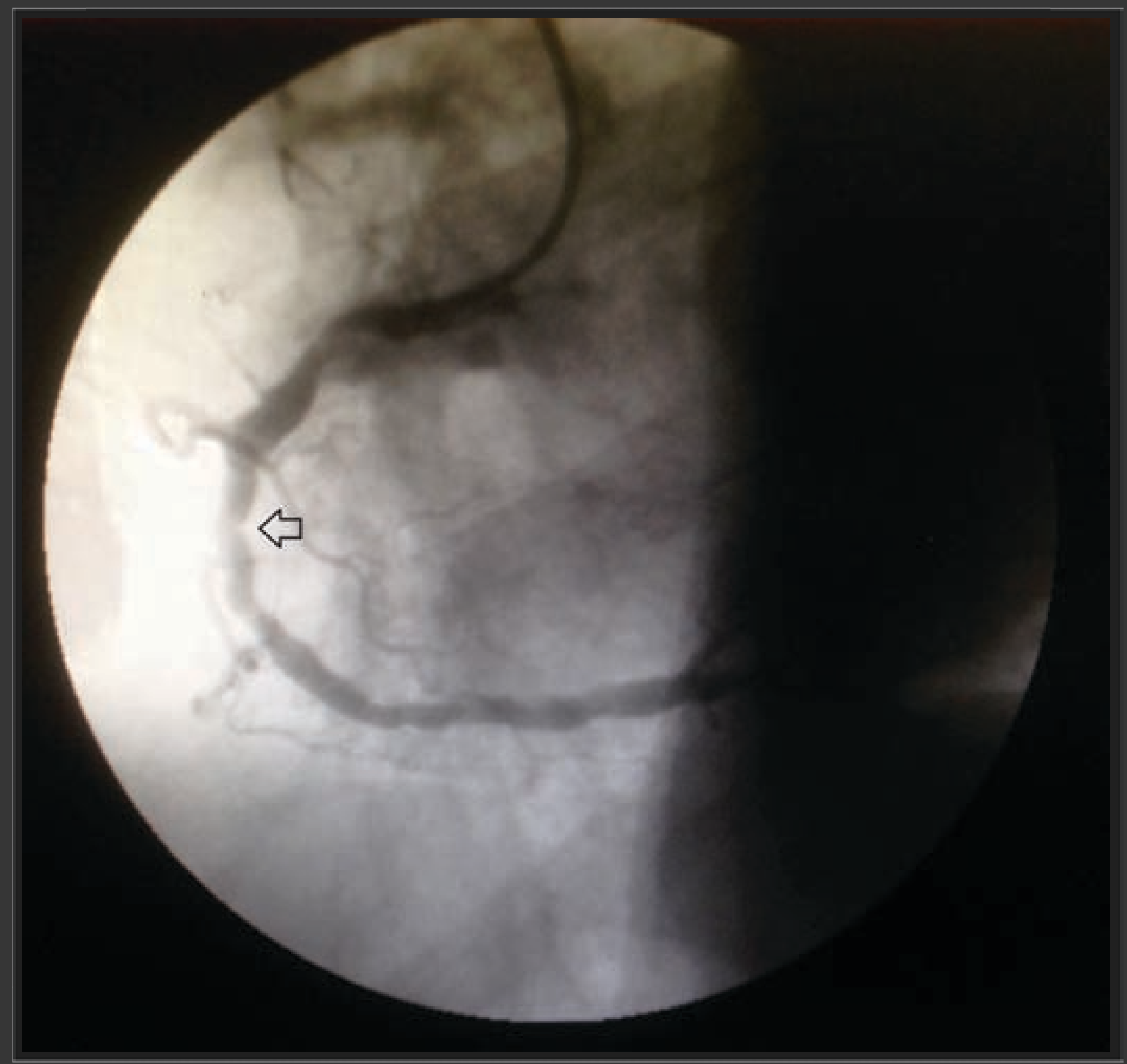

Figura 6- Exemplo de lesão em CD

Tabela 2- Indicações para a revascularização cirúrgica ou percutânea

A RM está indicada como tratamento primário na presença de choque cardiogênico após um infarto agudo do miocárdio, quando a anatomia coronariana é desfavorável para a realização de angioplastia percutânea. 


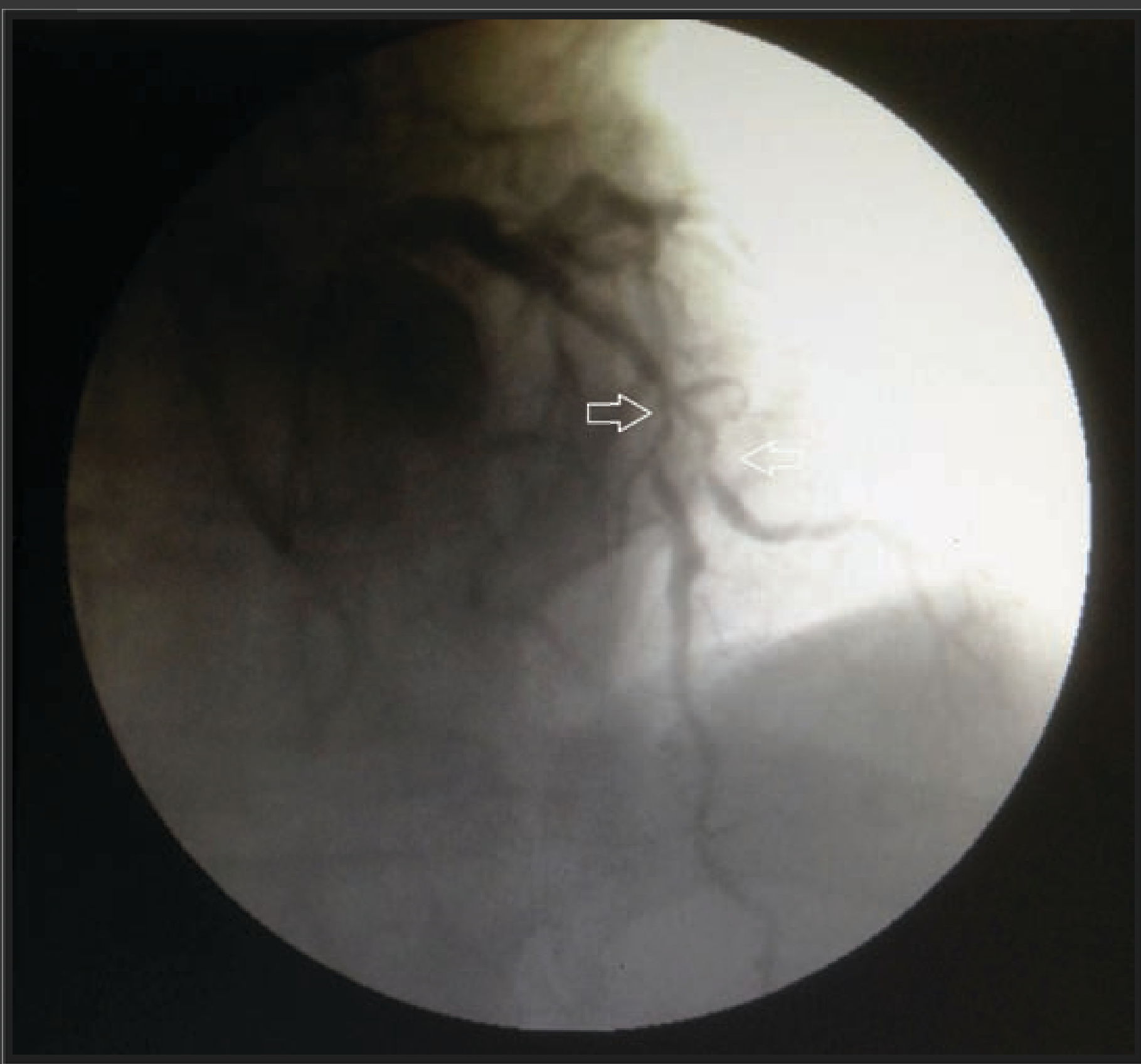

do nativo dos enxertos e a possibilidade da competição de fluxo. Todos esses aspectos possibilitam escolher o melhor enxerto para que o tratamento cirúrgico tenha sucesso em longo prazo (Tabela 3).

Os enxertos mais comumente utilizados são a artéria torácica interna esquerda (ATIE ou mamária esquerda), artéria torácica interna direita (ATID), artéria radial (AR), artéria gastroepiplóica (AG), artéria epigástrica inferior (AEI) e veia safena magna (VS).

Muitos estudos ainda estão sendo realizados para se determinar qual a melhor opção de enxertos para a RM, no entanto, já está estabelecido que a utilização da ATIE in situ (quando é mantida sua origem proximal na artéria subclávia) anastomosada na DA aumenta a sobrevida do paciente e diminui a incidência de futuros eventos cardíacos.

Figura 7- Exemplo de lesão em DA e ramo diagonal

\section{Opções de enxertos}

A escolha de qual tipo de enxerto utilizar deve levar em consideração as comorbidades do paciente, o estado nativo das coronárias, o esta-

\begin{tabular}{|c|c|c|c|}
\hline Enxerto & Patência após 1 ano & Patência após 4-5 anos & Patência após 10 anos \\
\hline ATIE & $>95 \%$ & $90-95 \%$ & $88-95 \%$ \\
\hline ATID & $>95 \%$ & $>90 \%$ & $65-90 \%$ \\
\hline AR & $92-96 \%$ & $90 \%$ & $63-83 \%$ \\
\hline VS & $75-95 \%$ & $65-85 \%$ & $32-71 \%$ \\
\hline
\end{tabular}

Tabela 3 - Patência dos enxertos coronarianos 
As RM podem ser realizadas com o uso da circulação extracorpórea (conjunto de técnicas e equipamentos que substituem temporariamente as atividades cardiopulmonares) ou não. A não utilização da circulação extracorpórea traz como benefícios a diminuição da resposta inflamatória sistêmica e da manipulação da aorta e está indicada para os casos com maior morbimortalidade.

\section{Complicações mecânicas do IAM}

\section{com indicação de tratamento cirúrgico}

Comunicação interventricular pós IAM: pode ocorrer entre $01^{\circ} \mathrm{e}$ o $7^{\circ}$ dia após o início do infarto, é uma complicação grave e a mortalidade varia de $50 \%$ a $87 \%$ na $1^{\circ}$ e na $6^{\circ}$ semana respectivamente. A cirurgia geralmente é de emergência nas primeiras 24 horas devido à intensidade das repercussões hemodinâmicas.

Insuficiência mitral isquêmica: a cirurgia deve ser considerada em casos de insuficiência moderada ou grave. Está associada com alta mortalidade cirúrgica (20-50\% na fase aguda) e menor taxa de sobrevida (85-45\% em cinco anos) quando comparada com outras doenças da válvula mitral.

Ruptura cardíaca: é a causa mais comum de morte súbita no período hospitalar, a terceira causa de morte devido ao IAM e está presente em cerca de $20 \%$ dos pacientes que foram a óbito devido ao IAM. O diagnóstico é feito através de um ecocardiograma e possui indicação de cirurgia de emergência.
Aneurisma ventricular: surge em até duas semanas após o IAM (50\% nas primeiras 48hs). A cirurgia deve ser considerada quando o paciente apresenta sintomas refratários ao tratamento clínico, arritmias ventriculares, episódios de tromboembolismo, insuficiência cardíaca congestiva, diminuição importante da fração de ejeção além da oportunidade cirúrgica durante a RM.

Abaixo segue vídeo que mostra passos principais de uma cirurgia de revascularização do miocárdio.

\section{Vídeo 1- PONTE de SAFENA}

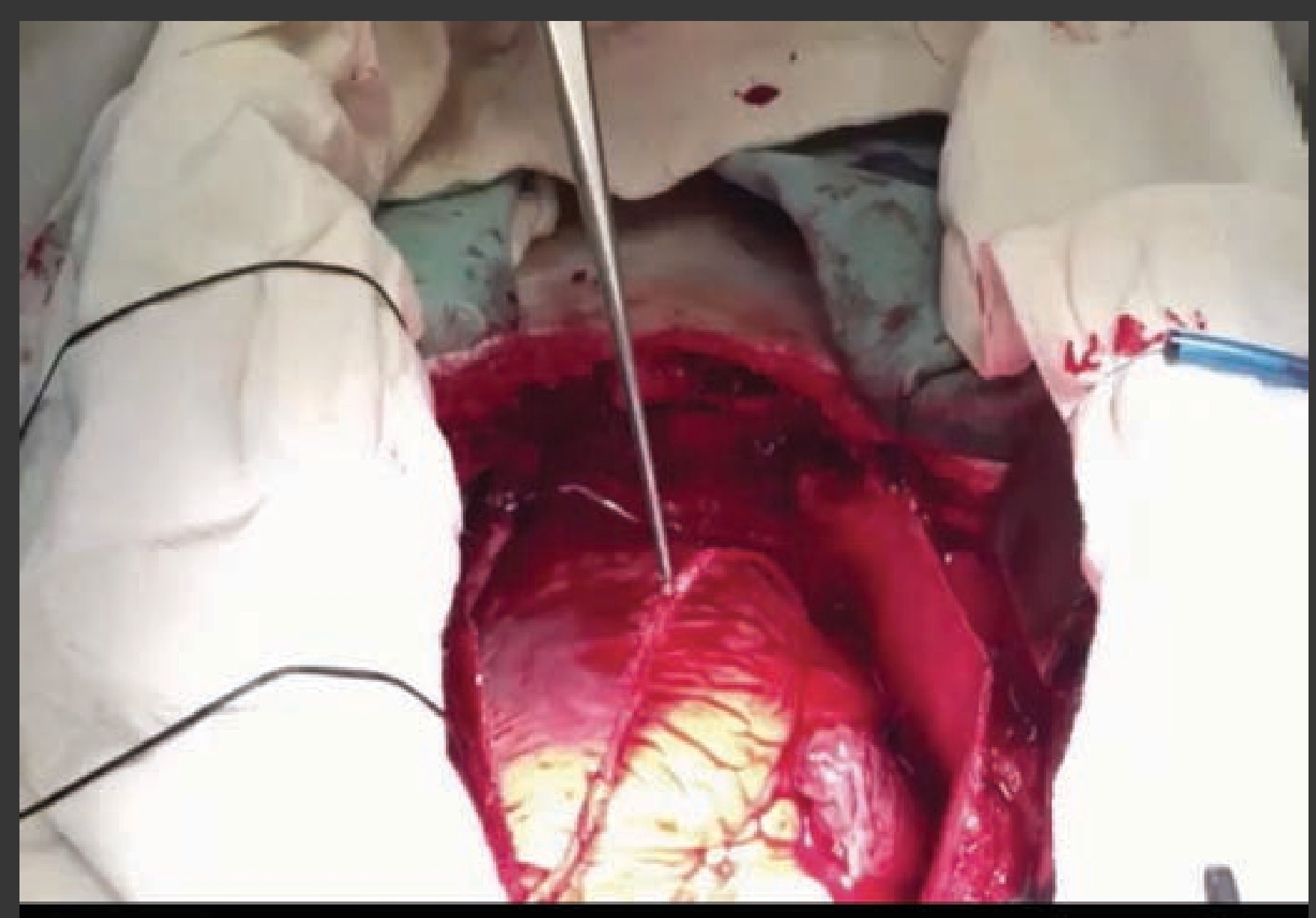

Artéria mamária esquerda já dissecada e com ótimo fluxo 


\section{Bibliografia}

Brick AV, Souza DSR, Braile DM, Buffolo E, Lucchese FA, Silva FPV, et al. Diretrizes da cirurgia de revascularização miocárdica valvopatias e doenças da aorta. Arq Bras Cardiol. 2004;82 Supl 5:1-20.

Hillis LD, Smith PK, Anderson JL, Bittl JA, Bridges CR, Byrne JG, et al. 2011 ACCF/AHA Guideline for Coronary Artery Bypass Graft Surgery: executive summary: a report of the American College of Cardiology Foundation/American Heart Association Task Force on Practice Guidelines. Circulation. 2011;124:e652-735.

Kirklin JK, Kouchoukos NT, Blackstone EH, Hanley FL. Cardiac surgery. 4th ed. Philadelphia: Elsevier; 2013. Ischemic heart disease; p. 353471.

Kolh P, Windecker S, Alfonso F, Collet J, Cremer J, Falk V, et al. 2014 ESC/EACTS Guidelines on myocardial revascularization: The Task Force on Myocardial Revascularization of the European Society of Cardiology (ESC) and the European Association for Cardio-Thoracic Surgery (EACTS)Developed with the special contribution of the European Association of Percutaneous Cardiovascular Interventions (EAPCI). Eur Heart J. 2014;35(37):2541-619.

Sianos G, Morel MA, Kappetein AP, Morice MC, Colombo A, Dawkins $K$, et al. The SYNTAX Score: an angiographic tool grading the complexity of coronary artery disease. Eurointervention. 2005;1:219-27. 


\section{DOENÇAS VALVARES}

André Monti Garzesi

Leonardo Rufino Garcia

Nelson Leonardo K. Leite de Campos

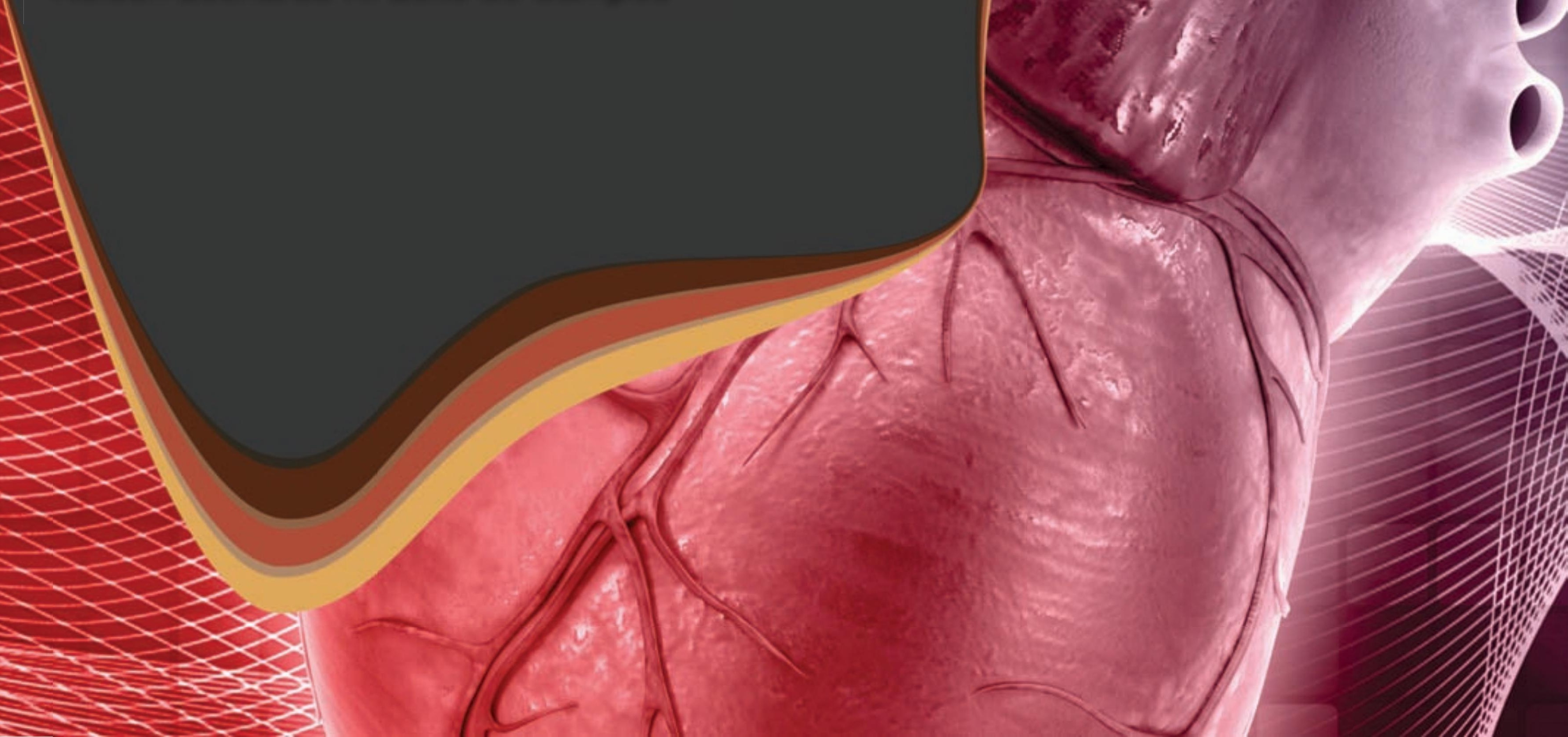




\section{Introdução}

A ecocardiografia e o seu aprimoramento possibilitaram um melhor estudo de aspectos anatômicos e dinâmicos do coração e também a identificação precoce das cardiopatias valvares. Entretanto, uma história adequada e um exame físico atencioso são fundamentais para a eleição de uma hipótese diagnóstica inicial e para a progressão da avaliação complementar.

Diferentemente dos países desenvolvidos a febre reumática é a principal causa das valvopatias no Brasil. Alguns estudos com grupos de escolares em capitais brasileiras estimaram prevalência de cardite reumática entre um e sete casos/ 1000, enquanto nos EUA esse número está entre 0,1 e 0,4 casos/ 1000 escolares.

Com o aumento do número de procedimentos invasivos (uso de cateteres, implante de próteses e marca- passos cardíacos, entre outros) a endocardite infecciosa não pode ser esquecida como causa de lesões valvares. Além disso, parcela significativa da população brasileira apresenta saúde bucal precária e pouco acesso a tratamento odontológico, mantendo alta incidência de endocardite estreptocócica em valvas nativas e próteses.

De uma forma geral o tratamento intervencionista é o único capaz de alterar a evolução natural das valvopatias se indicado no momento oportuno. Medicações tratam as comorbidades e aliviam sintomas além de serem ferramentas importantes para profilaxia de endocardite e de surtos de febre reumática.
Anatomicamente existem três alterações valvares principais: estenose, insuficiência e dupla lesão (ambas associadas). Estenoses causam obstrução ao fluxo anterógrado, insuficiências causam fluxos regurgitantes através de valvas incompetentes. A figura 1 mostra um coração durante a diástole, visto da base com os átrios removidos. As valvas mitral e tricúspide estao abertas permitindo o enchimento dos ventrículos e as valvas aórtica e pulmonar estão fechadas.

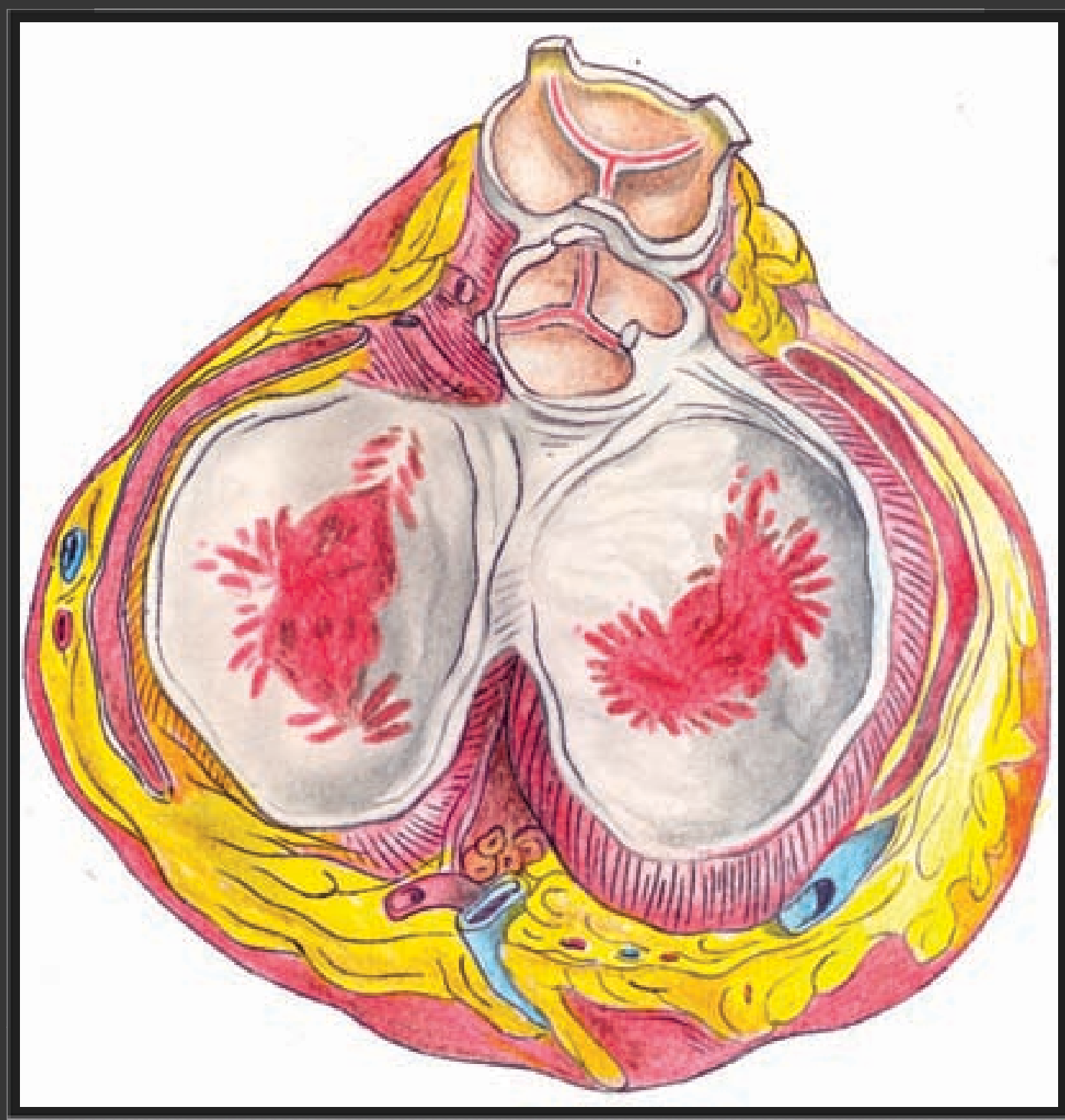

Figura 1: Coração durante a diástole, visto da base com os átrios removidos 
As doenças das valvas tricúspide e pulmonar não serão abordadas nesse capítulo por terem menor importância e frequência do que as valvopatias mitral e aórtica.

\section{Estenose mitral}

Caracteriza- se pela resistência ao fluxo sanguíneo transmitral devido ao espessamento e redução da mobilidade das cúspides valvares. No Brasil a principal causa é a doença reumática. Outras causas menos freqüentes são: lúpus eritematoso sistêmico, endocardite infecciosa, carcinóide maligno, mucopolissacaridoses e congênita.

O padrão anátomo- patológico principal é a fusão das comissuras, mas também são encontrados o espessamento dos folhetos valvares, áreas de calcificação e encurtamento das cordoalhas.

Normalmente a área valvar mitral varia de quatro a seis cm2 e áreas inferiores a dois cm2 geram obstrução ao esvaziamento atrial esquerdo. Dessa obstrução se origina um gradiente pressórico entre as câmaras esquerdas. Com a evolução da doença o aumento da pressão atrial esquerda é transmitido ao leito vascular pulmonar causando congestão local, hipertensão pulmonar e sintomas progressivos.

\subsection{Quadro clínico}

A partir do estabelecimento da lesão os sintomas podem demorar uma ou duas décadas para aparecer. O sintoma inicial é a dispnéia com piora durante os esforços, que também pode ser desencadeada por infecções e fibrilação atrial, a arritmia mais freqüente na valvopatia mitral. Durante a evolução, pode ocorrer edema agudo de pulmão. Em 15\% dos pacientes pode haver dor torácica por hipertensão ventricular direita. O átrio esquerdo aumentado pode comprimir o nervo laríngeo recorrente causando rouquidão. Nos casos avançados, em que a pressão pulmonar elevada se transmitiu para câmaras direitas pode haver hepatomegalia, ascite e edema de membros inferiores.

Não há desvio do ictus e à ausculta o sopro característico é diastólico e melhor ouvido em decúbito lateral esquerdo no foco mitral, diastólico, cuja intensidade depende do grau de estenose valvar.

\subsection{Exames complementares}

São importantes porque avaliam a repercussão hemodinâmica e orientam a conduta. O aumento do átrio esquerdo está presente em 90\% dos casos, revelando ao eletrocardiograma ondas $P$ entalhadas se 0 ritmo é sinusal. Em casos avançados há sinais de sobrecarga de câmaras direitas. A arritmia mais freqüente é a fibrilação atrial.

A depender dos efeitos hemodinâmicos da estenose o RX de tórax pode mostrar sinais de aumento da pressão pulmonar como aumento 
dos hilos e do tronco da artéria pulmonar, aumento da trama nos campos superiores e edema intersticial. O aumento do átrio esquerdo é o primeiro sinal a aparecer (duplo contorno).

Ao possibilitar a avaliação da área valvar, do gradiente transvalvar na diástole, da pressão sistólica na artéria pulmonar e da presença de trombos atriais esquerdos, o ecocardiograma é um exame fundamental. Manifestações clínicas durante o repouso aparecem a partir de uma área valvar inferior a 1,5cm. O ecocardiog̉rama transesofágico pode ser indicado para a exclusão de trombos atriais, após episódios embólicos ou nos casos em que o ecocardiograma transtorácico dá informações inconclusivas. Classifica-se estenose mitral em discreta, moderada e importante de acordo com os valores da área valvar e do gradiente diastólico (tabela 1).

\begin{tabular}{|c|c|c|}
\hline Lesão (grau) & Área $\left(\mathrm{cm}^{2}\right)$ & Gradiente médio $(\mathbf{m m H g})$ \\
\hline Discreta & $>1,5$ & $<5$ \\
\hline Moderada & 1,0 a 1,5 & 5 a 10 \\
\hline Grave & $<1,0$ & $>10$ \\
\hline
\end{tabular}

Tabela 1: Graduação da Estenose Mitral

O cateterismo cardíaco está indicado para homens com mais de 40 anos e mulheres após a menopausa ou com mais de um fator de risco coronariano. Também é um exame útil quando os achados clínicos e os ecocardiográficos são discrepantes.

\subsection{Tratamento}

O tratamento medicamentoso atua apenas contra os sintomas e não muda a evolução da doença já que não interfere na obstrução valvar. O paciente assintomático não se beneficia com nenhuma modalidade terapêutica. Já os sintomáticos com congestão pulmonar (dispnéia de esforço, dispnéia paroxística noturna e ortopneia) necessitam de diuréticos de alça e de antagonistas da aldosterona. Outro aspecto essencial é o controle da freqüência cardíaca na fibrilação atrial, principalmente porque as taquicardias podem descompensar a doença ao dificultar ainda mais o esvaziamento atrial esquerdo. Assim, os betabloqueadores são a primeira opção.

Embolias sistêmicas são eventos graves que estão presentes na evolução natural e estão associadas à fibrilação atrial. Ocorrem em 13\% a $26 \%$ dos casos. Para sua prevenção indica- se a anti- coagulação oral com manutenção da RNI (relação normatizada internacional) entre 2,0 e 3,0 nos pacientes com fibrilação atrial paroxística e permanente, com trombo atrial esquerdo e nos que tiveram embolia prévia. Apenas antiagregação plaquetária com ácido acetilsalicílico (AAS) não é uma alternativa eficaz.

O tratamento invasivo tem algumas modalidades: valvoplastia mitral por cateter- balão, e a cirurgia (comissurotomia ou troca valvar). A indicação do tratamento invasivo deve levar em conta o risco cirúrgico, a experiência da equipe e a anatomia valvar.

A valvoplastia mitral por cateter- balão tem boa taxa de sucesso, mas está contra- indicada nos casos com insuficiência mitral associada, 
trombos no átrio esquerdo, outra indicação cirúrgica presente, anatomia valvar desfavorável, área valvar maior que 1,5 cm. Para o̊ estudo da anatomia valvar é recomendado o escore de Wilkins. Através do ecocardiograma avaliam- se a mobilidade e a espessura dos folhetos, o acometimento subvalvar, e as calcificações. Os pacientes elegíveis para valvoplastia por cateter são aqueles com escore de Wilkins menor que oito. A mortalidade é baixa (menor que 0,5\%) e as complicações são acidente vascular encefálico, tamponamento cardíaco e insuficiência mitral. Exige centros de hemodinâmica com experiência nessa modalidade de tratamento e retarda a evolução da doença em cerca de 10 anos.

Para os pacientes muito sintomáticos (classe funcional III e IV), com contra- indicação ao tratamento por cateter- balão e ou com hipertensão pulmonar grave o tratamento cirúrgico é recomendado. A comissurotomia tem índices de sobrevida em 15 anos de 96\% e sobrevida livre de complicações valvares em torno de 92\%. Quando a preservação da valva não é possível pela comissurotomia, está indicada a troca da valva mitral. A mortalidade varia de três a 10\% e os principais complicadores são idade, classe funcional, hipertensão pulmonar e doença coronariana associada.

\section{Insuficiência mitral}

A principal função da valva mitral é impedir o retorno de sangue do ventrículo esquerdo para o átrio esquerdo durante a sístole ventricular. A insuficiência resulta da coaptação imperfeita dos folhetos mitrais durante a fase de ejeção ventricular ou de lesões nos folhetos valvares.

A valva mitral não pode ser avaliada como estrutura única, mas sim associada em função e anatomia a outros elementos que formam o aparato valvar: o anel, os folhetos, as cordas tendíneas e os músculos papilares. Tais estruturas devem funcionar em conjunto para a manutenção da função cardíaca. Qualquer alteração em um desses elementos pode ser causa de insuficiência.

As causas mais comuns são o prolapso da valva mitral, doença reumática, endocardite infecciosa, calcificação do anel, cardiomiopatia e doença coronariana isquêmica. Etiologicamente pode ser dividida em primária (a qual resulta de deformidade na estrutura valvar) ou secundária (resulta de doença cardíaca como o infarto do miocárdio com lesão de músculo papilar, por exemplo). De acordo com a evolução temporal também pode ser dividida em aguda e crônica.

\subsection{Quadro clínico}

As manifestações clínicas vão depender da gravidade da regurgitação mitral, da velocidade de progressão da doença, da capacidade do átrio esquerdo e veias pulmonares de receber o volume regurgitado do ventrículo esquerdo determinando aumentos de sua pressão (complacência), da presença de taquiarritmias atriais e de outras doenças cardíacas como coronariopatias e miocardiopatias associadas. Os sintomas mais comuns são fraqueza e fadiga. No momento em que os sintomas 
de baixo débito cardíaco e congestão pulmonar são aparentes uma disfunção do ventrículo esquerdo grave e talvez irreversível pode estar presente.

À inspeção pode haver desvio do ictus para a esquerda e à palpação pode haver frêmito sistólico. À ausculta o sopro tem pouca correlação com a gravidade da insuficiência e classicamente está presente no foco mitral, é sistólico, rude e irradia- se para a axila esquerda.

\subsection{Exames complementares}

Ao eletrocardiograma podem estar presentes sobrecarga atrial esquerda e fibrilação atrial, arritmia que no pré- operatório é fator independente de redução de sobrevida em longo prazo após cirurgia para correção de insuficiência mitral crônica.

O RX de tórax mostra, nos casos avançados, cardiomegalia com aumento de câmaras esquerdas. Nos casos agudos ou crônicos descompensados está presente edema intersticial pulmonar. Nos casos avançados pode haver aumento da trama vascular pulmonar e abaulamento do tronco da artéria pulmonar.

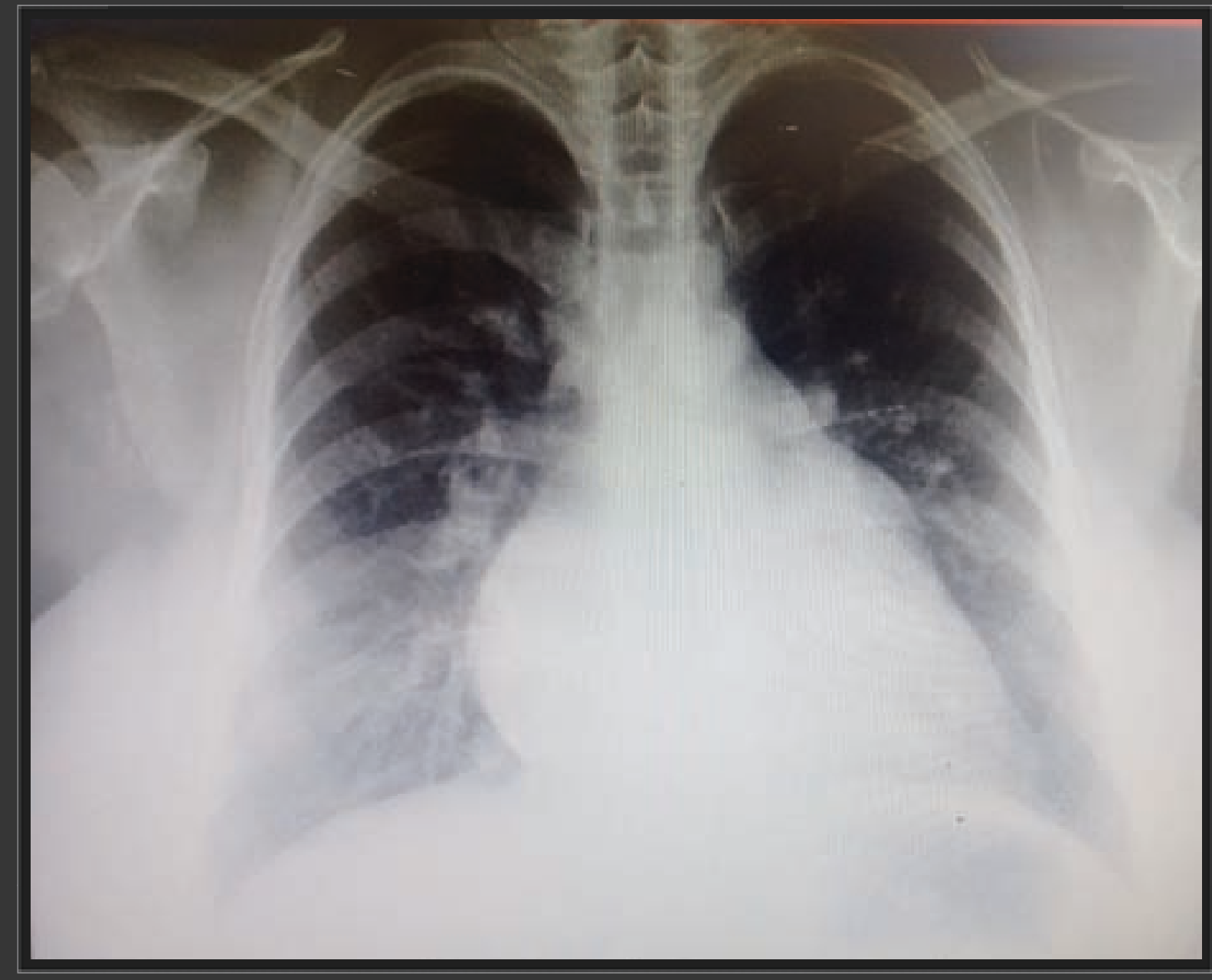

Figura 2: Aumento da trama vascular pulmonar e abaulamento do tronco da artéria pulmonar.

A ecocardiografia com doppler tem papel central porque permite a quantificação da regurgitação, o mecanismo de regurgitação (ajuda na etiologia) e a programação do tratamento cirúrgico ao predizer a probabilidade de plástica valvar. Além disso, permite medidas de variáveis importantes para a indicação do tratamento como a fração de ejeção e o diâmetro sistólico final do ventrículo esquerdo. 


\subsection{Tratamento}

O tratamento pode ser farmacológico ou cirúrgico. Nos casos agudos de insuficiência mitral são úteis os vasodilatadores e diuréticos endovenosos seguido de cirurgia de emergência. Os inotrópicos são indicados nos casos em que há baixo débito cardíaco. Nos casos crônicos sintomáticos o tratamento medicamentoso é pouco eficaz e os vasodilatadores e diuréticos apenas melhoram a classe funcional sem interferir na mortalidade. Os pacientes que desenvolveram fibrilação atrial permanente ou paroxística devem ser anticoagulados (RNI entre 2,0 e 3,0). O controle da frequência cardíaca pode ser feito com digitálicos, beta- bloqueadores, bloqueadores de canais de cálcio ou amiodarona.

O tratamento cirúrgico pode ser realizado sob duas formas: plástica valvar ou substituição da valva mitral. Na medida em que preserva o aparato mitral, a plástica valvar é o procedimento de escolha. Em comparação com a troca da valva apresenta maior sobrevida e menor mortalidade cirúrgica, porém nem sempre é passível de ser realizada. Sua realização depende da quantidade de tecido elástico viável e da calcificação no aparato valvar além da experiência da equipe cirúrgica. A troca da valva pode trazer as desvantagens da anticoagulação, no caso de prótese mecânicas ou necessidade de nova cirurgia, no caso de próteses biológicas. Porém é a melhor alternativa quando a plástica não é factível.

A indicação clássica de cirurgia é para os pacientes com insuficiência mitral importante e com sintomas (classe funcional II, III e IV). Para os assintomáticos, o momento ideal para a intervenção é controverso. A cirurgia está indicada se há disfunção ventricular (fração de ejeção menor que $60 \%$ ou diâmetro sistólico final do ventrículo esquerdo maior que 40 mm). Nesses casos, quanto melhor a função ventricular melhor a sobrevida após a correção da lesão. Se houver grave disfunção, com fração de ejeção menor que 30\% ou diâmetro sistólico final maior que $55 \mathrm{~mm}$ com regurgitação importante a cirurgia pode não trazer benefícios.

Também há indicação de cirurgia para os pacientes assintomáticos com insuficiência importante e fração de ejeção normal que apresentarem hipertensão pulmonar ou fibrilação atrial de início recente. A incidência de fibrilação atrial nos pacientes com insuficiência mitral moderada e importante chega a 5 \% ao ano e tem implicações não desprezíveis.

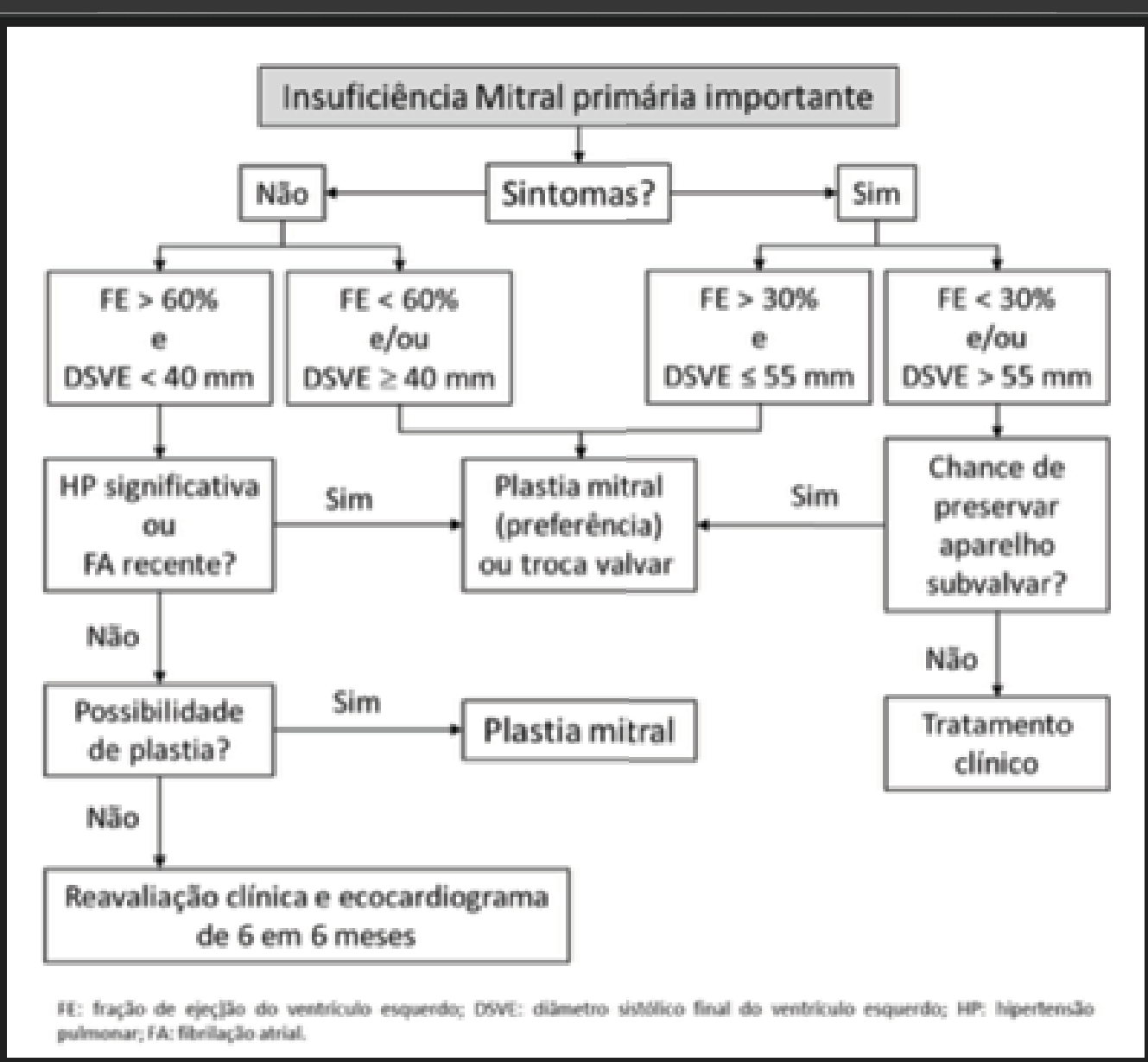

Figura 3: Fluxograma para tratamento da insuficiência mitral 


\section{Estenose aórtica}

Consiste na obstrução da via de saída do ventrículo esquerdo devido à calcificação das estruturas valvares podendo associar- se à fusão das comissuras nos casos de estenose reumática. Outras causas descritas são a degenerativa ou senil , a qual ocorre nos idosos com fatores de risco para doença arterial coronariana, a congênita e a calcificação de uma valva aórtica bicúspide em que o fluxo turbulento e o estresse hemodinâmico aumentado aceleram as alterações valvares.

Nos adultos a obstrução se desenvolve e aumenta gradualmente ao longo de um período prolongado e a sobrecarga crônica de pressão resulta em hipertrofia concêntrica do ventrículo esquerdo com espessamento da parede e tamanho normal das câmaras cardíacas. Com isso a função contrátil inicialmente é mantida, porém, o aumento da massa do miocárdio e da fibrose intersticial resulta em disfunção diastólica com aumento das pressões de enchimento do ventrículo esquerdo.

\subsection{Quadro clínico}

Os sintomas geralmente ocorrem entre os 50 e 70 anos e a partir do momento de seu aparecimento há piora do prognóstico com média de sobrevida de dois a três anos além do aumento do risco de morte súbita. A apresentação clínica mais comum naqueles com diagnóstico conhecido de estenose aórtica é uma perda gradual de tolerar o exercício, com fadiga e dispneia aos esforços. O que explica a dispneia é a disfunção diastólica com aumento da pressão de enchimento e finalmente congestão pulmonar.
Angina pode estar presente e se assemelha àquela do paciente com doença arterial coronariana: precipitada pelo exercício e com melhora ao repouso. Pode resultar da própria aterosclerose coronária concomitante e também de uma combinação entre uma demanda de oxigênio do miocárdio hipertrofiado aumentada e a redução da oferta secundária a uma compressão excessiva dos vasos coronários.

Também é descrita síncope que pode ocorrer durante atividade física. Há redução da perfusão cerebral e da pressão sistêmica em decorrência de um débito cardíaco fixo. Durante o repouso síncopes podem ser causadas por fibrilação ventricular transitória e por fibrilação atrial já que a elevação das pressões de enchimento do ventrículo esquerdo aumenta a dependência da contração atrial para um volume sistólico efetivo. Nas graves calcificações valvares pode haver extensão da lesão para o sistema condutor elétrico cardíaco ocorrendo bloqueios atrioventriculares e suas manifestações como tonturas e desmaios. Na fase final da doença, com grave comprometimento do desempenho ventricular os sinais de insuficiência cardíaca estão presentes.

Cabe aqui discutir sobre um grupo de pacientes assintomáticos que minimizam os sintomas e ajustam seu estilo de vida atribuindo assim a fadiga e a dispneia à perda de condicionamento ou à idade. Nesses casos um teste de esforço pode revelar os sintomas ocultos como intolerância à atividade física e hipotensão. Entretanto, o teste de esforço é contraindicado nos pacientes sintomáticos e naqueles com velocidade do jato transvalvar maior que $4 \mathrm{~m} / \mathrm{s}$ e gradiente médio transvalvar maior que $40 \mathrm{mmHg}$.

Durante o exame físico o sopro se caracteriza por ser sistólico, ejetivo, melhor auscultado no foco aórtico e com irradiação para o pescoço. 


\subsection{Exames complementares}

No eletrocardiograma a alteração mais notável é a sobrecarga ventricular esquerda, principalmente nas lesões moderadas a importantes (figura 4). A correlação entre as voltagens no ECG e a gravidade da obstrução é fraca nos adultos e melhor nas crianças em que a doença se apresenta de forma congênita. A depender da extensão dos infiltrados calcificados para o sistema de condução podem ocorrer bloqueios intraventriculares e atrioventriculares.

No RX de tórax a dilatação pós- estenótica da aorta é achado comum, principalmente nos pacientes com valva aórtica bicúspide. Como a hipertrofia ventricular esquerda é concêntrica a cardiomegalia não é acentuada. O átrio esquerdo pode aumentar levemente, entretanto, quando esse aumento é muito acentuado devemos suspeitar de valvopatia mitral associada.

O ecocardiograma é muito útil para diagnóstico e seguimento clínico dos pacientes com estenose da valva aórtica. Define parâmetros que, em conjunto com os sintomas apresentados pelo paciente, auxiliam na indicação cirúrgica como a velocidade do jato transvalvar, a área valvar, função contrátil e hipertrofia do ventrículo esquerdo. Além disso, permite a exclusão segura de doença subvalvar, por exemplo, uma membrana fibrosa que pode se comportar como estenose aórtica.

Como nas outras valvopatias, o cateterismo cardíaco tem indicação para os pacientes com fatores de risco para doença arterial coronaria-

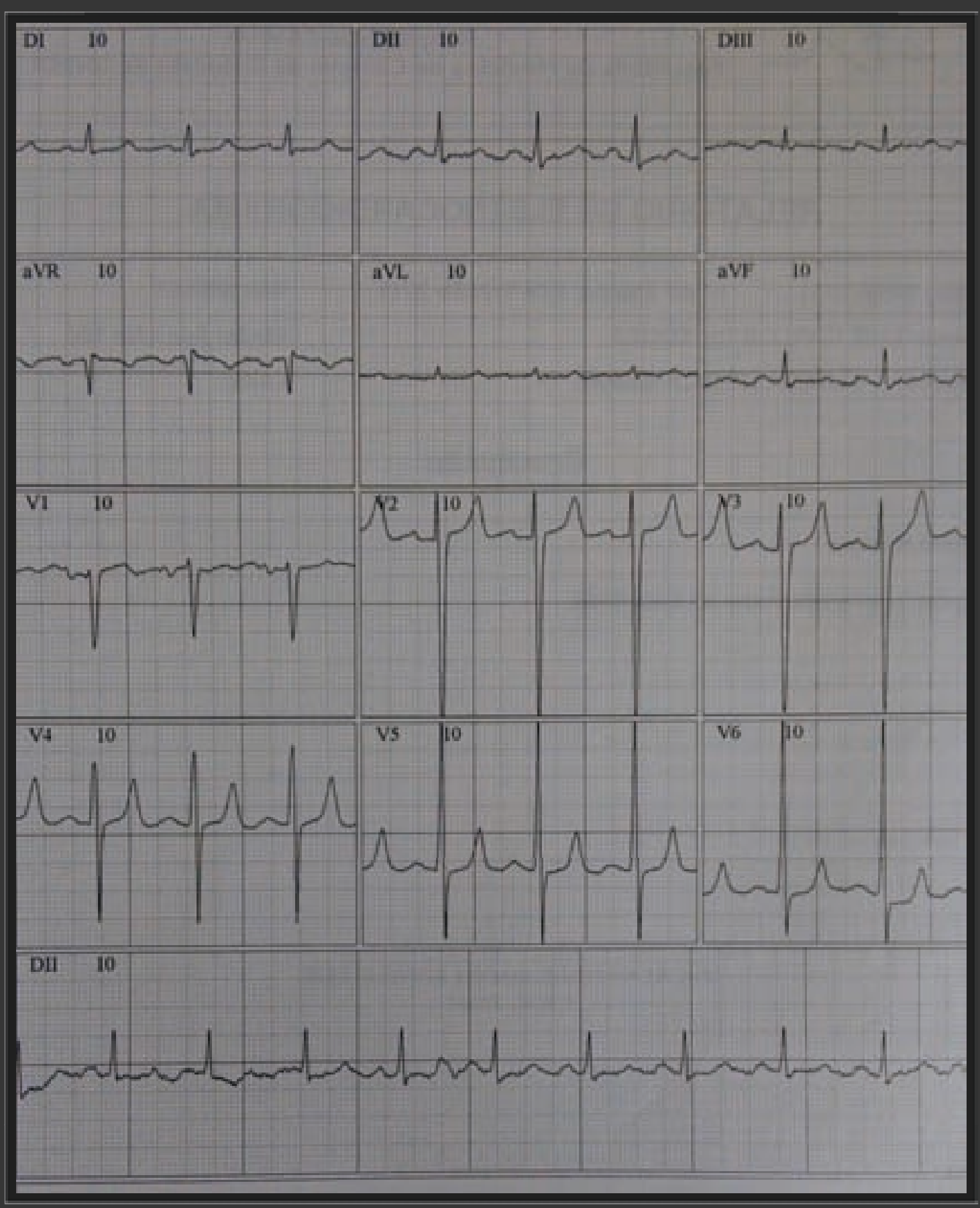

Figura 4: Sobrecarga ventricular esquerda.

na e nos poucos casos em que os dados clínicos e os achados ecocardiográficos são discrepantes. A tomografia computadorizada de tórax serve de avaliação pré- operatória para os pacientes com evidência de dilatação na raiz da aorta vista pelo RX de tórax. 


\subsection{Tratamento}

O tratamento clínico deve contemplar as comorbidades cardiovasculares associadas como a doença arterial coronariana e hipertensão arterial sistêmica bem como a profilaxia para endocardite infecciosa. Como os efeitos vasodilatadores de algumas medicações podem não ser contrabalanceados pelo aumento do débito cardíaco, medicações como inibidores da enzima conversora de angiotensina e diuréticos devem ser iniciados em baixas doses se necessário. Os betabloqueadores devem ser evitados por deprimirem a função ventricular esquerda.

A troca cirúrgica da valva aórtica é o procedimento de escolha para o tratamento na medida em que promove melhora hemodinâmica e dos sintomas aumentando a sobrevida. Suas principais indicações são para:

- Adultos sintomáticos com estenose grave;

- Estenose grave com fração de ejeção menor que 50\%;

- Estenose grave em paciente sem sintomas que será submetido à outra cirurgia cardíaca ou cirurgia da aorta.

Como já mencionado, muitos pacientes assintomáticos podem o ser devido a modificações de seus estilos de vida, sendo, na verdade, pseudoassintomáticos. Nesses casos devem ser investigados alguns fatores de risco que podem indicar cirurgia:

- Teste de esforço que provoca sintomas ou hipotensão;

- Área valvar menor que 0,7 cm2;
- Diminuição da área valvar maior que 0,1cm2/ ano;

- Velocidade do fluxo transvalvar maior que $4 \mathrm{~m} / \mathrm{s}$;

- Doença arterial coronariana associada;

- Disfunção ventricular associada;

- Hipertrofia de ventrículo esquerdo (12 - 14 mm para mulheres e 14 $16 \mathrm{~mm}$ para homens).

A principal via de acesso é pela esternotomia mediana e é um procedimento com mortalidade global em torno de 3 a 4\% nos grandes centros. As principais complicações são disfunção da prótese, vazamento ao redor da prótese (escape paravalvar), formação de trombos e êmbolos arteriais, endocardite infecciosa e complicações da anticoagulação nas próteses mecânicas.

Diferentemente da valva mitral a plástica cirúrgica e a valvotomia por cateter não têm indicação na estenose valvar aórtica por terem alto risco e pouco benefício hemodinâmico.

Uma nova modalidade no tratamento da estenose aórtica tem sido realizada com resultados satisfatórios no curto prazo. Trata- se do implante por cateter de biopróteses específicas (TAVI - transcatheter aortic valve implantation). É indicada para pacientes com elevado risco cirúrgico, com doença importante e sintomática, idosos (mais que 80 anos), comorbidades importantes como cirrose hepática e doença pulmonar grave, múltiplas cirurgias cardíacas prévias, aorta muito calcificada ("em porcelana"), hipertensão pulmonar acentuada (maior que 60 $\mathrm{mmHg}$ ) e anatomia favorável ao implante protético. Embora a via de 
acesso mais usada seja a transfemoral, outras são descritas como a transapical e a transaórtica com indicações específicas para cada uma delas. Algumas das principais contra- indicações são expectativa de vida menor que um ano, demência avançada, endocardite ativa, trombo no ventrículo esquerdo e insuficiência mitral importante.

Entretanto, ainda faltam dados de longo prazo sobre a evolução dos pacientes submetidos a esse procedimento.

\section{Insuficiência aórtica}

Resulta do fechamento imperfeito das cúspides da valva aórtica ocorrendo refluxo de sangue para o ventrículo esquerdo durante a diástole. Pode ser causada por alteração valvar primária ou lesão na parede da aorta.

Em nosso meio a principal causa é a reumática. Outras causas são descritas, como hipertensão arterial sistêmica (causa dilatação progressiva do anel valvar), sífilis (causa inflamação na parede da aorta - aortite sifilítica), endocardite infecciosa, síndrome de Marfan, cardiopatias congênitas e trauma. Doenças com prevalência não desprezível como lúpus eritematoso sistêmico, artrite reumatóide e doença de Crohn também podem causar insuficiência aórtica.

A principal alteração determinada pela regurgitação aórtica é a sobrecarga de volume do ventrículo esquerdo, o que leva ao estiramento da fibra cardíaca, que mantém a função de bomba pelo mecanismo de Frank- Starling.Com o tempo a massa ventricular e o volume diastólico final se elevam. A partir de certo ponto crítico, os mecanismos compensatórios descritos entram em falência levando à redução da fração de ejeção. Durante a diástole, a valva incompetente, a baixa resistência periférica e a alta complacência do ventrículo esquerdo se relacionam com a baixa pressão diastólica aórtica e o sopro característico. Como as necessidades de oxigênio estão aumentadas devido à hipertrofia ventricular excêntrica e o fluxo coronariano se dá na diástole, essa redução da pressão diastólica diminui a pressão de perfusão coronária podendo haver isquemia do miocárdio.

\subsection{Quadro clínico}

A insuficiência aórtica se desenvolve de forma lenta e insidiosa, com baixa morbidade durante uma longa fase assintomática. Alguns pacientes com doença discreta permanecem sem sintomas por décadas e podem não necessitar de tratamento. Sintomas de reserva cardíaca reduzida ou de isquemia miocárdica se desenvolvem na quarta ou quinta décadas, em geral depois que tenham ocorrido cardiomegalia e redução da fração de ejeção. Dispneia de esforço, ortopneia e dispneia paroxística noturna costumam surgir gradualmente. Angina se manifesta tardiamente na evolução da doença e pode ocorrer à noite pela queda da pressão arterial diastólica.

Alguns pacientes com insuficiência importante se queixam de sensação desconfortável dos batimentos cardíacos quando deitados e dor torácica devido ao batimento do coração contra a parede do tórax. 
Durante o exame físico pode haver vários sinais clássicos. A cabeça do paciente pode oscilar a cada batimento (sinal de Musset) e pulsos arteriais são em "martelo d' água", com distensão abrupta e colapso rápido (pulso de Corrigan). O sinal de Traube se refere aos ruídos sistólicos e diastólicos na ausculta da artéria femoral. O sinal de Muller consiste em pulsações sistólicas da úvula e o sinal de Quincke se deve às pulsações capilares que podem ser vistas após pressão suave sobre a ponta de uma unha.

O ictus pode ser difuso e hiperdinâmico, deslocado lateral e inferiormente e pode haver um frêmito sistólico na base cardíaca, fúrcula e sobre as carótidas a depender do aumento do volume sistólico. O sopro é de alta frequência, decrescente através da diástole e sua duração se relaciona com a gravidade da doença. É melhor ouvido no foco aórtico.

\subsection{Exames complementares}

O eletrocardiograma mostra, nos casos crônicos e importantes, desvio do eixo cardíaco para a esquerda e sobrecarga de ventrículo esquerdo. As ondas T são frequentemente invertidas nas derivações precordiais, com depressão do segmento ST. Se a doença é provocada por processo inflamatório pode haver aumento do intervalo PR.

Ao RX de tórax o achado mais característico é a cardiomegalia nos casos com lesões crônicas e importantes. O ventrículo esquerdo aumen- ta na direção inferior e para a esquerda. Aumento atrial esquerdo sugere doença mitral associada. Dilatação da aorta pode ser notável e sugere causas secundárias como síndrome de Marfan ou ectasia do anel aórtico, por exemplo. Calcificações na aorta ascendente são inespecíficas podendo ocorrer na doença degenerativa e na sífilis.

Como nas outras valvopatias o ecocardiograma é fundamental, tanto para diagnóstico como para seguimento e indicação cirúrgica. Pode indicar a etiologia ao evidenciar espessamento das cúspides, prolapso valvar, vegetações e dilatação da raiz aórtica. A imagem transtorácica em geral é satisfatória, mas o exame transesofágico fornece mais detaIhes acerca da raiz da aorta. Ajuda a indicar o melhor momento cirúrgico ao permitir medidas seriadas das dimensões, volumes e massa do ventrículo esquerdo, assim como da fração de ejeção.

\subsection{Tratamento}

Inicialmente o paciente deve ser orientado quanto à possibilidade de aparecimento de sintomas ao longo do tempo uma vez que após o seu surgimento a função cardíaca piora junto com o prognóstico. Deve ser feita profilaxia para endocardite infecciosa, dieta hipossódica e manutenção do peso corporal ideal.

Vasodilatadores são usados para os pacientes assintomáticos com alteração volumétrica importante para retardar a evolução natural da doença. Nesse caso, os inibidores da enzima conversora de angiotensina são a primeira escolha. Diuréticos são usados quando há sinais de con- 
gestão sistêmica e pulmonar. Beta- bloqueadores são evitados por piorar a função cardíaca.

O tratamento cirúrgico da insuficiência aórtica é a substituição valvar. Em comparação com o tratamento clínico a cirurgia aumenta a fração de ejeção e a sobrevida do paciente. Classicamente está indicada para os sintomáticos e assintomáticos que apresentem disfunção ventricular evidenciada por:

- Fração de ejeção menor que 50\%;

- Dilatação do ventrículo esquerdo com diâmetro diastólico final maior ou igual a 75 mm ou diâmetro sistólico final maior ou igual a 55 mm;

- Sintomas de insuficiência cardíaca após o teste de esforço.

Pacientes com regurgitação aórtica moderada e com indicação de revascularização do miocárdio ou cirurgia de aorta ascendente também se beneficiam com a troca da valva aórtica. O maior determinante do prognóstico após a correção cirúrgica da lesão é a função ventricular prévia e, quando esta é adequada há melhora hemodinâmica e a sobrevida passa a depender apenas das complicações das próteses valvares.

\subsection{Insuficiência aórtica aguda}

É uma doença que pode se apresentar como emergência médica. O prognóstico depende do tempo até o tratamento cirúrgico definitivo.
As causas principais são endocardite infecciosa, dissecção aórtica e trauma.

O ventrículo esquerdo não é capaz de aumentar o seu volume diastólico de forma aguda, levando então à diminuição do débito cardíaco. Taquicardia e sinais de disfunção ventricular esquerda (sudorese fria, palidez, diminuição do nível de consciência e hipotensão) são evidentes.

O paciente se beneficia do tratamento farmacológico com vasodilatadores e inotrópicos endovenosos enquanto é preparado para cirurgia e é importante ressaltar que o balão de contra- pulsação intra- aórtico não é indicado por prejudicar a hemodinâmica ventricular esquerda.

\section{Valvas protéticas cardíacas}

Existem dois tipos de valvas artificiais cardíacas, as mecânicas e as biológicas. As diferenças principais entre elas dizem respeito ao risco de tromboembolismo maior nas valvas mecânicas e ao risco de deterioração estrutural maior nas próteses biológicas.

\subsection{Valvas mecânicas}

Atualmente as próteses de duplo folheto são as mais usadas por apresentarem melhor perfil hemodinâmico. São compostas por um anel e dois folhetos semicirculares que giram entre as posições aberta e fechada e feitas de carbono pirolítico. Existem outros tipos como as de disco único e a valva esférica do tipo "bola- gaiola" (Starr- Edwards) 


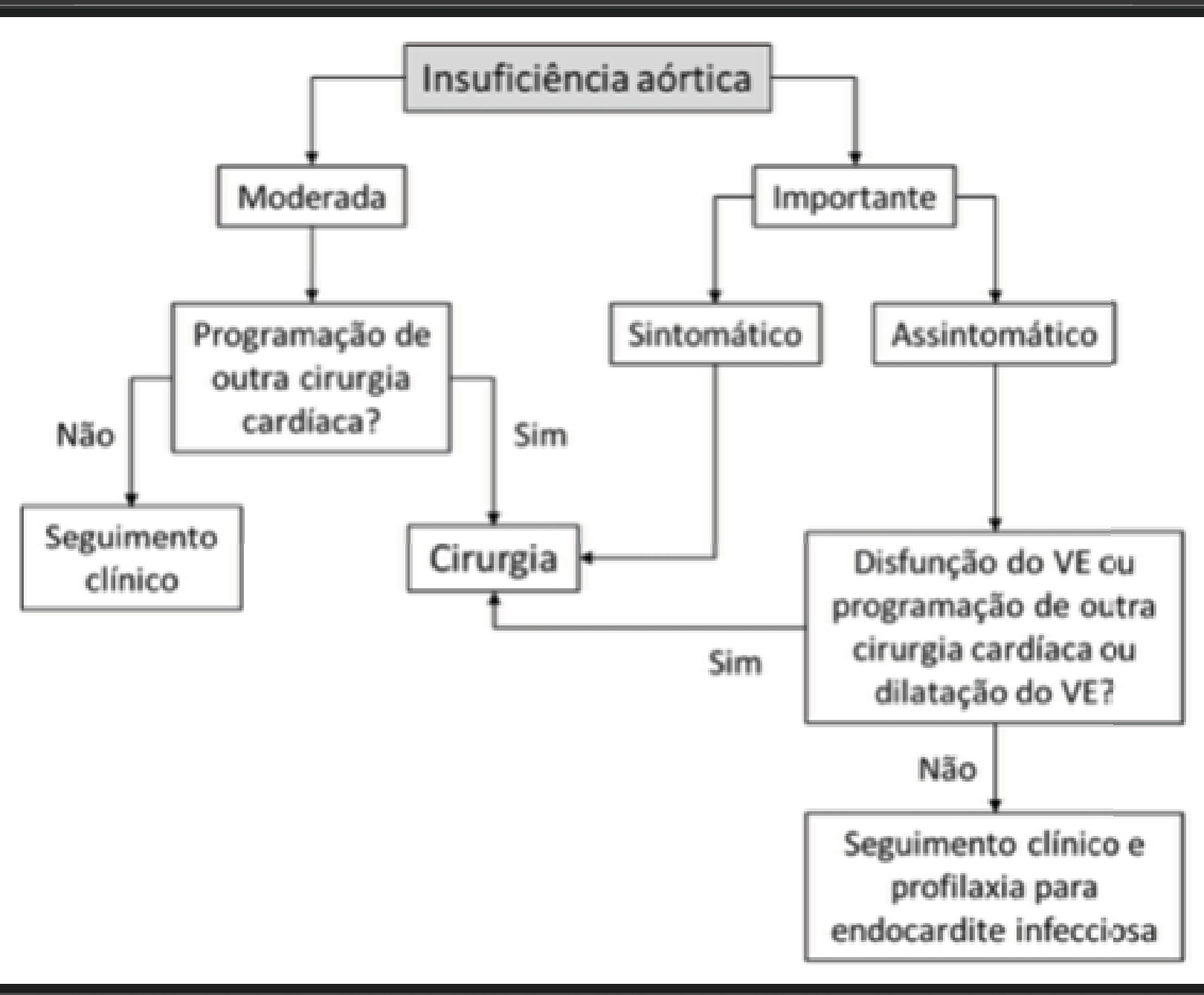

3,5 para aqueles com próteses na posição mitral. Devemos lembrar que o uso isolado de antiagregantes plaquetários e dos novos anticoagulantes orais (Dabigatran, Rivaroxaban e Apixaban) não oferece proteção adequada contra eventos trombóticos. A trombose na valva artificial é uma grave complicação e deve ser investigada nos pacientes com dispneia súbita, abafamento de bulhas e novos sopros cardíacos. Deve ser diagnosticada pela ecocardiografia. Pacientes sintomáticos que se apresentem nas classes funcionais III e IV da New York Heart Association (NYHA) ou com grande trombo obstruindo a prótese devem passar por cirurgia de emergência. O tratamento com fibrinolíticos se presta àqueles com sintomas leves e trombo pequeno na prótese.

Figura 5: Fluxograma para tratamento de insuficiência aórtica crônica

com características menos favoráveis ao fluxo sanguíneo e pouco usadas atualmente.

Há necessidade vitalícia de anticoagulação e maior risco de trombose na posição mitral em relação à aórtica assim como no primeiro ano de pós- operatório. Em geral os anticoagulantes orais são iniciados dois dias após a substituição valvar. Há então necessidade de monitorização da relação normatizada internacional (RNI) que deve ficar entre 2,0 e 3,0 para os pacientes com próteses na posição aórtica e entre 2,5 e 


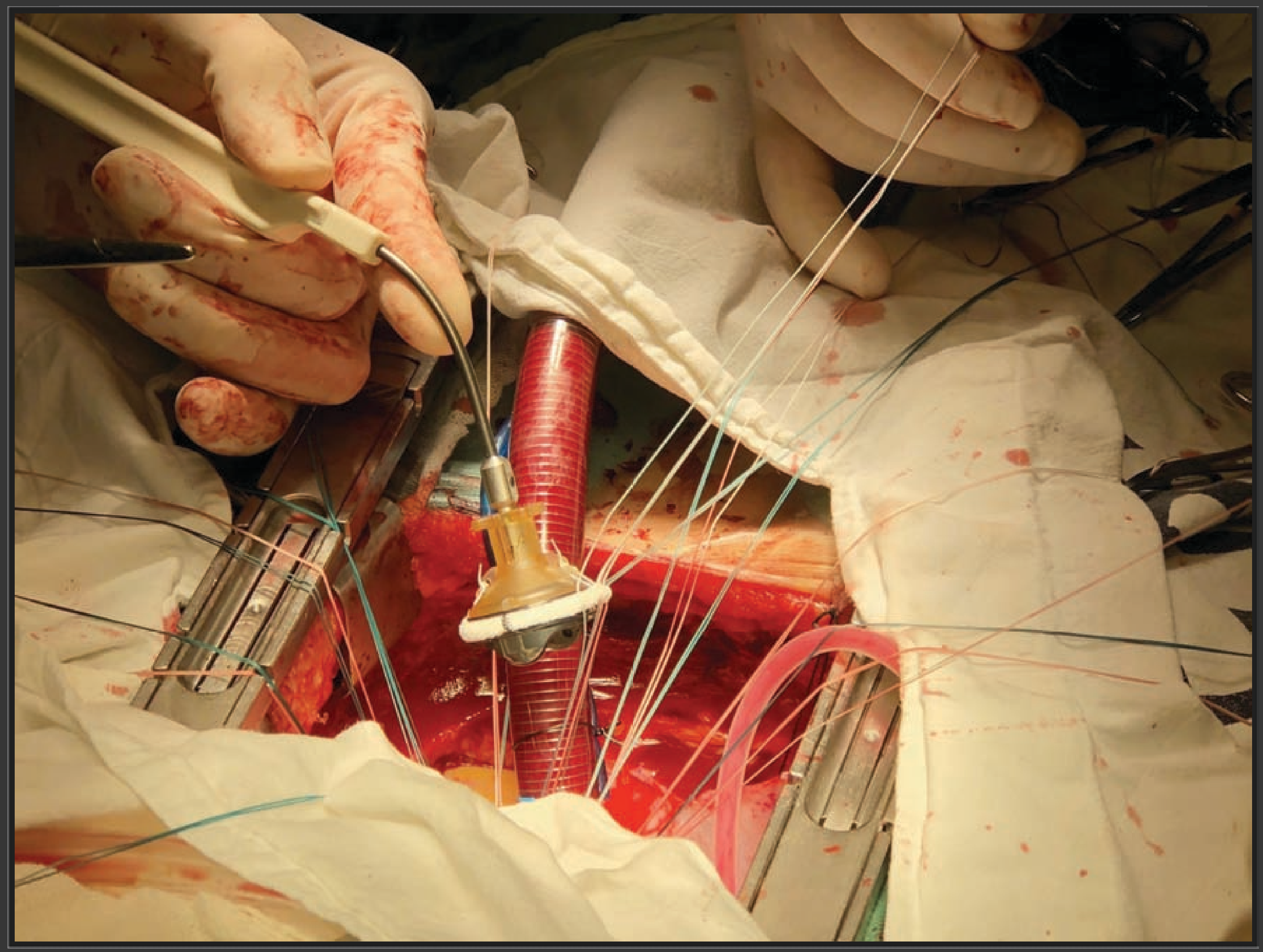

Figura 6: Implante de prótese aórtica mecânica 


\subsection{Valvas biológicas}

Foram desenvolvidas principalmente para diminuir os riscos relacionados ao tromboembolismo e à anticoagulação perene. As mais usadas são os heteroenxertos bovinos e suínos.

Nos três primeiros meses após a cirurgia a endotelização do material protético está em curso juntamente com uma alta trombogenicidade local, sendo então desejável a anticoagulação apenas nesse período. A principal desvantagem dessas próteses é a durabilidade limitada, entretanto, raramente ocorre disfunção súbita da valva, mas sim gradual. Dessa forma há necessidade de seguimento clínico e ecocardiográfico dos pacientes.

Nas crianças e nos pacientes com menos de 35 anos a falência da valva ocorre mais rapidamente em comparação com pacientes mais idosos. Assim, prefere- se nesses casos o uso de próteses mecânicas ou mesmo plástica valvar se for possível.

\subsection{Escolha da prótese valvar}

Estudos mostram resultados globais semelhantes em relação à mortalidade, endocardite infecciosa e necessidade de reoperação nos primeiros cinco anos para próteses mecânicas e biológicas. Devemos frisar que o resultado geral após uma cirurgia de troca valvar depende mais de dados pré- operatórios (idade, função cardíaca prévia, comorbida- des e doença arterial coronariana) e menos do tipo de valva implantada.

São elegíveis para o uso de próteses biológicas os pacientes que:

- Apresentem doença cujo risco de sangramento é grande como angiodisplasias e doença diverticular dos cólons;

- Se recusem a usar anticoagulantes orais;

- Tenham idade superior a 65 anos, em que o ritmo de degeneração protética é mais lento;

- Não tenham outra indicação formal para anticoagulação sendo as mais comuns a fibrilação atrial e trombos atriais;

- Sejam mulheres em idade fértil pelos riscos da antiacoagulação oral nas gestantes.

Em outros casos não contemplados acima há preferência para o uso de valvas mecânicas, mas não podemos esquecer que um julgamento clínico cuidadoso e a preferência do paciente devem ser levados em conta para a escolha da prótese a ser implantada.

\section{Bibliografia}

Amato M, Moffa PJ. Cardiopatias Valvares. In: Lopes AC, editor. Tratado de Clínica Médica. $1^{a}$ edição. São Paulo: Roca; 2006. p. 624-47. 
Otto CM, Bonow RO. Doença Valvar Cardíaca. In: Libby P, Bonow RO, Mann DL, Zipes DP, editores. Braunwald: Tratado de Doenças Cardiovasculares. $8^{a}$ edição. Rio de Janeiro: Elsevier; 2010. p. 1625-1712.

Pomerantzeff PMA, Dinato FJS, Lapenna GS, Brandão CMA. Novas perspectivas no tratamento cirúrgico da estenose aórtica. Rev Soc Cardiol Estado de São Paulo. 2014; 24(2): 56-63.

Tarasoutchi F, Montera MW, Grinberg M, Barbosa MR, Piñeiro DJ, Sánchez CRM, Barbosa MM, Barbosa GV et al. Diretriz Brasileira de Valvopatias - SBC 2011 / I Diretriz Interamericana de Valvopatias - SIAC 2011. Arq Bras Cardiol 2011; 97(5 supl. 1): 1-67.

Nishimura RA et al. 2014 AHA ACC Valvular Heart Disease Guideline 


\section{TAMPONAMENTO CARDÍACO}

André Monti Garzesi

Antônio Sérgio Martins

Leonardo Rufino Garcia

Guilherme Trípoli

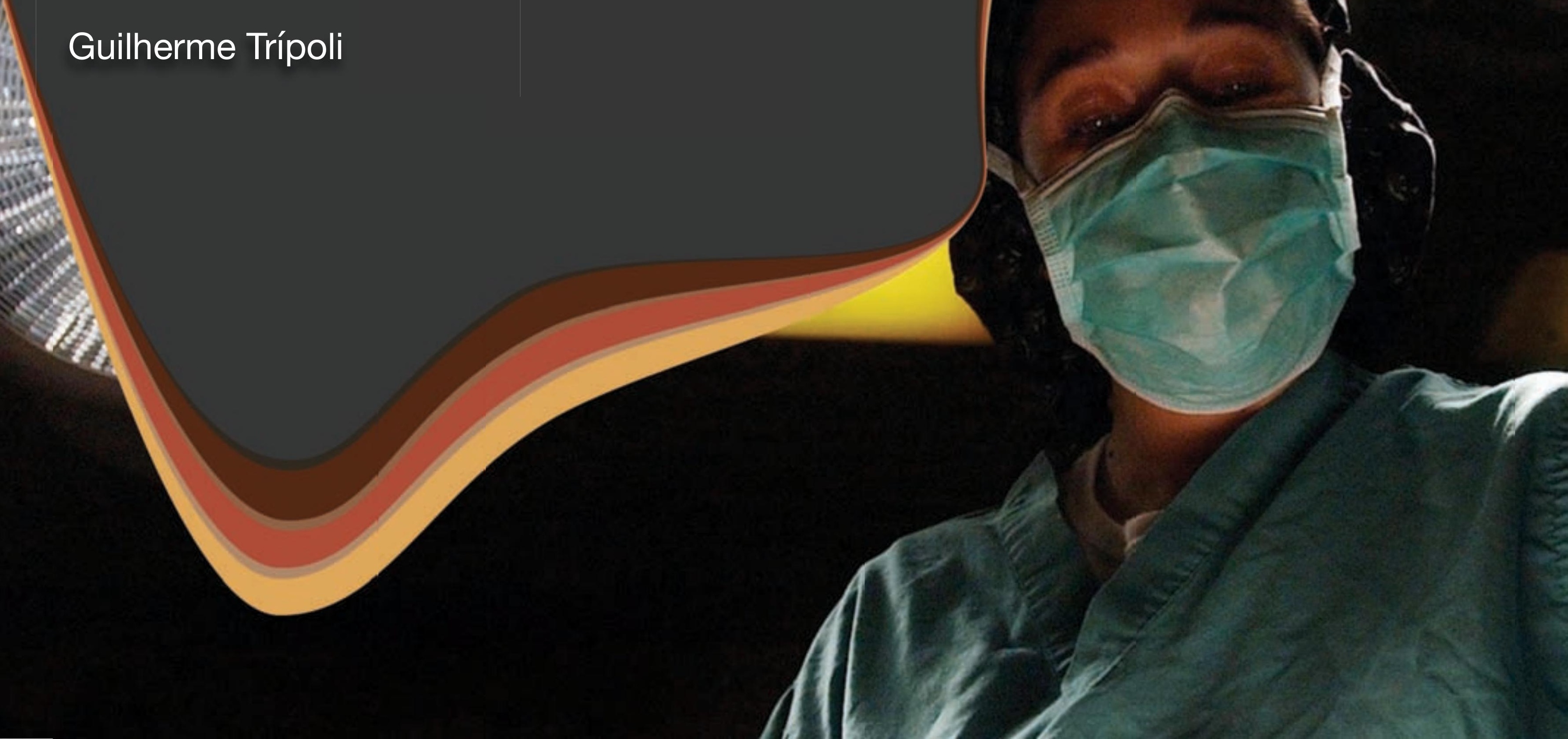




\section{Anatomia e fisiologia do pericárdio}

De forma simples, podemos definir o pericárdio como a membrana que envolve o coração. Pode ser dividido em visceral e parietal. O pericárdio visceral é composto por células justapostas ao epicárdio e o parietal é fibroso, composto por colágeno e tem espessura em torno de dois milímetros. Entre essas camadas existe a cavidade pericárdica, que acomoda cerca de $50 \mathrm{ml}$ de fluido.

A reflexão do pericárdio engloba pequenas porções dos vasos da base e da veia cava inferior, o que tem importância anátomo-clínica. A cavidade pericárdica apresenta um volume de reserva a partir do qual pequenos incrementos de volume podem comprometer a hemodinâmica por restrição de enchimento das câmaras direitas durante a diástole. Entretanto, em resposta a um estiramento crônico do tecido pericárdico, ocorre um aparente crescimento do mesmo. É isso que acontece nos derrames de formação lenta, que dificilmente provocam tamponamento.

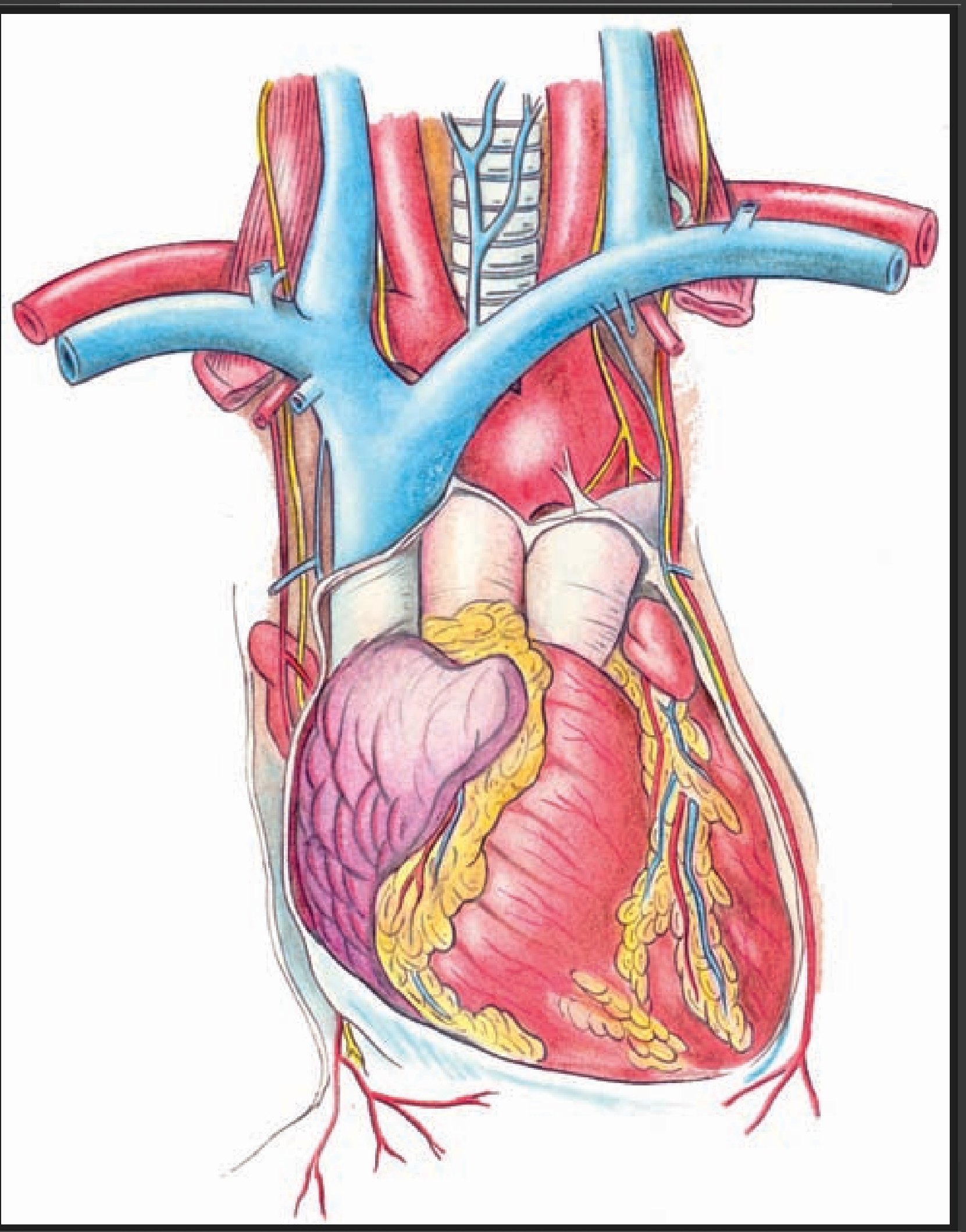

Figura 1: Coração localizado no mediastino médio. Porções de grandes vasos no interior da cavidade pericárdica. 


\section{Definição e etiologia}

É uma doença causada pela compressão do coração por acúmulo de líquido (pus, sangue, transudatos) ou ar na cavidade pericárdica levando à diminuição do débito cardíaco pelo aumento de pressão intrapericárdica.

Para uma triagem inicial dos pacientes, devemos ter em mente as causas de doenças pericárdicas que com frequência progridem para tamponamento cardíaco e que podem exigir abordagem emergencial.

Podem progredir para tamponamento

Neoplasias (pulmào, linfomas, esôfago, mama)

Infeç̧òes (HIV, outros virus como Coxsackic, tuberculose, outras bactérias

como Staphilococcus sp e Streptococcus sp)

Hemopericairdio iatrogênico

Hemopericárdio pós-traumático

Hemopericairdio por dissecçầo de aorta

Derrame pericárdico após cirurgia cardiaca

Ruptura de parede ventricular após infarto do miocárdio Insuficiência renal

Raramente progridem para tamponamento

Doenças auto-imunes (artrite reumatoide, lūpus eritematoso sistêmico são as

principais)

Hipotireodismo ou hipertireoidismo

Pericardite após infarto do miocárdio (sindrome de Dressler)

Derrames pericairdicos por insuficiéncia cardiaca

Derrames pericárdicos do último trimestre da gestaçào

Tabela 1: Causas de doença pericárdica

\section{Sinais e sintomas}

Os sinais e sintomas do tamponamento refletem a diminuição do débito cardíaco causada pela compressão do coração. Assim, estão presentes desconforto, taquipneia, sudorese, extremidades frias, cianose periférica e depressão sensorial. A clássica tríade de Beck composta por hipotensão, abafamento de bulhas e estase jugular é descrita mas em geral um ou dois sinais apenas estão presentes. Nos estágios precoces a hipotensão pode não existir devido a mecanismos compensatórios como a taquicardia.

Pode haver o pulso paradoxal que é a diminuição dos pulsos periféricos durante a inspiração profunda. Tal sinal ocorre pelas alterações do retorno venoso durante a ventilação. Nos casos muito avançados pode haver bradicardia reflexa.

\section{Exames complementares}

Sempre devem ser solicitados se disponíveis.

\subsection{Eletrocardiograma}

Podem ocorrer reduções das voltagens e alternância elétrica dos complexos QRS. A alternância elétrica é a variação das amplitudes dos complexos QRS e é mais específica, porém menos sensível para tam- 
ponamento do que a redução da voltagem. Se há pericardite sobreposta são descritos infradesnivelamento do segmento PR e supradesnivelamento do segmento ST em todas as derivações.

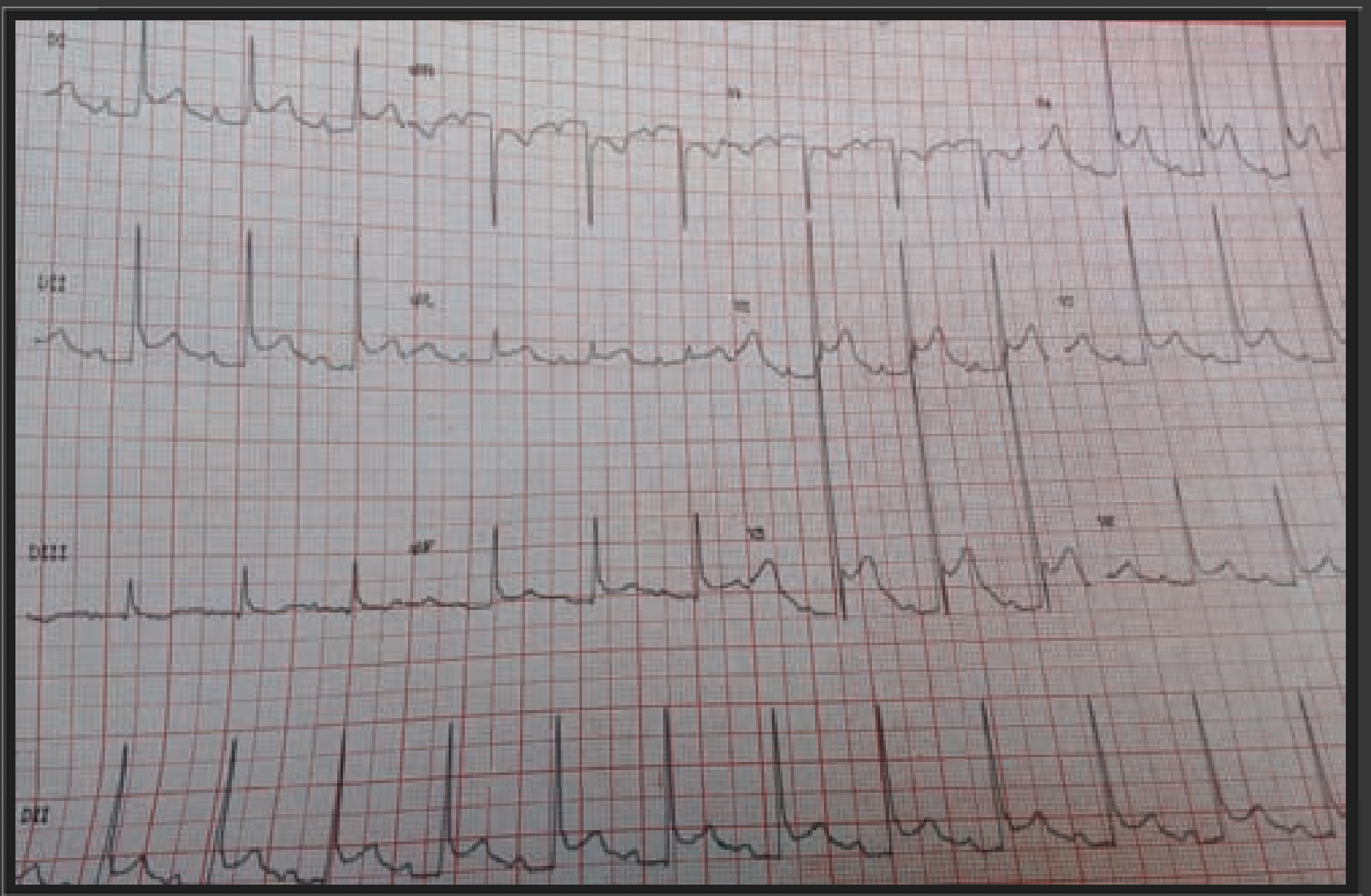

Figura 2: Infradesnivelamento de PR e supradesnivelamento de ST difusos.

\subsection{Raio $X$ de tórax}

A partir de derrames moderados (cerca de $200 \mathrm{ml}$ ) a silhueta cardíaca toma a forma arredondada ("coração em moringa"). O aumento da área cardíaca reflete o acúmulo de líquido na cavidade pericárdica.

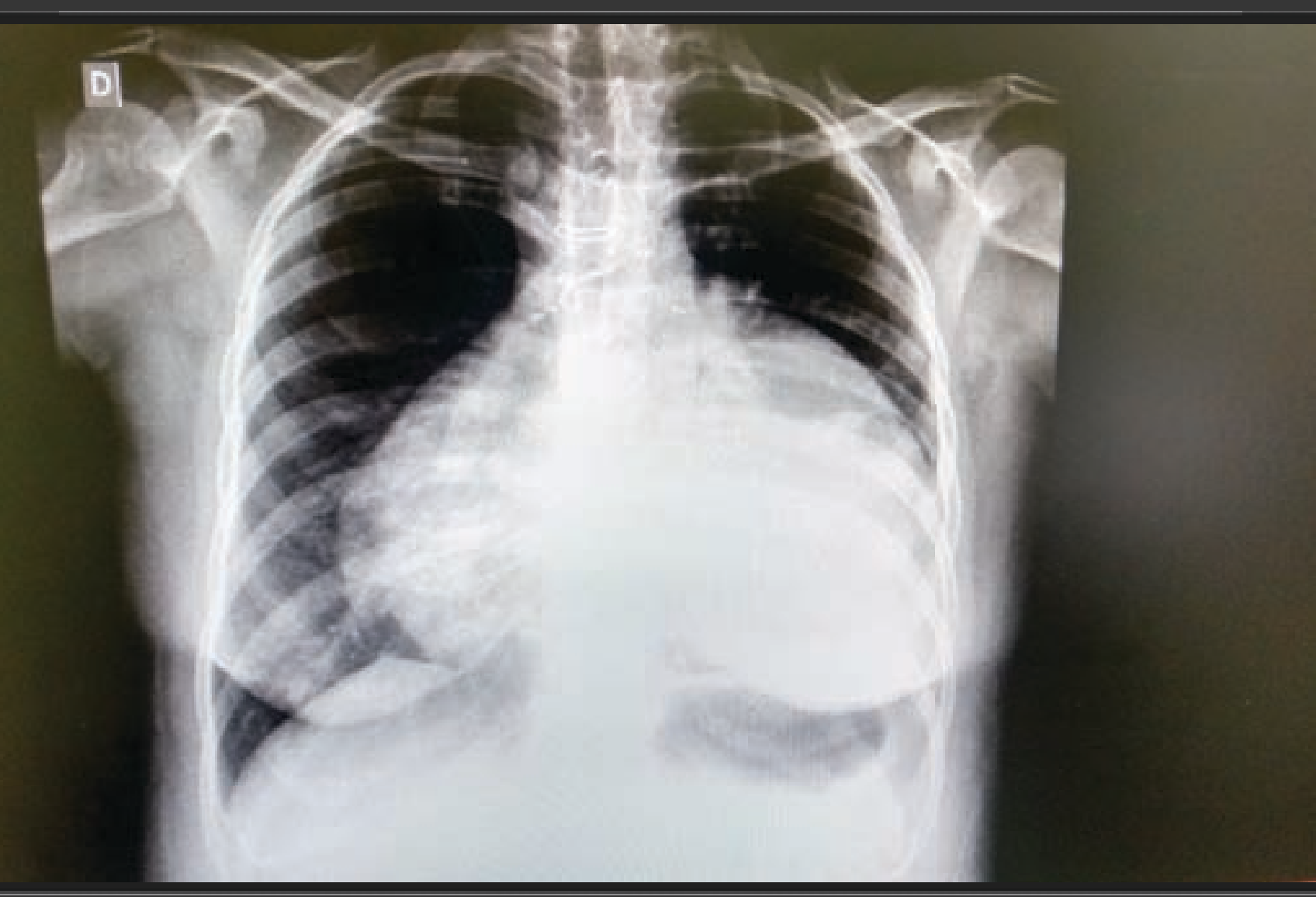

Figura 3: Imagem típica de "coração em moringa". Tamponamento cardíaco durante pós- operatório de troca valvar mitral.

\subsection{Ecocardiograma}

É o método padrão- ouro para diagnóstico e auxiliar no tratamento via pericardiocentese ou drenagem cirúrgica. O colapso de câmaras direitas é sensível e específico para o diagnóstico. Derrames pericárdicos circunferenciais e maiores que dois centímetros de espessura também têm forte associação com progressão para tamponamento cardíaco. 


\subsection{Tratamento}

O tamponamento cardíaco presente ou iminente deve ser encarado como emergência médica devido ao risco de parada cardiorrespiratória em atividade elétrica sem pulso (AESP). À beira do leito a pericardiocentese é o procedimento de escolha para a evacuação de líquido da cavidade pericárdica, de preferência guiada por ecocardiograma. Se há risco de vida imediato o auxílio do exame de imagem pode ser dispensado se não for disponível. Quando há certeza de tamponamento a hidratação endovenosa deve ser indicada, principalmente naqueles que receberam doses de diuréticos devido a um diagnóstico inicial de insuficiência cardíaca. Nos pacientes em franca piora hemodinâmica o uso de inotrópicos intravenosos deve ser considerado, porém, tais medidas não devem atrasar a pericardiocentese.

Em algumas situações o paciente necessitará de uma abordagem cirúrgica que trate tanto o tamponamento como a sua causa: dissecção de aorta tipo A, ruptura de parede livre ventricular após infarto do miocárdio, trauma torácico com lesão cardíaca ou de grandes vasos.

Em uma unidade de saúde com poucos recursos e se o paciente está estável, sem perspectiva de tamponamento imediato, existem algumas indicações de transferência para serviço terciário acompanhada por médico: coagulopatia, relação normatizada internacional (RNI) maior que 1,5, contagem de plaquetas menor que 50.000 por milímetro, derrames pericárdicos posteriores, loculados e pequenos, os quais aumentam a chance de complicações da pericardiocentese.
Abaixo segue um fluxograma para ajudar a abordagem:

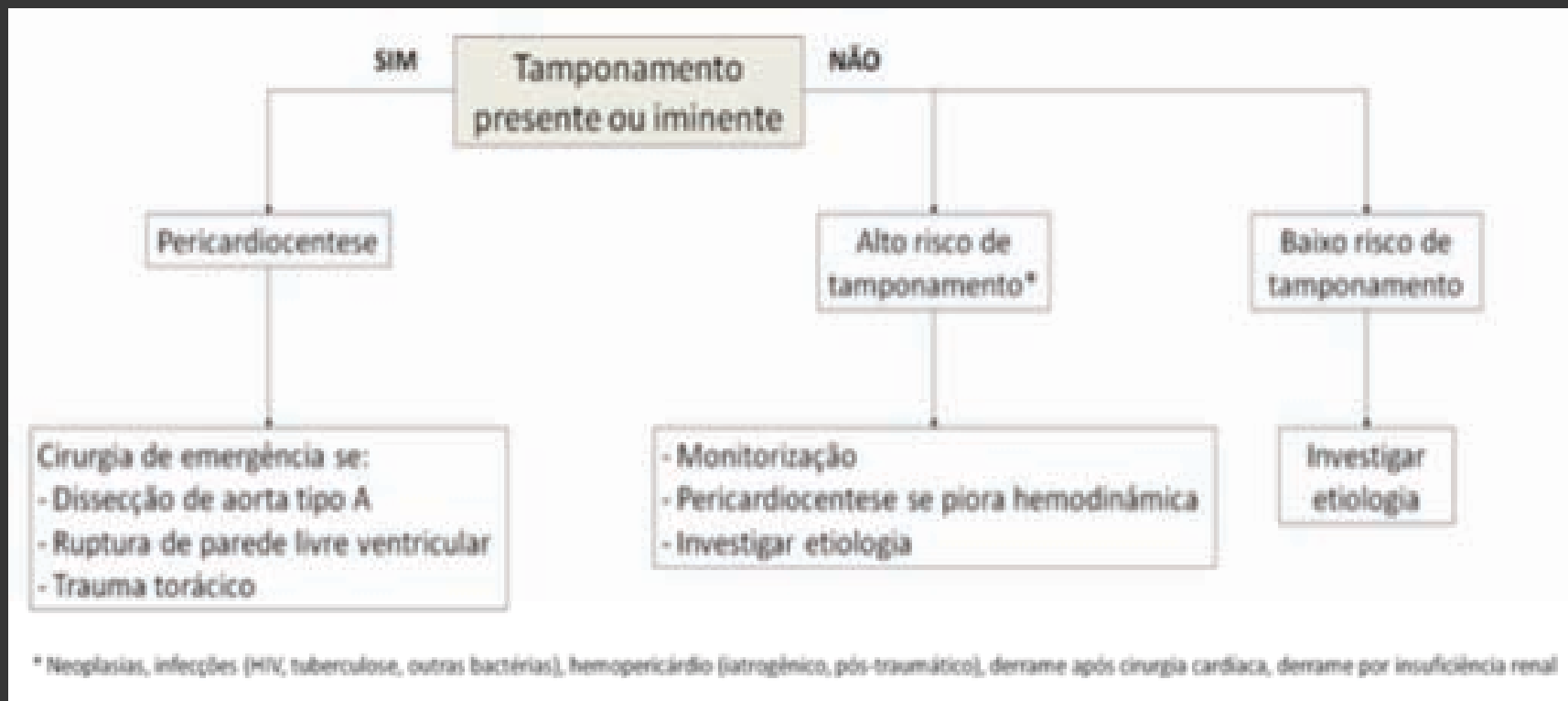

Sempre que possível a pericardiocentese deve ser realizada com o auxílio de ecocardiograma para minimizar o risco de complicações. O paciente deve estar monitorado (sinais vitais, cardioscopia e oximetria), deve ser realizada antissepsia nas regiões xifóidea e subxifóidea e anestesia local se o paciente não estiver sedado. A punção é realizada de um a dois centímetros inferior e à esquerda da junção xifocondral num ângulo de 45 graus em relação à pele. A agulha deve ser avançada com cuidado em direção ao ombro esquerdo. Nesse momento, se a ponta da agulha puncionar o miocárdio aparecerão alterações do segmento ST ou alargamento dos complexos QRS indicando que a aguIha deve ser recuada. Quando a agulha penetra a cavidade pericárdica ocorre uma diminuição súbita de resistência e o líquido deve ser aspirado. Um fio guia pode ser introduzido através da agulha e na sequência pode ser colocado na cavidade um cateter de punção venosa central (técnica de Seldinger). Após a fixação do cateter, o paciente deve continuar sob constante monitorização e mais líquido pode ser removido de 
acordo com o padrão hemodinâmico. É importante lembrar que, diferentemente do sangue ventricular o sangue aspirado da cavidade pericárdica não coagula devido às propriedades do pericárdio.

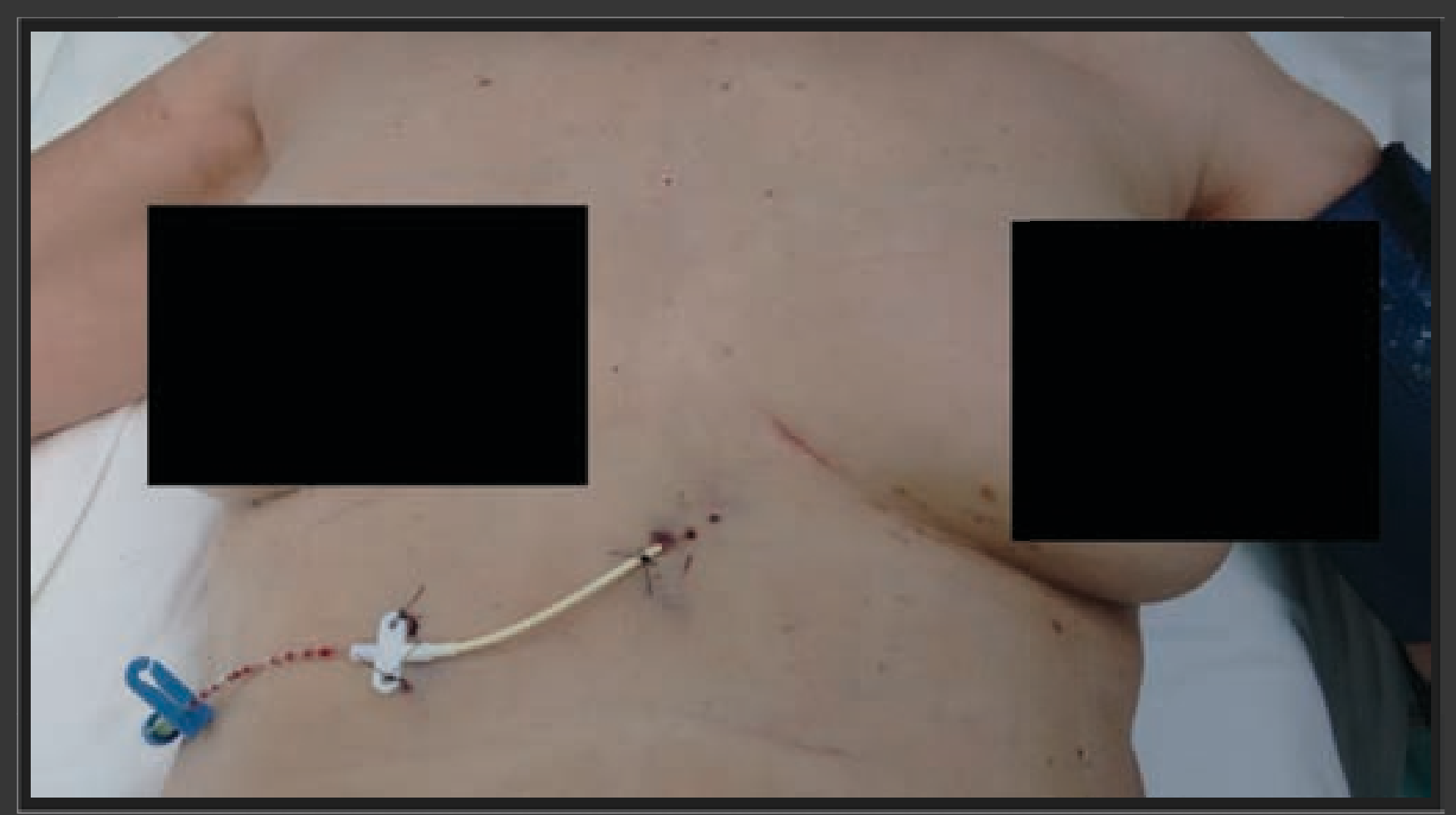

Figura 4: Paciente com cateter intrapericárdico devido a derrame com comprometimento hemodinâmico.

Algumas complicações do procedimento são: laceração do miocárdio com aspiração de sangue ventricular, lesão de vasos coronários com hemopericárdio, fibrilação ventricular, pneumotórax, punção do esôfago e mediastinite e punção do peritônio com peritonite secundária.

Em resumo, trata- se de um procedimento cujas complicações são de aproximadamente $4,7 \%$ mas que se bem indicado e realizado pode salvar a vida do paciente. Suas principais vantagens são o fato de poder ser realizado à beira do leito sem necessidade de anestesia geral.
Para alguns casos como derrames pericárdicos sem etiologia definida e derrames posteriores de difícil acesso via pericardiocentese é melhor indicada uma abordagem cirúrgica que pode ser realizada através de uma toracotomia ântero- lateral esquerda ou por uma incisão mediana subxifóide. Essas vias de acesso proporcionam a realização de uma biópsia pericárdica, porém há necessidade de colocação de um dreno e de anestesia geral.

\section{Bibliografia}

Fildes J. ATLS - Suporte avançado de vida no trauma para médicos. 8a ed. Chicago, IL; American College of Surgeons; 2004. p. 85-109.

Otto CM, Bonow RO. Doenças do pericárdio. In: Libby P, Bonow RO, Mann DL, Zipes DP, editores. Braunwald: tratado de doenças cardiovasculares. 8a ed. Rio de Janeiro: Elsevier; 2010. p. 1829-53.

Ristic AD, Imazio M, Adler Y, Anastasakis A, Badano LP, Brucato A, et al. Triage strategy for urgent management of cardiac tamponade: a position statement of the European Society of Cardiology Working Group on Myocardial and Pericardial Diseases. Eur Heart J. 2014;35:2279-84. 


\section{MARCAPASSOS CARDÍACOS}

Marcello Laneza Felicio

Rubens Ramos de Andrade

Rubens Tofano de Barros 


\section{Introdução}

O marcapasso é um dispositivo de estimulação cardíaca artificial, capaz de monitorar o ritmo cardíaco e estimular o miocárdio. Este sistema tem a finalidade de garantir uma frequência cardíaca adequada, além de poder sincronizar os batimentos dos átrios com os ventrículos.

O marcapasso é necessário quando o caminho do impulso elétrico que faz o coração contrair está comprometido por alguma razão, levando a mudanças na frequência e no ritmo cardíaco.

O sistema de estimulação é composto por um gerador e por eletrodos. O gerador é uma pequena caixa metálica que contém um circuito eletrônico miniaturizado e uma bateria compacta de longa duração. O eletrodo é composto por fios de ligas metálicas específicas e revestido por silicone. Pode ser fixado no átrio e/ou no ventrículo. O eletrodo transmite o pulso elétrico ao coração, verifica a atividade cardíaca e transmite esta informação até o gerador de marcapasso.

\section{Técnica cirúrgica}

Em adultos o gerador de marcapasso fica sob a pele e o tecido subcutâneo, geralmente na região subclavicular direita ou esquerda. Menos frequentemente, o gerador pode ser implantado em outras regiões do corpo como no abdômen. Já os eletrodos são posicionados no endocárdio (endocavitário) ou no epicárdio (na superfície externa do coração).
A técnica endocárdica é a mais utilizada pela possibilidade de ser feita com anestesia local, por ser mais simples, com menor tempo de cirurgia e de recuperação pós-operatória. O implante epicárdico é realizado por toracotomia, com o paciente sob anestesia geral.

A introdução de eletrodos dentro do coração pode ser feita através da dissecção da veia cefálica no sulco deltopeitoral, pela dissecção da veia jugular interna ou externa, ou por punção da veia subclávia. Os eletrodos são guiados e posicionados com auxílio de equipamento de radioscopia. A fixação pode ocorrer no átrio direito e/ou no ventrículo direito. O número de eletrodos depende do tipo de arritmia a ser tratada, como veremos adiante.

\section{Tipos de marcapasso}

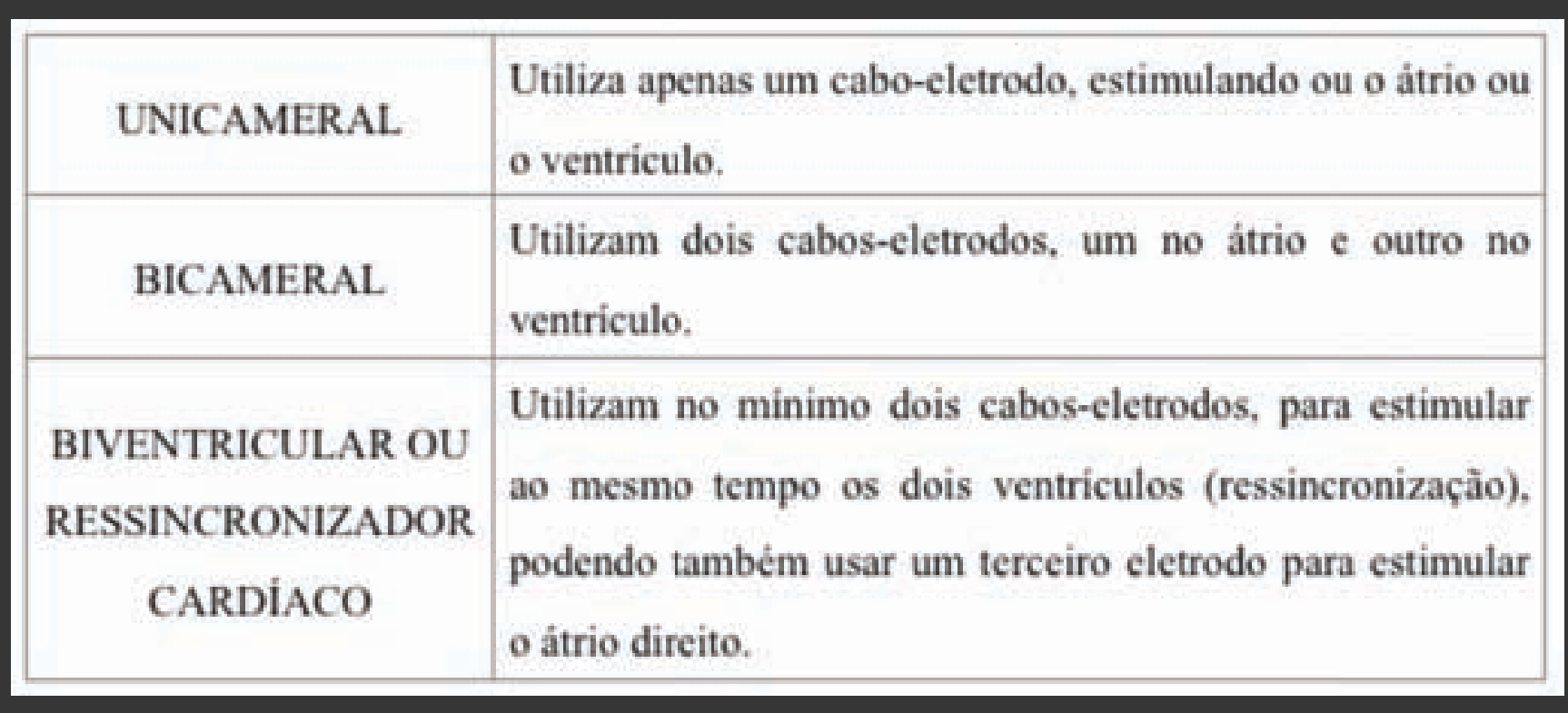

Tabela 1: Tipos de Marcapasso 


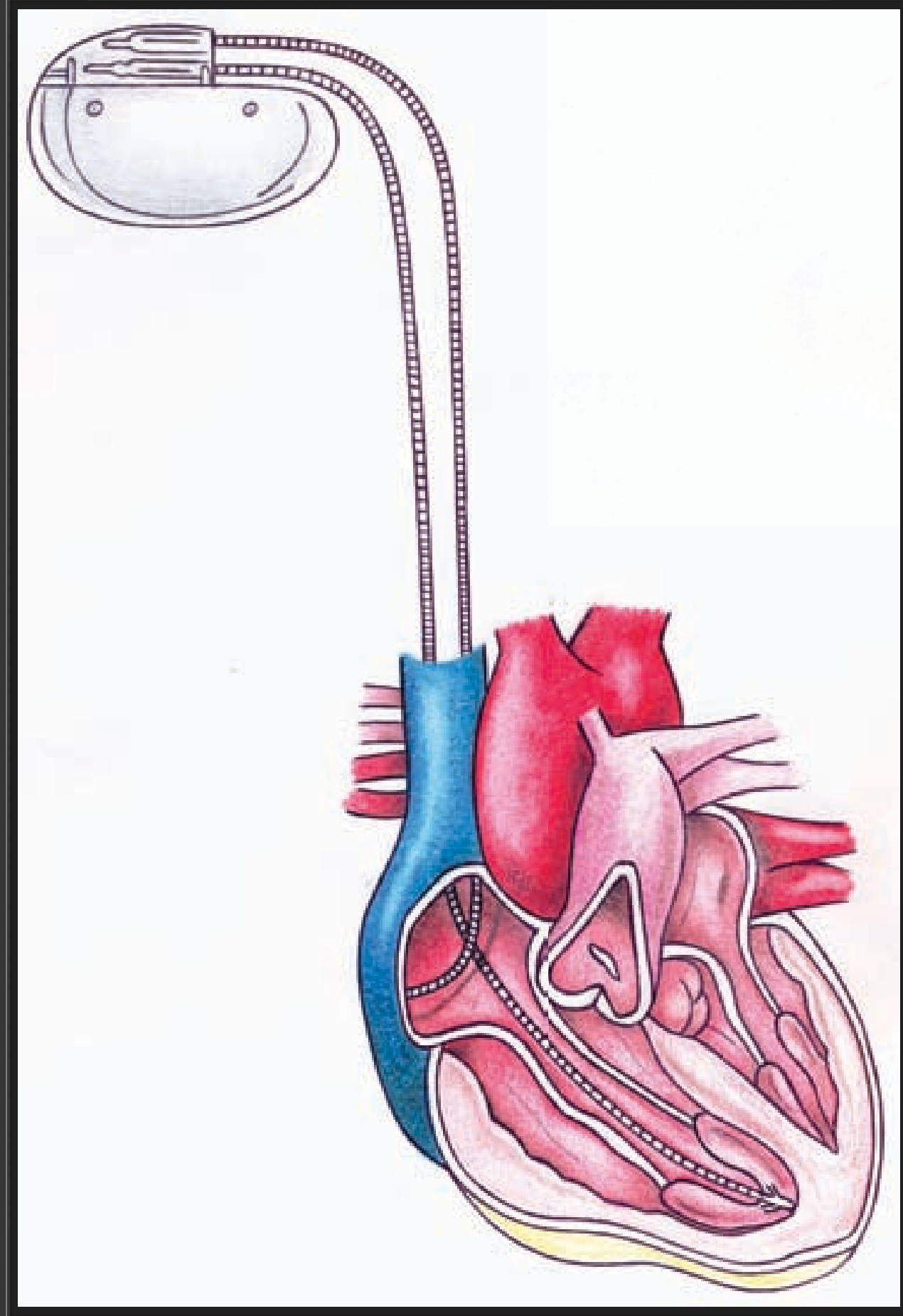

Figura 1: Exemplo de marcapasso bicameral. Notam- se um eletrodo atrial e um ventricular nas câmaras direitas (modo DDD explicado no fim do capítulo).

\section{Recomendações para o implante de} marcapasso

A indicação de implante de marcapasso definitivo é realizada conforme a classe de recomendação e o nível de evidência científica de acordo com as Tabelas 1 e 2.

\begin{tabular}{|l|l|}
\hline Recomendação & \multicolumn{1}{c|}{ Definição } \\
\hline Classe I & $\begin{array}{l}\text { Condições para as quais há evidências conclusivas, ou, na sua falta, } \\
\text { consenso geral de que o procedimento é seguro, e útil/eficaz. }\end{array}$ \\
\hline Classe II & $\begin{array}{l}\text { Condições para as quais há evidências conflitantes e/ou divergência } \\
\text { de opinião sobre segurança, e utilidade/eficácia do procedimento. }\end{array}$ \\
\hline Classe IIa & $\begin{array}{l}\text { Peso ou evidência/opinião a favor do procedimento. A maioria } \\
\text { aprova. }\end{array}$ \\
\hline Classe IIb & $\begin{array}{l}\text { Segurança e utilidade/eficácia menos bem estabelecida, não } \\
\text { havendo predominio de opiniões a favor. }\end{array}$ \\
\hline Classe III & $\begin{array}{l}\text { Condições para as quais há evidências e/ou consenso de que o } \\
\text { procedimento não é útil/eficaz e, em alguns casos, pode ser } \\
\text { prejudicial. }\end{array}$ \\
\hline
\end{tabular}

Tabela 1: Classificação de Recomendação do implante de marcapasso definitivo 


\begin{tabular}{|l|l|}
\hline Niveis de Evidência & \multicolumn{1}{|c|}{ Definição } \\
\hline Nivel A & $\begin{array}{l}\text { Dados obtidos a partir de múltiplos estudos randomizados de } \\
\text { bom porte, concordantes e/ou de meta-análise robusta de } \\
\text { estudos clinicos randomizados. }\end{array}$ \\
\hline Nivel B & $\begin{array}{l}\text { Dados obtidos a partir de meta-análise menos robusta, a partir } \\
\text { de um único estudo randomizado ou de estudos não } \\
\text { randomizados (observacionais). }\end{array}$ \\
\hline Nivel C & Dados obtidos de opiniões consensuais de especialistas. \\
\hline
\end{tabular}

Tabela 2: Nível de Evidência Científica para implante de marcapasso definitivo

\section{Disfunção do Nó Sinusal (DNS)}

A DNS pode manifestar-se com as seguintes alterações eletrocardiográficas: bradicardia sinusal, parada sinusal, bloqueio sino-atrial ou síndrome bradi-taquicardia. A indicação de implante de marcapasso definitivo para DNS é apresentada na Tabela 3.
Espontânea, irreversivel ou induzida por färmacos necessários e insubstituiveis, com manifestações documentadas de sincopes, pré-sincopes ou tonturas, ou com IC relacionadas à bradicardia.

Com intolerância aos esforços, claramente relacionada à incompetência

cronotrópica.

Espontânea, irreversivel ou induzida por fármacos necessários e insubstituiveis, com manifestações de sincopes, pré-síncopes ou tonturas

relacionadas com a bradicardia, mas não documentadas.

Sincope de etiologia indefinida, na presença de DNS documentada ao EEF

Bradiarritmia sinusal que desencadeia ou agrava IC, angina do peito ou

\section{taquiarritmias.}

Pacientes oligossintomáticos com $\mathrm{FC}$ crônica $<40 \mathrm{bpm}$, durante vigilia.

DNS assintomática ou com sintomas comprovadamente nào relacionados à

bradicardia.

DNS na presença de bradicardia sintomática por uso de fármacos não essenciais ou substituiveis. bpm: batimentos por minuto, DNS: disfunção do nó sinusal, EEF: estudo eletrofisiológico, FC: frequência cardíaca, IC: insuficiência cardíaca

Tabela 3: Indicação de Implante de Marcapasso na Disfunção do Nó Sinusal

\section{Síndrome do Seio Carotídeo (SSC)}

A SSC é uma manifestação rara com incidência maior em idosos. O comprometimento da parede das artérias pelo processo de aterosclerose pode provocar maior excitabilidade dos pressorreceptores. A com- 
pressão ou a mobilização das artérias, principalmente a nível cervical, pode estimular de maneira intensa esses receptores levando à bradicardia intensa.

A SSC pode se manifestar com resposta cardioinibitória ou vasodepressora. Durante a forma cardioinibitória ocorre a lentificação da resposta sinusal ou o prolongamento do intervalo PR com bloqueio átrio ventricular (BAV) avançado. Já na resposta vasodepressora, há a perda do tônus vasomotor e hipotensão devido à redução da atividade simpática. A Indicação de implante de marcapasso na Síndrome do Seio Carotídeo está representada na Tabela 4.

Sincope recorrente $\mathrm{em}$ situações cotidianas que envolvem a estimulação mecânica do seio carotideo provocando assistolia $>3$ segundos documentada, na ausência de medicamentos depressores da função sinusal ou conduçâo.

Sincope recorrente, não documentada, em situações cotidianas que envolvam a

estimulação mecânica do seio carotideo e com resposta cardioinibitória à lla C massagem do seio carotideo.

Sincope recorrente de etiologia indefinida reprodutivel por massagem do seio carotideo.

Sincope recorrente de etiologia indefinida na presença de resposta cardioinibitória à massagem do seio carotideo.

Resposta cardioinibitória à massagem do seio carotideo na ausência de manifestações clínicas de baixo fluxo cerebral.

Resposta vasodepressora exclusiva, à massagem do seio carotideo. independentemente das manifestações clinicas.

\section{IB}

Tabela 4: Indicação de Implante de Marcapasso na Síndrome do Seio Carotídeo

\section{Síncope Neurocardiogênica (SNC)}

Ao contrário da SSC, a síncope neurocardiogênica ocorre mais em pacientes jovens. Neste caso, ocorre síncope por bradicardia ou assistolia, podendo estar associada à intensa vasodilatação. Durante a SNC ocorre acentuada resposta vagal e redução do tônus simpático. O diagnóstico é feito com o Tilt Test ou teste de inclinação. O marcapasso está indicado em situação descrita na Tabela 5.

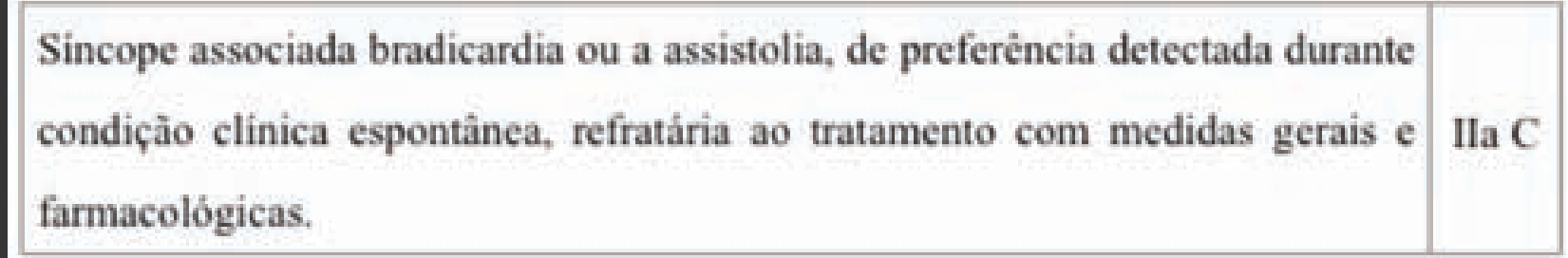

Tabela 5: Indicação de Implante de Marcapasso na Síncope Neurocardiogênica

\section{Bloqueio Atrioventricular (BAV)}

O BAV é definido quando ocorre um atraso ou falha da condução do estímulo elétrico dos átrios para os ventrículos. No BAV, a alteração do sistema de condução pode localizar-se ao nível atrial, no nódulo atrioventricular ou ao nível do sistema Hiss-Purkinje. Além disso, pode ser temporário ou permanente.

A principal causa de BAV é a senescência, com degeneração do sistema de condução, caracterizada pela fibrose ou esclerose progressiva de suas fibras. A cardiopatia isquêmica é a segunda causa mais fre- 
quente. Outras causas são a Doença de Chagas, pós-operatório de cirurgia cardíaca, endocardite infecciosa com comprometimento do aparelho subvalvar aórtico e o BAV congênito. Esta alteração de condução do impulso elétrico pode ser classificada em BAV de $1^{\circ} \mathrm{Grau}, \mathrm{BAV}$ de $2^{\circ}$ Grau e BAV de $3^{\circ}$ Grau (Tabela 6).

\begin{tabular}{|c|c|}
\hline BAV $1^{\circ}$ Grau & $\begin{array}{l}\text { Todas as ondas P sào conduzidas, porém com } \\
\text { prolongamento do intervalo } \mathrm{PR}(>200 \mathrm{~ms}) \text {. }\end{array}$ \\
\hline $\begin{array}{l}\text { BAV } 2^{\circ} \text { Grau Tipo I } \\
\text { Mobitz I ou Wenckebach }\end{array}$ & $\begin{array}{l}\text { Prolongamento progressivo do intervalo PR com falha de } \\
\text { condução de um batimento atrioventricular. }\end{array}$ \\
\hline $\begin{array}{l}\text { BAV } 2^{\circ} \text { Grau Tipo II } \\
\text { Mobitz II }\end{array}$ & $\begin{array}{l}\text { Quando ocorre condução atrioventricular, o intervalo } \mathrm{PR} \\
\text { é constante, porém algumas ondas } \mathrm{P} \text { nào são seguidas de } \\
\text { complexo } \mathrm{QRS} \text {. }\end{array}$ \\
\hline BAV $2^{\circ}$ Grau tipo 2:1 & $\begin{array}{l}\text { Duas ondas P por complexo QRS. Intervalo PR normal e } \\
\text { constante nos batimentos conduzidos. }\end{array}$ \\
\hline BAV $2^{\circ}$ Grau Avançado & $\begin{array}{l}\text { Relaçào AV maior do que o dobro ( } 2: 1) \text {, isto é, pelo } \\
\text { menos duas ondas P não conduzidas para cada QRS. }\end{array}$ \\
\hline $\begin{array}{l}\text { BAV de } 3^{\circ} \text { Grau ou } \\
\text { BAV total (BAVT) }\end{array}$ & $\begin{array}{l}\text { Nào há condução de nenhum impulso do átrio para os } \\
\text { ventriculos, com total dissincronia AV. }\end{array}$ \\
\hline
\end{tabular}

Tabela 6: Classificação de Bloqueio Atrioventricular

Nas Tabelas 7 e 8 estão descritas as indicações respectivas de marcapasso definitivo em pacientes portadores de BAV $1^{\circ}$ e $2^{\circ}$.
Irreversivel, com sincopes, pré-sincopes ou tonturas, de localização intra ou $\mathrm{Ila} \mathrm{C}$ infra-His e com agravamento por estimulação atrial ou teste farmacológico.

Com sintomas consequentes ao acoplamento AV anormal.

Assintomático

AV: atrioventricular.

Tabela 7: Indicação de Implante de marcapasso em BAV $1^{\circ}$ Grau

\begin{tabular}{|c|c|}
\hline $\begin{array}{l}\text { Permanente ou intermitente, irreversivel ou causado por drogas necessárias e } \\
\text { insubstituiveis, independente do tipo e localizacào, com sintomas definidos de } \\
\text { baixo fluxo cerebral ou IC consequentes à bradicardia. }\end{array}$ & $1 \mathrm{C}$ \\
\hline $\begin{array}{l}\text { Tipo II, com QRS largo ou infra-His, assintomático, permanente ou } \\
\text { intermitente e irreversivel. }\end{array}$ & $1 \mathrm{C}$ \\
\hline $\begin{array}{l}\text { Com flutter atrial ou FA, com periodos de resposta ventricular baixa, em } \\
\text { pacientes com sintomas definidos de baixo fluxo cerebral ou IC consequentes } \\
\text { a bradicardia. }\end{array}$ & IC \\
\hline $\begin{array}{l}\text { Tipo avançado, assintomático, permanente ou intermitente e irreversivel ou } \\
\text { persistente após } 15 \text { dias de cirurgia cardiaca ou infarto agudo do miocárdio. }\end{array}$ & Ila C \\
\hline $\begin{array}{l}\text { Tipo II, QRS estreito, assintomático, permanente ou intermitente e } \\
\text { irreversivel. }\end{array}$ & Ila C \\
\hline $\begin{array}{l}\text { Com flutter atrial ou FA, assintomático, con frequência ventricular média } \\
\text { abaixo de } 40 \mathrm{bpm} \text { em vigilia, irreversivel ou por uso de färmaco necessário e } \\
\text { insubstituivel. }\end{array}$ & Ila C \\
\hline $\begin{array}{l}\text { Tipo avançado, assintomático, permanente ou intermitente e irreversivel nào } \\
\text { relacionada à cirurgia cardiaca ou infarto agudo do miocárdio. }\end{array}$ & Illb C \\
\hline $\begin{array}{l}\text { Tipo 2:1, assintomático, permanente ou intermitente e irreversivel associado a } \\
\text { arritmias ventriculares que necessitam de tratamento medicamentoso com } \\
\text { farmacos insubstituiveis depressores da conduçào AV. }\end{array}$ & IIb C \\
\hline $\begin{array}{l}\text { Tipo I, assintomático, com normalizaçào da conduçào AV com exercicio ou } \\
\text { atropina. }\end{array}$ & III C \\
\hline
\end{tabular}

Tabela 8: Indicação de Implante de marcapasso em BAV $2^{\circ}$ Grau 
Está indicado o implante de marcapasso definitivo em pacientes apresentando BAVT, salvo em algumas situações como as listadas na tabela 9.

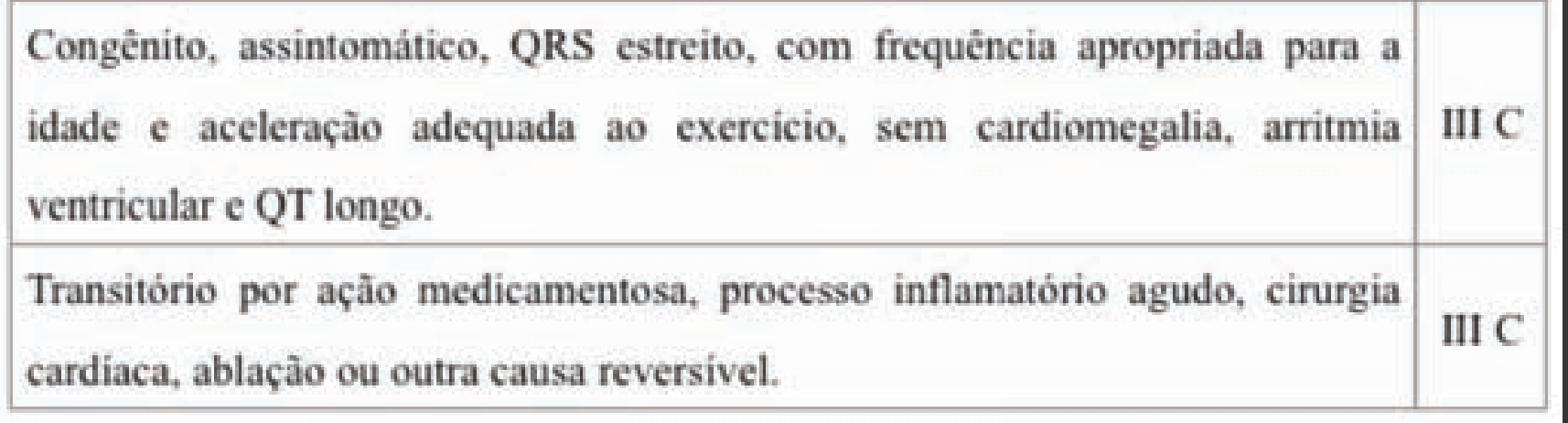

Tabela 9: Situações em que não se indica o implante de marcapasso definitivo

No BAVT congênito recomendam-se avaliações periódicas e criteriosas nos pacientes assintomáticos, com eletrocardiograma e ecocardiografia, permitindo assim a detecção precoce de alterações potencialmente deletérias, passíveis de prevenção com a implantação do marcapasso definitivo.

\section{Código de Nomenclatura de marca- passos}

O modo de funcionamento de um dispositivo de estimulação cardíaca artificial, isto é, que câmara(s) é (são) estimulada(s) e/ou sentidas(s), segue um padrão internacionalmente aceito. Existe um código de quatro letras que indica como o aparelho funciona.
A primeira letra indica a(s) câmara(s) estimulada(s), sendo que a letra A serve para átrio, V para ventrículo e D quando ambas as câmaras são estimuladas. A segunda letra indica a(s) câmara(s) sentida(s), a terceira letra indica o modo de resposta frente à sensibilidade aos eventos cardíacos do paciente podendo ser I (inibida), T (deflagrada - pouco usada) e D (dupla). Já a quarta letra indica a reposta de frequência, ou seja, os marca- passos atuais, multiprogramáveis, podem aumentar sua frequência de estimulação quando o paciente realiza alguma atividade física em que o débito cardíaco precisa aumentar. Assim, para a quarta letra pode haver habilitação da resposta de frequência indicada pela letra R, ou esse parâmetro pode estar desativado o que é indicado pela letra $\mathrm{O}$ ou simplesmente pela ausência de letra nessa posição.

Os modos de estimulação mais frequentes do nosso serviço são:

- WI: estimula e sente o ventrículo direito e se inibe frente a um evento elétrico ventricular (QRS). Usado em casos em que o átrio não precisa ser estimulado, como em fibrilações atriais com baixa resposta ventricular;

- VDD: funciona estimulando o ventrículo direito e sentindo tanto átrio e ventrículo. Pode ser usado nos casos em que existe algum tipo de bloqueio AV, porém o átrio tem competência cronotrópica, ou seja, trabalha numa frequência acima de 60 batimentos por minuto e não precisa ser estimulado. O marcapasso sincroniza átrios e ventrículos;

- DDD: estimula e sente tanto átrio quanto ventrículo direito. Sua indicação é essencial para os casos de doença do nó sinusal, podendo também ser indicado nos casos de bloqueio AV em que o átrio direito tam- 
bém é bradicárdico. Nos casos de doença do nó sinusal também pode ser usada a modalidade AAI, entretanto, se o paciente desenvolver com o envelhecimento algum tipo de bloqueio AV haverá a necessidade de implante de um outro eletrodo ventricular e troca do gerador para uma estimulação bicameral.

\section{Bibliografia}

Andrade JCS, Ávila Neto V, Braile DM, Brofman PRS, Costa ARB, Costa $\mathrm{R}$, et al. Diretrizes para o implante de marcapasso cardíaco permanente. Arq Bras Cardiol. 2000;74(5):475-80.

Clarke M, Sutton R, Ward D, Camm AJ, Rickards A, Ingram A, et al. Recommendations for pacemaker prescription for symptomatic bradicardia. Br Heart J. 1991;66:185-91.

Lorga AM, Lorga Filho A, D’Ávila A, Rassi Jr A, Paola AAV, Pedrosa A, et al. Diretrizes para tratamento de pacientes com arritmias cardíacas. Arq Bras Cardiol. 2002;79(5):1-50.

Martinelli Filho M, Zimerman LI, Lorga AM, Vasconcelos JTM, Rassi A Jr. Guidelines for implantable electronic cardiac devices of the Brazilian Society of Cardiology. Arq Bras Cardiol. 2007;89(6):e210-38.

Michaëlsson M, Jonzon A, Riesenfeld T. Isolated congenital complete atrioventricular block in adult life. A prospective study. Circulation. 1995;2(3):442-9.
Oliveira Júnior RM, Silva KR, Kawauchi TS, Alves LB, Crevelari ES, Martinelli Filho M, et al. Functional capacity of patients with pacemaker due to isolated congenital atrioventricular block. Arq Bras Cardiol. 2015;104(1):67-77. 
Agência Brasileira do ISBN

ISBN 978-85-65318-55-6

||||||||||||||||||||||

\|\|$_{788565}||||||||||||||||||$

NंEAD.TIS 